\title{
A new megalosaurid theropod dinosaur from the late Middle Jurassic (Callovian) of north-western Germany: Implications for theropod evolution and faunal turnover in the Jurassic
}

\author{
Oliver W.M. Rauhut, Tom R. Hübner, and Klaus-Peter Lanser
}

\begin{abstract}
Fragmentary remains of a large, robustly built theropod dinosaur were recovered from the marine middle Callovian Ornatenton Formation of north-eastern NorthrhineWestphalia, Germany. The specimen includes a premaxilla, maxilla, lacrimal, postorbital, dentary, several caudal vertebrae, ribs, fibulae, astragalus, and partial calcaneum. It is here described as a new species of megalosauroid, Wiehenvenator albati $\mathrm{n}$. gen. n. sp., diagnosed by a strongly reduced maxillary antorbital fossa on the base of the ascending process of the maxilla, a very short anterior ramus of the lacrimal with an additional pneumatic depression anteroventral to the lacrimal fenestra, a transversely expanded orbital facet in the postorbital, and a laterally flexed proximal end of the ascending process of the astragalus. Phylogenetic analysis recovers Wiehenvenator as a megalosaurine megalosaurid, sister taxon to the Late Jurassic genus Torvosaurus. It thus adds to the considerable diversity of megalosauroids in the Middle Jurassic. A time-calibrated phylogeny of theropods indicates a rapid radiation of averostran theropods between the Toarcian and the Bathonian. This radiation was probably triggered by the Pliensbachian-Toarcian extinction event, which might have been more important for theropod evolution than the Triassic-Jurassic extinction. The fossil record indicates a faunal turnover from megalosauroid dominated Middle Jurassic to allosauroid / coelurosaur dominated Late Jurassic faunas. However, differences in the Middle and Late Jurassic theropod fossil records both in respect to geographic distribution of localities, as well as sampled environments make this inference problematic, at least in respect to allosauroids. An analysis of environmental preferences of allosauroids and megalosauroids indicates that the former preferred inland environments, whereas the latter are more common in nearshore environments.
\end{abstract}

Oliver W.M. Rauhut. Staatliche naturwissenschaftliche Sammlungen Bayerns (SNSB), Bayerische Staatssammlung für Paläontologie und Geologie, Department for Earth and Environmental Sciences and GeoBioCenter, Ludwig-Maximilians-University, Richard-Wagner-Str. 10, D-80333 München, Germany.

http://zoobank.org/89E8C946-70F3-4C4F-A591-770649B4126D

Rauhut, Oliver W.M., Hübner, Tom R., and Lanser, Klaus-Peter. 2016. A new megalosaurid theropod dinosaur from the late Middle Jurassic (Callovian) of north-western Germany: Implications for theropod evolution and faunal turnover in the Jurassic. Palaeontologia Electronica 19.2.26A: 1-65

palaeo-electronica.org/content/2016/1536-german-jurassic-megalosaurid

Copyright: Palaeontological Association August 2016 
o.rauhut@Irz.uni-muenchen.de

Tom R. Hübner. Posener Str. 10, 30659 Hannover, Germany. Current address: paläon - Forschungs- und Erlebniszentrum Schöninger Speere, Paläon 1, 38364 Schöningen, Germany. Tom-Ray@gmx.net Klaus-Peter Lanser. Landesverband Westfalen-Lippe (LWL), Museum für Naturkunde, Sentruper Str. 285, D-48161 Münster, Germany. Current address: Langebusch 948159 Münster, Germany. klaus.peter.lanser@gmx.de

Keywords: Megalosauroidea; Ornatenton Formation; theropod evolution; Jurassic

\section{INTRODUCTION}

The first dinosaur to be described scientifically was a Middle Jurassic theropod from Europe, Megalosaurus, from the Bathonian of England (Buckland, 1824), although the species name, $M$. bucklandii Mantell, 1827, was not coined until three years later (Mantell, 1827). The taxon was based on an assortment of bones from the Taynton Limestone Formation of Stonesfield, Oxfordshire, of which an isolated dentary was recently selected as lectotype (Benson et al., 2008). As this was the first theropod dinosaur known, almost all theropod remains found in subsequent decades were referred to the genus Megalosaurus, and so this genus became a wastebasket taxon for theropod taxa ranging from the Late Triassic to the latest Cretaceous (see Benson et al., 2008; Benson, 2010a; Carrano et al., 2012). Even though a revision of this situation and a restriction of the name Megalosaurus to certain taxa from the Jurassic of Europe started with the work of von Huene (1923, 1926), it remained common practice to refer isolated remains to this genus until late in the 20th century (e.g., del Corro, 1974), and the family Megalosauridae long remained the receptacle for theropod taxa that could not readily be placed in one of the more derived families (e.g., Tyrannosauridae, Ornithomimidae). Following the growing recognition that Megalosaurus was a problematic taxon (e.g., Molnar et al., 1990; Allain and Chure, 2002; Day and Barrett, 2004) and that there were two distinct clades that can be distinguished at the base of Tetanurae and outside Coelurosauria (e.g., Sereno et al., 1994, 1998; Sereno, 1999; Allain, 2002; Rauhut, 2003), the name Megalosauridae became less frequently used in recent decades (Holtz et al., 2004). However, it was not until the recent work of Benson (2008, 2009, 2010a, 2010b; Benson et al., 2008) that the taxonomic status of Megalosaurus bucklandii and several of the referred materials from the British Middle Jurassic have been finally resolved, and Benson (2010a) and Carrano et al. (2012) recently provided a phylogenetic framework for the recognition of a monophyletic superfamily Megalosauroidea, including a monophyletic Megalosauridae (with phylogenetic definitions for these clades first having been proposed by Holtz et al., 2004).

The Middle Jurassic of Europe has yielded the highest diversity of theropod dinosaurs currently known for this time, yet diagnostic remains have so far only been described from England and France. The recognition of a monophyletic Megalosauridae and the phylogenetic work by Benson (2010a) and Carrano et al. (2012) indicate that the majority (at least seven out of 10) of these taxa can be referred to this clade. Middle Jurassic species from Europe that are currently regarded as valid include the megalosaurids Megalosaurus bucklandii Mantell, 1827 (see Benson et al., 2008; Benson 2009, 2010a; Carrano et al., 2012), Poekilopleuron bucklandii Eudes-Deslongchamps, 1837 (see Allain and Chure, 2002), Magnosaurus nethercombensis (von Huene, 1923) (see von Huene, 1926; Benson, 2010b), Eustreptospondylus oxoniensis Walker, 1964 (see von Huene, 1926, 1932; Sadleir et al., 2008), Piveteausaurus divesensis (Walker, 1964) (see Taquet and Welles, 1977), Dubreuillosaurus valesdunensis (Allain, 2002) (see also Allain, 2005), and Duriavenator hesperis (Waldman, 1974) (see Benson, 2008), the Megalosauroidea incertae sedis Streptospondylus altdorfensis von Meyer, 1832 (see Allain, 2001), the Tetanurae incertae sedis Cruxicheiros newmanorum Benson and Radley, 2010, and the basal tyrannosauroid Proceratosaurus bradleyi (Woodward, 1910) (see Rauhut et al., 2010). Stratigraphically, these taxa range from the Early Bajocian (Magnosaurus nethercombensis) to the Late Callovian (Eustreptospondylus, Piveteausaurus, Streptospondylus). As most of Europe was covered by shallow seas in the Middle Jurassic (Smith et al., 1994), all of the remains from England and France come from 


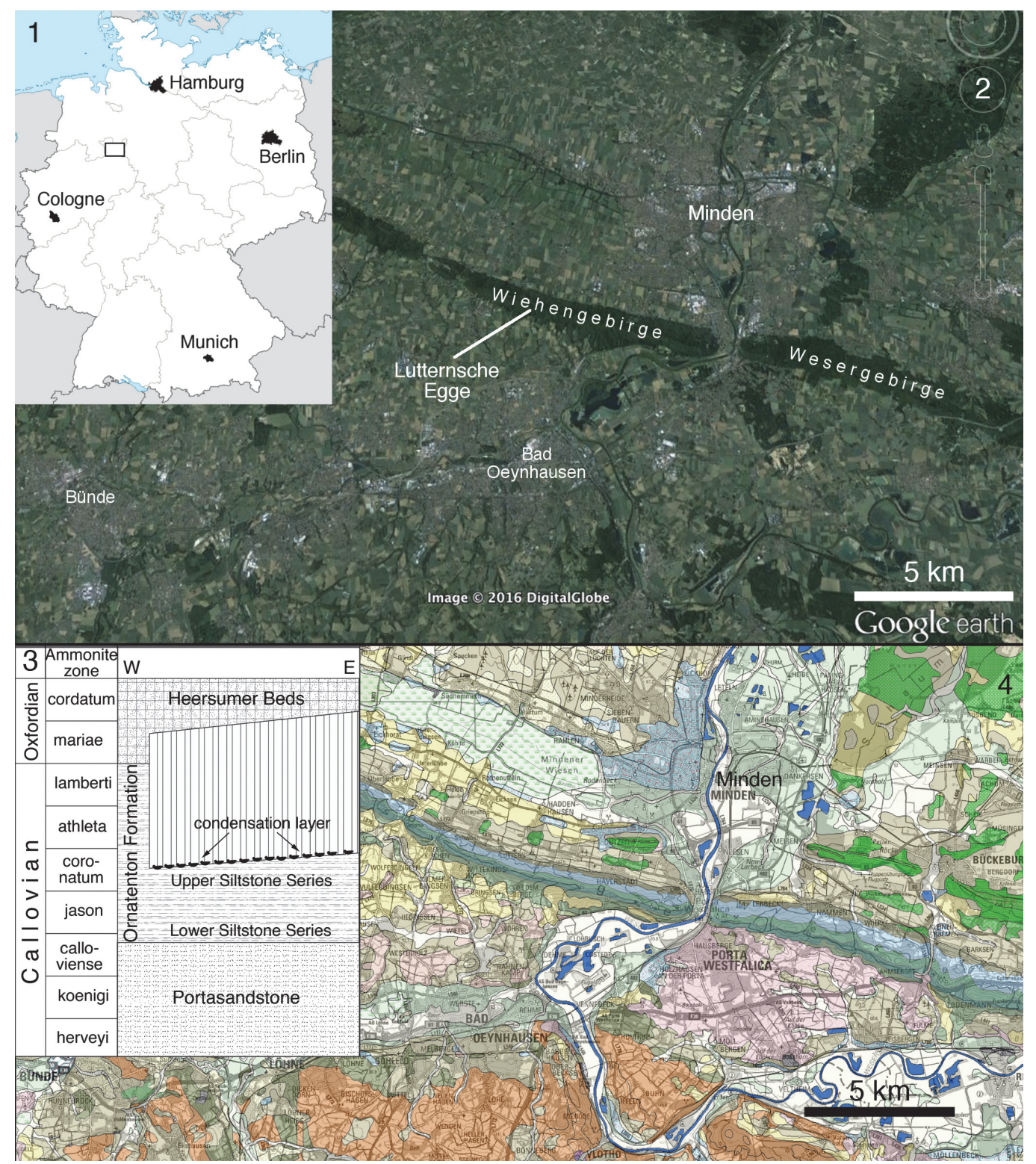

FIGURE 1. Geographic and stratigraphic position of the locality where the new theropod was found. 1, Overview map of Germany, indicating the area of the locality of the new theropod in north-eastern Northrhine-Westphalia. 2, locality of the disused Pott quarry at Lutternsche Egge in the Wiehengebirge. 3, Simplified stratigraphic column of the rocks that crop out in the Wiehengebirge ( $E$ = east; $W=$ west). Modified from Riegraf (1994). 4, Geological map of the area between Bünde and Minden. Middle Jurassic units, including the Ornatenton, are represented by the dullish dark green that follows the course of the Wiehengebirge; light blue-grey colours represent Upper Jurassic units; light green marks the Lower Cretaceous ('Wealden') outcrops; orange colours represent Upper Triassic rocks. From the Northrhine-Westphalian Geological Survey (www.gd.nrw.de).

marine deposits and thus obviously represent animals that inhabited the numerous smaller and larger islands in the area that is now north-western central Europe. As noted by Benson (2010a), there might have been some regional endemism at least during the Bathonian, as there are no taxa shared between deposits of that time in England and France.
In 1998, Friedrich Albat, a geologist prospecting for the LWL (Landschaftsverband WestfalenLippe) Museum of Natural History in Münster, discovered remains of a large theropod dinosaur in an abandoned quarry within the Ornatenton Formation (Callovian) at Lutternsche Egge, in the Wiehengebirge near the city of Minden (Figure 1). Subsequent excavation at the site by the LWL Nat- 
ural History Museum from 1998 to 2001 resulted in the recovery of a fragmentary theropod skeleton, together with abundant marine invertebrates and fossil wood. This specimen, which represents the first diagnostic dinosaur remain from the Middle Jurassic of Germany, is described here.

\section{GEOLOGICAL AND PALAEONTOLOGICAL CONTEXT}

The Wiehengebirge is a chain of hills up to $320 \mathrm{~m}$ high with a NW-SE orientation, which belongs to the northernmost ranges of the central German mountain range at the southern rim of the northern German plain. Together with the Teutoburg forest further to the south, it forms a hilly wedge that extends far into the plains. The Wiehengebirge extends from the city of Bramsche in Lower Saxony in the west to the city of Porta Westfalica in Northrhine-Westphalia in the east, where the Weser river cuts through the range. East of the Weser, the range continues under the name Wesergebirge (Figure 1). The Wiehengebirge consists of sediments of Middle and Late Jurassic age, which crop out along the heights of the range, closely following its course. They dip at $35^{\circ}$ to $40^{\circ}$ towards the north-east and are overlain by Lower Cretaceous sediments in the north. The Lower Jurassic crops out in the plains south of the hills.

In the area of the Weser- and Wiehengebirge, the sediments of the Upper Jurassic consist mainly of hard sandstones and quartzites of Oxfordian and Kimmeridgian age, which were formerly quarried in numerous, now disused quarries. The quarry operations thus exposed the underlying Callovian Ornatenton. According to Mönnig (1993), these layers represent the Eremnoceras coronatum biozone of the upper Middle Callovian and the upper siltstone series of the Ornatenton Formation. Thus, these sediments are of similar age to the lower Oxford Clay, such as the Peterborough Member of the Oxford Clay Formation in England. The soft, rapidly eroding sediments dip at an angle of $35^{\circ}$ to $40^{\circ}$ towards the NE, which leads to frequent slumpings over large areas. Thus, the constantly changing outcrop situation makes repeated prospecting of these abandoned quarries necessary. Over the years, these outcrops have mainly yielded a rich invertebrate fauna, which was described by Lange (1973) and Klassen (1984), among others.

Since 1996, the LWL Museum of Natural History, which is in charge of the palaeontological patrimony within the Landschaftsverband WestfalenLippe, has carried out intensive prospection cam- paigns in the area of the Wesergebirge and Wiehengebirge. These were triggered by the information about vertebrate remains having been discovered and excavated by private collectors, especially in the Störmer quarry at Wallücke, a few kilometres east of Bergkirchen. These remains discovered by private collectors were subsequently largely described by Michelis et al. (1996). In preparation of this publication, the majority of these specimens, especially the remains of Leedsichthys problematicum, were transferred from several private collections to the LWL Museum of Natural History. The remains described by Michelis et al. (1996) as fragments of the stegosaurian dinosaur Lexovisaurus were also later identified as belonging to Leedsichthys problematicum (Liston, 2010).

The first step in the prospection for vertebrate occurrences was the registration of all outcrops in the area of the Weser- and Wiehengebirge, together with visits to and an evaluation of these outcrops. This represented an actualization of an existing catalogue of outcrops within the entire area of Westfalen-Lippe. The surveillance of the outcrops was transferred to young scientists who acted as contractors of the LWL Museum of Natural History. This soon led to first discoveries. Thus, Gregor Bishop, a PhD student at the University of Hannover, found parts of a crocodylomorph skull in the float underneath the outcropping sediments in a quarry at the Wülpker Egge in the Wesergebirge east of Minden. Additional cranial remains were subsequently found in situ and were recovered with technical support from the quarry owner. These remains were identified as Steneosaurus $\mathrm{sp}$. This success led to the continuation of the prospection in the following year, this time carried out by Friedrich Albat from Münster. In October 1998, the latter found remains of a theropod maxilla in the disused Pott quarry, at Lutternsche Egge, a few kilometres west of Bergkirchen, within the city limits of Minden (Figure 1). This triggered an excavation by a team from the LWL Museum für Naturkunde from October 1998 to October 2001.

The disused quarry is approximately $650 \mathrm{~m}$ long, and the outcropping layers of the Ornatenton Formation dip north-east at c. $40^{\circ}$. The upper edge of the outcropping sediments form the crest of the Wiehengebirge in this area. The Ornatenton Formation crops out over a height of 25 to $35 \mathrm{~m}$ from this crest to the now forested rubble at the foot of the column. The locality is placed directly below the crest of the Wiehengebirge, a short distance below the overlying, lower Oxfordian Heersumer Beds, which were here preserved with a thickness of $c$. 


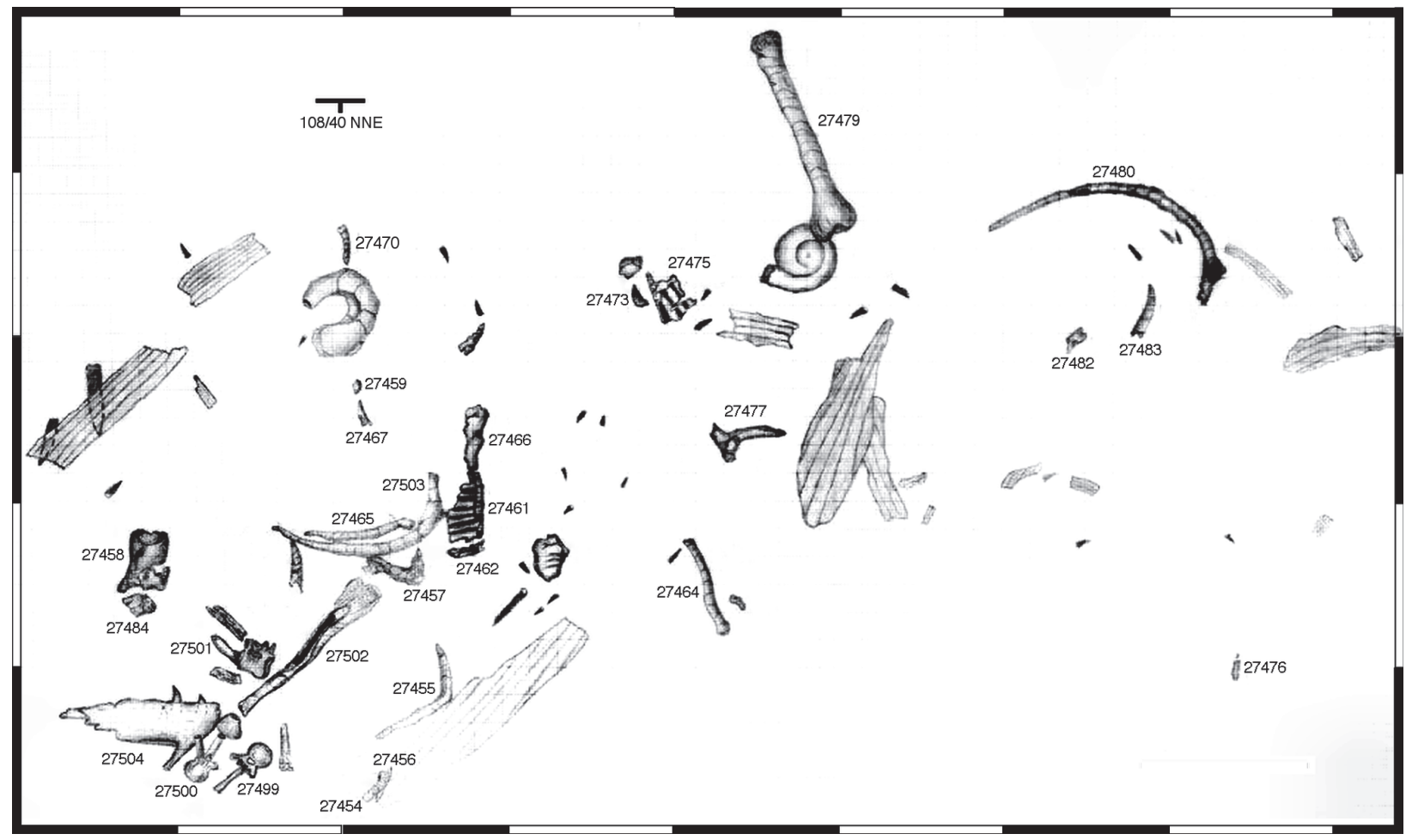

FIGURE 2. Quarry map of the excavation at Lutternsche Egge, showing the position of the different elements of the new taxon in situ. Numbers refer to the specimen numbers of the separate elements (see text). Scale is in $50 \mathrm{~cm}$ increments.

$1.5 \mathrm{~m}$. Until the beginning of winter in December 1998, several theropod skeletal elements were exposed over some $4.5 \mathrm{~m}$ (Figures 2, 3). These remains were associated with marine invertebrates, such as ammonites, belemnites, brachiopods, serpulids, and bivalves, especially the oyster Gryphaea dilatata. Further notable were numerous coalified wood remains, which occurred over the entire outcropping surface of the Ornatenton Formation and reached several metres in length.
The vertebrate remains were found in concentrations of the oyster Gryphaea dilatata, which occurs in large numbers in the contact layer towards the overlying Heersumer Beds at the top of the Ornatenton Formation. This layer thus represents a condensation horizon at the unconformity between the Middle Callovian Upper Siltstone Series of the Ornatenton Formation and the Lower Oxfordian of the Heersumer Beds (Mönnig, 1993). This condensation horizon at the top of the middle

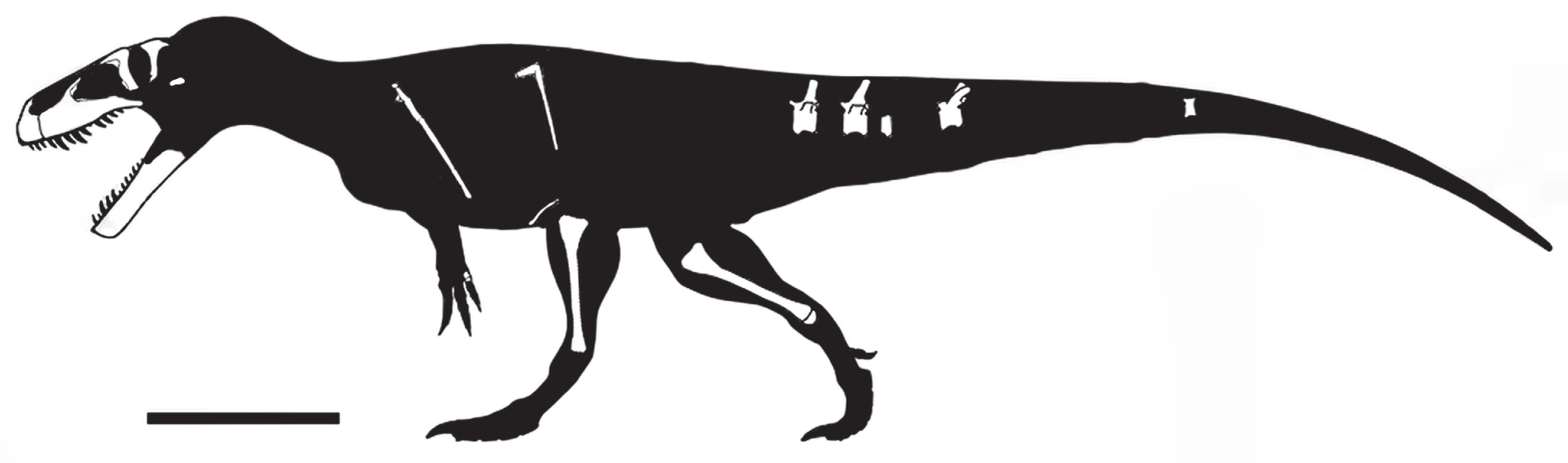

FIGURE 3. Outline reconstruction of Wiehenvenator albati n. gen., n. sp., indicating recovered elements. Based on the reconstruction of Torvosaurus by Scott Hartman; used with permission. Scale bar equals $1 \mathrm{~m}$. 
member of the Ornatenton Formation (the Upper Siltstone Series of Mönnig, 1993) is widely distributed in the Ornatenton Formation in northern Germany and also present some kilometres to the west in the Störmer quarry at Wallücke, where it is also unconformably overlain by the Heersumer Beds, so that the uppermost member of the Ornatenton Formation is missing (Michelis et al., 1996).

According to Mönnig (1993), the Upper Siltstone Series of the Ornatenton Formation was deposited in a shallow marine environment with an input of clastic sediments from the west, presumably the Rhenian or London-Brabant Massif. This predominant direction of sedimentation might indicate that remains of terrestrial vertebrates could also have been washed in from these areas. The condensation horizon itself represents a gap in sedimentation, most probably due to a marked rise in sea level in the Middle Callovian (Mönnig, 1993).

The bones had largely weathered out of the surrounding sediments at the time of their discovery and are thus rather poorly preserved. Bones and teeth showed numerous breaks and cracks, so that an extraction at the site would have led to the destruction of the specimens. They were thus excavated in jackets, which were subsequently prepared in the laboratories of the LWL Museum für Naturkunde. Following the excavation of the main bone concentration, the surroundings were searched for further remains. Some weathered bone remains were found in the rubble below the excavation site. Furthermore, a broken theropod vertebral centrum had been found by collectors (family Bragado from Petershagen) some 10 years earlier c. $10 \mathrm{~m}$ east of the excavation site in the rubble and was donated to the LWL Museum für Naturkunde. Thus, the Ornatenton Formation was searched over $35 \mathrm{~m}$ both east and west of the locality for further remains over its entire exposed height from the Heersumer Beds to the rubble at the foot of the outcrops. Some weathered vertebral centra and teeth of Liopleurodon sp. were found. Almost exactly one year after the original discovery, in mid-October 1999, remains of a second theropod were found some $28.5 \mathrm{~m}$ north-west of the first locality. These remains had largely weathered out of the sediment and floated a few metres down the slope. However, a maxillary fragment was subsequently found in situ above the bone and tooth fragments in the float.

Only a few hundred metres away from these finds, a honorary member of the LWL Museum für Naturkunde found a skull and lower jaws of the crocodylomorph Metriorhynchus sp. on October 3, 2014, in a largely overgrown quarry further to the west. As with the theropod remains from the Pott quarry, this skull occurred directly below the Heersumer Beds. These discoveries in the Middle Callovian beds over a rather short distance demonstrate the potential of these sediments and indicate that more material might be found in the future.

\section{MATERIALS AND METHODS}

\section{Bone Histology}

In order to establish the ontogenetic stage of the holotype specimen of the new taxon, we sectioned one of the fibulae for a histological analysis. The thin sections were produced in the preparation lab of the Geomuseum at the Westfälische Wilhelms-Universität Münster. The left fibula (WMN P27479) was transversely cut approximately at the border between the distal and middle third of the shaft, close to an already present break, using a Woco 50 precision saw. The obtained slice was hardened with two-component RECKLI injection resin EP and mounted on a glass slide, using twocomponent Körapox 439 resin. After a second transverse cut close to the glass slide, the section was ground down to a thickness of approximately $30 \mu \mathrm{m}$, because of its dark inherent color and abundant diagenetic alterations obscuring many parts of the tissue. A second transverse thin section of approximately $60 \mu \mathrm{m}$ was made from the remaining slab for comparison. The thin sections were examined and photographed using a Leitz Laborlux 12 Pol polarization microscope and a Zeiss Axio Cam ICC3 camera. The whole-section photo was made on a light table using a Nikon D3 camera with a $105 \mathrm{~mm}$ Micro Nikkor lens.

\section{Phylogenetic Analysis}

To establish the phylogenetic position of the new taxon, we coded it in a revised version of the matrix of Carrano et al. (2012). Several character definitions of the original list of Carrano et al. (2012), especially of cranial characters, were revised and taxa recoded correspondingly (see Appendix 1). In addition, we added the basal tyrannosaur Guanlong to the matrix in order to improve taxon and character sampling in coelurosaurs (Xu et al., 2006). Character codings for this taxon are based on Xu et al. (2006) and own observations on the type specimen (IVPP V-14531) by OWMR. Furthermore, one taxon was deleted from the matrix. The deleted taxon is the Chinese theropod Leshansaurus, as neither Carrano et al. (2012) nor 
we studied this taxon personally, and the published description (Li et al., 2009) is in Chinese, so codings could only be based on the sparse illustrations. Following Xing et al. $(2013,2014)$, the Chinese taxon 'Dilophosaurus' sinensis is considered to be a junior synonym of Sinosaurus triassicus, and thus the latter name is used in the matrix. Although of considerable potential biogeographic interest, we did not include the Kimmeridgian Portuguese megalosaurid Torvosaurus gurneyi in the matrix (Hendrickx and Mateus, 2014a). In respect to this species, we accept its referral to the genus Torvosaurus, as this was based on synapomorphies that are not present in any other megalosauroid, including the new taxon described here, such as the presence of a laterodorsal ridge within the anteroventral part of the antorbital fossa (Hendrickx and Mateus, 2014a), and it has thus been subsumed in this genus in our analysis. The resulting matrix thus had 62 taxa scored for 351 characters. The matrix is published in Morphobank (www.morphobank.org) under project 2368.

The matrix was analysed under equally weighted parsimony in TNT (Goloboff et al., 2008a, 2008b), performing a heuristic tree search starting from 1000 replicates of Wagner trees (with random addition sequence of taxa), followed by TBR branch swapping (saving 10 trees per replicate). Bootstrap and Bremer support values were calculated in TNT, and the same program was used to identify wildcard taxa and calculate strict and reduced consensus trees. Character optimizations and number of additional steps needed for alternative topologies were evaluated on the strict and reduced consensus trees in Mesquite 3.04 (Maddison and Maddison, 2015).

\section{Analysis of Theropod Faunal Changes}

Apart from looking at the taxonomic composition of Middle and Late Jurassic theropod faunas (see below), we also looked at the theropod fossil record for the two epochs to track changes in theropod faunas. For that, we extracted data for Middle and Late Jurassic theropod localities from the Paleobiology Database (paleobiodb.org), which was updated on the basis of the literature and own data (see Appendix 2). Only localities yielding skeletal specimens were considered, as a referral of tracks to distinct clades is only possible in exceptional cases. The dataset included a total of 100 localities for the Middle and 256 localities for the Late Jurassic. Of these localities, a total of 52 localities yielded remains that are at least identifiable in the clades Ceratosauria, Megalosauroidea,
Allosauroidea, and Coelurosauria for the Middle Jurassic; for the Late Jurassic, the number of localities with identifiable remains is 152 . Only these localities were considered in the analyses.

In addition to the stratigraphic and geographic data on theropod occurrences, we also tried to report ecological data, at least in the rather rough categories, whether the theropod-bearing localities occur within marine, marginal (coastal, tidal), or fully terrestrial geological units. This data was partially taken from the Paleobiology Database, and confirmed with the help of the primary literature in many cases. For the analysis of environmental preferences, we only distinguished two rough categories, inland terrestrial and 'nearshore" (coastal/tidal/marine) environments, as theropods are generally terrestrial animals, and occurrences in marine environments thus reflect transport of terrestrial animals (which presumably mainly lived close to the coast or on islands) into such deposits. We then calculated the expected number of representatives of the clades mentioned above for each environment, using the formula

$$
\mathrm{NexpA}=(\mathrm{OX} * \text { EnvA }) / \text { EnvT }
$$

with $N_{\text {expA }}$ being the expected number of occurrences of clade $X$ in environment $A, O_{X}$ the total number of occurrences of taxon $X, E v_{A}$ the total number of localities for environment $A$ recorded in the dataset, and $E v_{T}$ the total number of localities (and thus environments) sampled (see Waite, 2000; Butler and Barrett, 2008). To test whether the recorded number of occurrence of the distinct taxa significantly deviates from the expected values, we used Pearson's Chi square test (Waite, 2000). In order to increase sample size, we analysed occurrence data for the Middle and Late Jurassic for the different clades together, as the reliability of the Chi square test decreases with low sample sizes, and is not given for sample sizes of five or lower in any given data cell (Hammer and Harper, 2006).

Institutional abbreviations. BYU, Brigham Young University, Provo, Utah, USA; CM, Carnegie Museum of Natural History, Pittsburgh, USA; IVPP, Institute for Vertebrate Paleontology and Paleoanthropology, Beijing, China; MNHN, Muséum national d'Histoire naturelle, Paris, France; MNN, Musée National du Niger, Niamey, Niger; NHMUK, Natural History Museum, London, UK; OUMNH, Oxford University Museum of Natural History, Oxford, UK; USNM, United States National Museum, Washington D.C., USA; WMN, LWLMuseum für Naturkunde, Münster, Germany 


\section{SYSTEMATIC PALAEONTOLOGY}

\author{
DINOSAURIA Owen, 1842 \\ THEROPODA Marsh, 1881 \\ MEGALOSAUROIDEA (Fitzinger, 1843) \\ MEGALOSAURIDAE Fitzinger, 1843 \\ WIEHENVENATOR gen. nov. \\ zoobank.org/95638CFF-5618-4D31-9086-D821F6EE6B39
}

Etymology. Wiehen, for the Wiehengebirge, a chain of hills south of Minden, where the holotype specimen was found and venator, Latin for hunter. The gender of the genus is masculine.

Type species. Wiehenvenator albatisp. nov. Diagnosis. As for type and only known species (see below).

Wiehenvenator albati sp. nov.

zoobank.org/262FA776-9ABC-4565-9A17-931CB4BEFBFC

Etymology. The species epithet honours Friedrich Albat, who found the holotype specimen.

Holotype. Fragmentary skull and skeleton of a single individual; right premaxilla (WMN P27475), right maxilla (WMN P27504), right lacrimal (WMN P27457), right postorbital (WMN P27477), (?)anterior ramus of right quadratojugal (WMN P27470), partial right dentary (WMN P27461, 27462, 27466), six isolated teeth (WMN P27454, 27456, 27459, $27467,27473,27483$ ), three caudal vertebrae (WMN P27499, 27500, 27501), five dorsal ribs and rib fragments (WMN P27464, 27465, 27476, 27480,27503 ), a pair of fused posterior medial gastralia (WMN P27455), a manual phalanx (WMN P27482), both fibulae (WMN P27479, 27502), right astragalus (WMN P27458), and a partial right calcaneum (WMN P27484). Two further partial caudal vertebrae (WMN P29131, 47417) were found at different times in the float at the type locality and probably belong to the same individual.

Type locality and horizon. Former Pott quarry, Lutternsche Egge, near Minden, north-eastern Northrhine-Westphalia, Germany. The bone-bearing layer is a condensation horizon with abundant bivalves of the species Gryphaea dilatata in the middle Ornatenton, Erymnoceras coronatum ammonite zone, middle Callovian (Riegraf, 1994).

Diagnosis. Large megalosauroid theropod diagnosable by the following autapomorphies: Lacrimal with small oval depression in the antorbital fossa anterior to the lacrimal fenestra; very short and high anterior process of the lacrimal, its length being less than half the height of the bone; postorbital with a transversely notably concave orbital facet in the dorsal part of its anterior side, with markedly raised lateral and medial margins; oblique ridge on the medial side of the fibula at about the level of the iliofibularis tubercle; proximal part of the ascending process of the astragalus deflected laterally, resulting in a marked kink in the lateral margin of this process.

Several further characters can also be used to diagnose the new taxon; although at least several of them are found in some other non-coelurosaurian theropod taxa, and the distribution of others is unclear due to lack of detailed descriptions, their combination is unique to Wiehenvenator albati: Anterior margin of the nasal process of the premaxilla offset from anterior margin of premaxillary body by a slight concavity (also present in Sciurumimus); anteriormost premaxillary tooth considerably smaller than second premaxillary tooth (also present in spinosaurids); medial premaxillary foramen placed over the second alveolus, not the third; maxillary antorbital fossa reduced; small pneumatic depression (excavatio pneumatica) on the ascending process of the maxilla (also present in Ceratosaurus and some allosauroids).

\section{Description}

The bones are generally well-preserved and largely undistorted, but suffered from recent weathering, so that they show numerous fractures and are sometimes preserved in several pieces. Some of the elements are overgrown by marine invertebrates (Gryphaea, serpulids, brachiopods), testifying to subaqueous exposure before burial.

Skull. The sparse cranial material only allows for a tentative reconstruction of the skull (Figure 4). However, the material shows that the skull was rather low and long, as it is the case in most megalosauroids (Carrano et al., 2012). The nares was obviously anteroposteriorly elongated and rather large, and the antorbital fenestra was ventrodorsally low and also elongated anteroposteriorly. The orbit was most probably a high oval in outline, but there is no evidence for a ventral narrowing, resulting in a keyhole-shaped orbit, as it is present in several large theropod dinosaurs, such as Monolophosaurus (Brusatte et al., 2010a), Allosaurus (Gilmore, 1920; Madsen, 1976a) or Tyrannosaurus (Osborn, 1912; Molnar, 1991; Brochu, 2002).

Premaxilla. Most of the body of the right premaxilla and the ventral part of the nasal process are preserved (Figure 5). The posterior border of the bone and the subnarial process are missing, and the premaxillary alveoli are broken open medially. The bone preserves three alveoli; assuming that originally four alveoli were present, as in the vast majority of non-avian theropods (Currie and Zhao, 1993), an estimated $30-40 \mathrm{~mm}$ of the premaxillary 


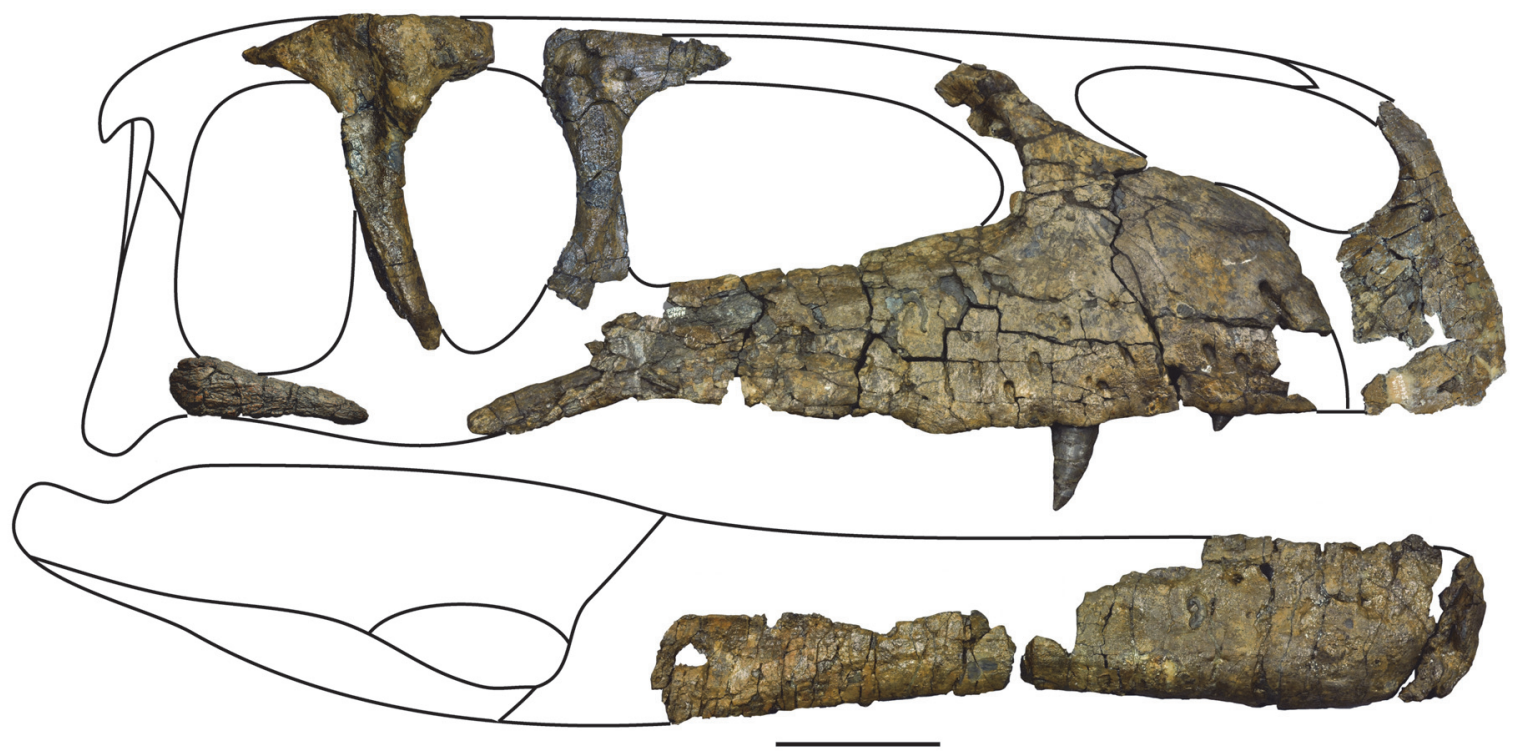

FIGURE 4. Tentative reconstruction of the skull of Wiehenvenator albati, with the recovered elements shown in their approximate relation to each other. Scale bar equals $10 \mathrm{~cm}$.

body is missing posteriorly. Thus, the body was probably rectangular to quadrangular in outline and approximately as long as high $(128 \mathrm{~mm}$ between the ventral border of the nares and the alveolar border). The anterior margin of the premaxillary body is slightly convex and forms an almost right angle with the alveolar margin. The base of the nasal process is almost vertical over its ventralmost c. $30 \mathrm{~mm}$, but flexes slightly posterodorsally in its dorsal part; approximately $60 \mathrm{~mm}$ of the process are preserved in total. There is a slight concavity in lateral outline between the anterior margin of the premaxillary body and the anterior margin of the nasal process (Figure 5.1, 5.2). In the vast majority of theropods, including Torvosaurus, in which the general shape of the premaxilla is similar (Britt, 1991), the anterior margin of the body and the process are confluent; a similar small concavity is only found in the early juvenile holotype of Sciurumimus albersdoerferi (Rauhut et al., 2012). The narial border is confluent between the dorsal margin of the premaxillary body and the posterior margin of the nasal process, so that the anteroventral margin of the external nares was gently concave.

The lateral surface of the premaxillary body is slightly convex dorsoventrally and more notably so anteroposteriorly. Although the bone surface is not smooth, it lacks the strong lateral ornamentation typical for abelisaurids and carcharodontosaurids (e.g., Bonaparte et al., 1990; Sampson and Witmer, 2007; Carrano et al., 2012). A strongly depressed subnarial fossa is absent, but there is a smooth, dorsolaterally inclined surface in the dorsal third of the lateral side. Below this surface, the bone is, unfortunately, too damaged to identify any border of this narial facet. Several small foramina are present on the lateral surface, and there is at least one larger, slit-like foramen at the alveolar border that opens anteriorly (Figure 5.1). Another large foramen ( $8 \mathrm{~mm}$ long and $9 \mathrm{~mm}$ high) is present just at the base of the nasal process, approximately at the mid-width of the latter (Figure 5.1), as in Dubreuillosaurus (Allain, 2002) and many other basal tetanurans. From the foramen, a slight depression extends ventrally, where it becomes wider and shallower and flexes posteroventrally. At least two smaller foramina are placed in this depression. The transverse thickness of the premaxilla is slightly reduced at the level of the large foramen at the base of the nasal process, resulting in a slightly concave lateral outline in anterior view in this area (Figure 5.3). This concave area coincides with the slight concavity in the anterior margin described above.

From the large foramen at the base of the nasal process, a low ridge extends dorsally and then flexes posterodorsally to join the posterior margin of the nasal process; this ridge obviously marks the anterior margin of the narial fossa. Anterior to the ridge, the lateral surface of the nasal process is strongly convex anteroposteriorly in the 

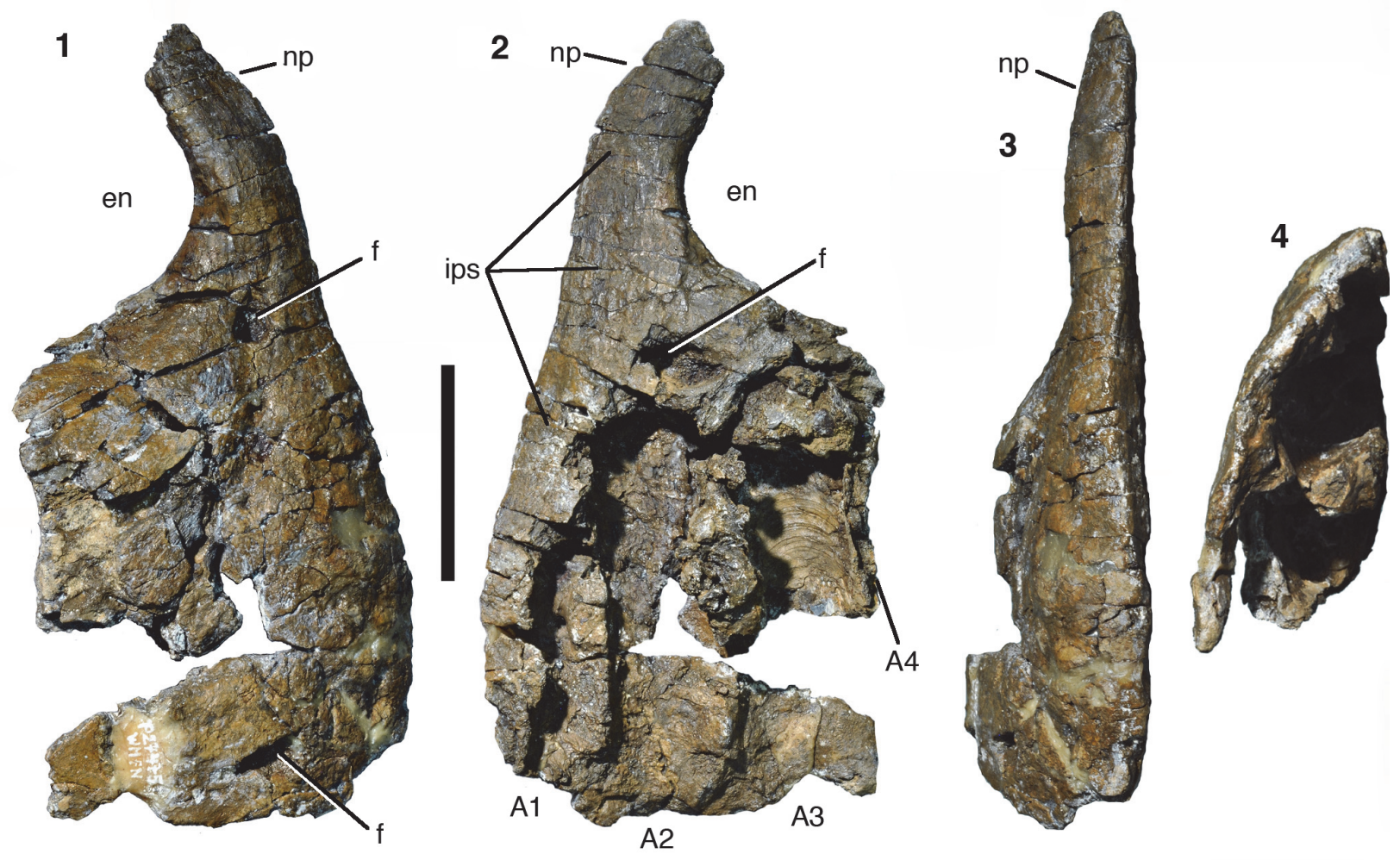

FIGURE 5. Right premaxilla of Wiehenvenator albati in lateral (1), medial (2), anterior (3) and ventral (4) views. Abbreviations: en, external nares; f, foramen; ips, interpremaxillary suture facet; np, nasal process; numbers A1 to A4 indicate alveoli. Scale bar equals $50 \mathrm{~mm}$.

basal part of the process, but becomes flattened dorsally.

Only few details of the medial side of the premaxilla can be established, due to the breakage of the medial wall of the alveoli (Figure 5.2). The interpremaxillary suture is marked by a flat medial surface of the nasal process, the anterodorsal surface of the premaxillary body, and the anterior margin. The preserved parts of this suture indicate that it extended over approximately the anteriormost two alveoli, and thus slightly less than the half length of the bone. Together with the general shape of the premaxilla, this extensive suture indicates a narrow anterior end of the snout.

At the dorsal end of the premaxillary body, the interpremaxillary suture seems to border the internal opening of the foramen at the base of the nasal process, though the anterior border of this foramen is damaged. This internal opening is slightly larger (c. $10.3 \mathrm{~mm}$ high) than the external opening of the foramen and is placed further posteriorly and slightly ventral to the external opening (Figure 5.2), so that this foramen forms a short, anterodorsally directed channel through the dorsal portion of the premaxillary body. The internal opening of the fora- men is placed above the posterior end of the second alveolus, in contrast to Torvosaurus (Britt, 1991), Dubreuillosaurus (Allain, 2002), Majungasaurus (Sampson and Witmer, 2007), Marshosaurus (Madsen, 1976b), Genyodectes (Rauhut, 2004), and many other theropods, where it is placed above the third alveolus.

The anterior, external and most of the posterior margin of three premaxillary alveoli are preserved (Figure 5.2). The second alveolus is the highest, its height $(104 \mathrm{~mm})$ being more than threefourths of the height of the premaxillary body. The anteroposterior width of this alveolus is approximately $30 \mathrm{~mm}$ ventrally. Whereas the third alveolus is only insignificantly lower and approximately as wide as the second alveolus, the first alveolus is markedly smaller, being approximately $66 \mathrm{~mm}$ high and c. $20 \mathrm{~mm}$ wide. A similar condition is seen in spinosaurids (e.g., Charig and Milner, 1997), but is otherwise not present in megalosauroids. The tooth row is slightly curved, with the first alveolus being placed notably medially in respect to the level of the third alveolus (Figure 5.4). The border between alveoli is marked by this interalveolar bone that thickens medially; however, not enough 


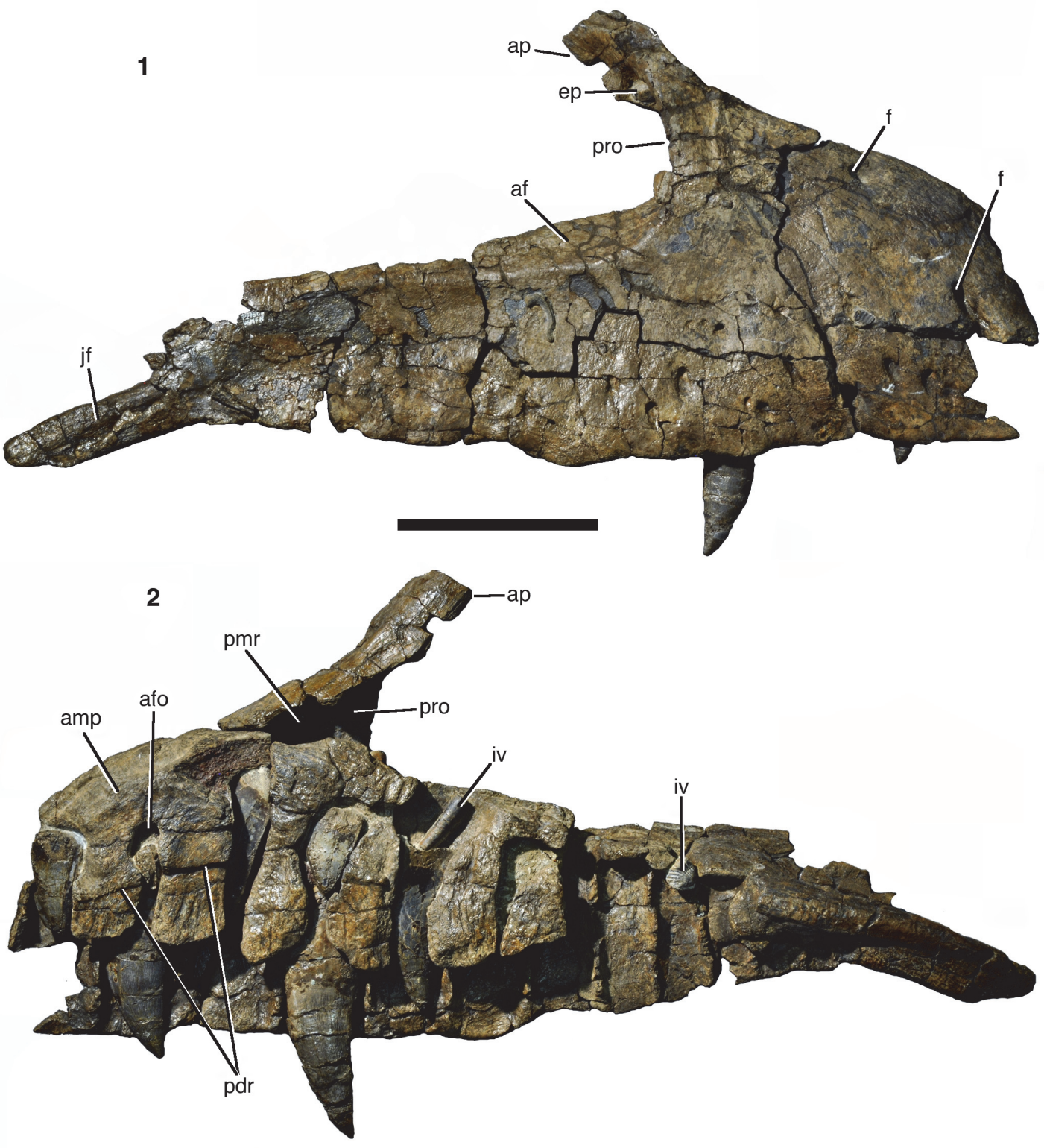

FIGURE 6. Right maxilla of Wiehenvenator albati in lateral (1) and medial (2) views. Abbreviations: af, antorbital fossa; afo, alveolar foramen; amp, base of anteromedial process; ap, ascending process; ep, excavatio pneumatica; $\mathrm{f}$, foramen; iv, invertebrate; jf, jugal facet; pdr, paradental ridge; pmr, promaxillary recess; pro, promaxillary foramen. Scale bar equals $100 \mathrm{~mm}$.

of the medial part of the alveoli is preserved to say anything about the presence and morphology of interdental plates. Of the presumably last (fourth) alveolus, only a small dorsal part of the anterior border is preserved (Figure 5.2). Nothing can be said about the paradental groove.

Maxilla. The right maxilla is preserved in six pieces, which together account for almost the entire element, with only minor parts of the anteroventral and posterodorsal ends, the anteromedial process, and the dorsal part of the ascending pro- cess being missing (Figures 6,7 ). The maxilla is elongate, with a total length of approximately 500 $\mathrm{mm}$ and a notably high preantorbital body. The height from the alveolar border to the highest part of the ascending process is $230 \mathrm{~mm}$. The bone is notably robust, the maxillary body being maximally c. $45 \mathrm{~mm}$ wide at the level of the ascending process. The maxilla has a total of 13 tooth positions, with the tooth row having a total length of $410 \mathrm{~mm}$. The preantorbital body (see Hendrickx and Mateus, 2014a) accounts for approximately 180 


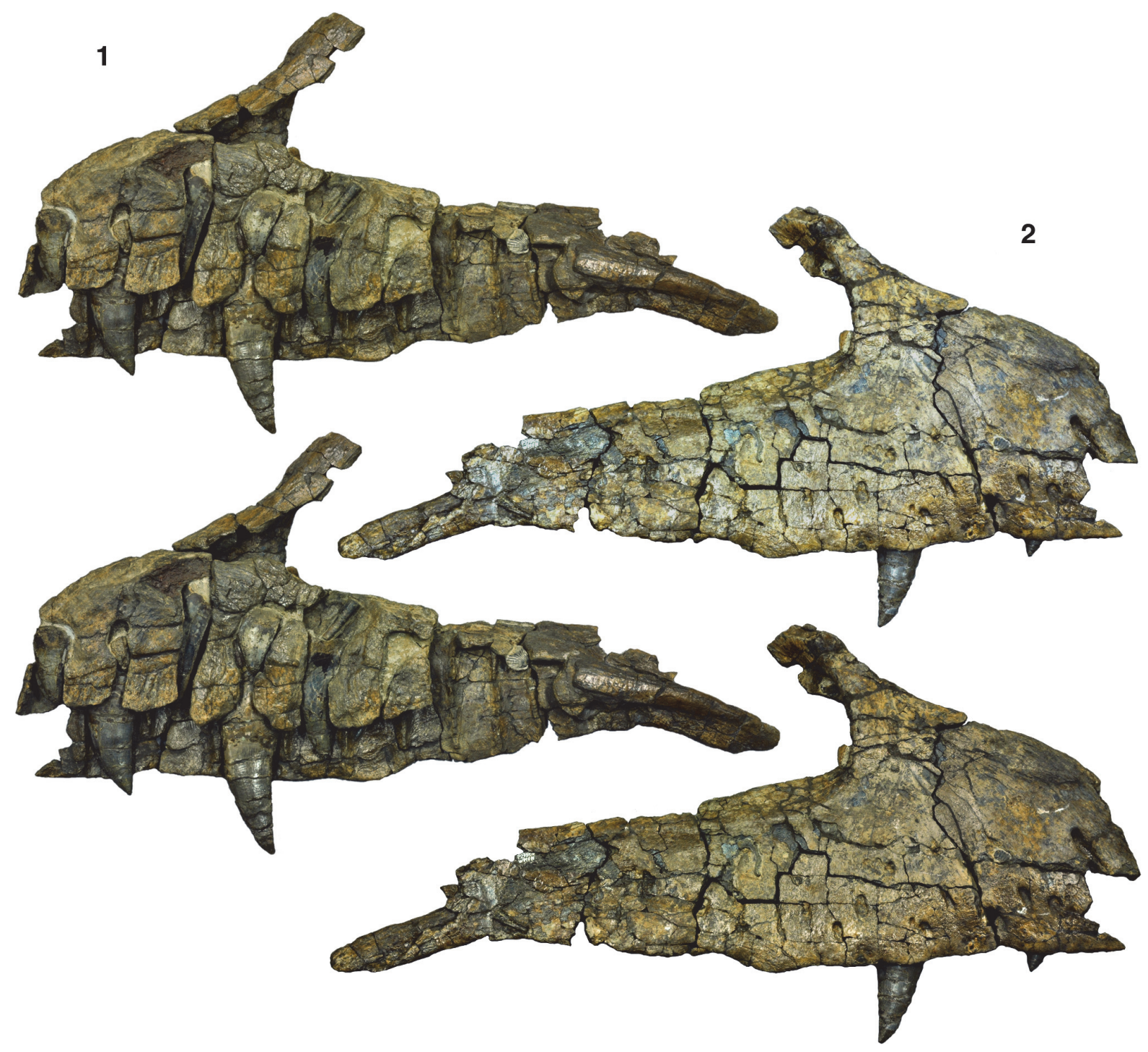

FIGURE 7. Stereophotographs of the right maxilla of Wiehenvenator albati in medial (1) and lateral (2) views.

$\mathrm{mm}$ of the total length of the bone. The anterior ramus is approximately $140 \mathrm{~mm}$ long and the same in height at about its mid-length. However, its dorsal border rises gradually from the premaxillary contact to the base of the ascending process. Thus, the anterior height of the ramus is approximately $111 \mathrm{~mm}$, while it is c. $170 \mathrm{~mm}$ high just anterior to the ascending process. The premaxillary contact is slightly inclined posterodorsally, so that its dorsal end is placed at about the level of the posterior margin of the first alveolus, very similar to the situation in Torvosaurus tanneri (Britt, 1991). The dorsal margin of the anterior ramus is very slightly convex up to the point where it flexes in a gentle concave arch into the anterior margin of the ascending process. This point is placed above the anterior margin of the fourth alveolus. The anterior margin of the ascending process is slightly concave at its base, but flexes posterodorsally in its dorsal part. The point of flexure is marked as a kink in the anterodorsal margin of the ascending process, as in the megalosaurids Dubreuillosaurus (Allain, 2002) and Duriavenator (Benson, 2008), and in some non-megalosaurid theropods, such as Coelophysis rhodesiensis (Raath, 1977) and Monolophosaurus (Brusatte et al., 2010a). Posterior to the kink, the margin of the ascending process is straight over the preserved $35 \mathrm{~mm}$ and ascends considerably less steeply posterodorsally. The ventral margin of the maxilla is very slightly convex over the alveolar border, with slight, irregular undulations. Posterior to the alveolar mar- 

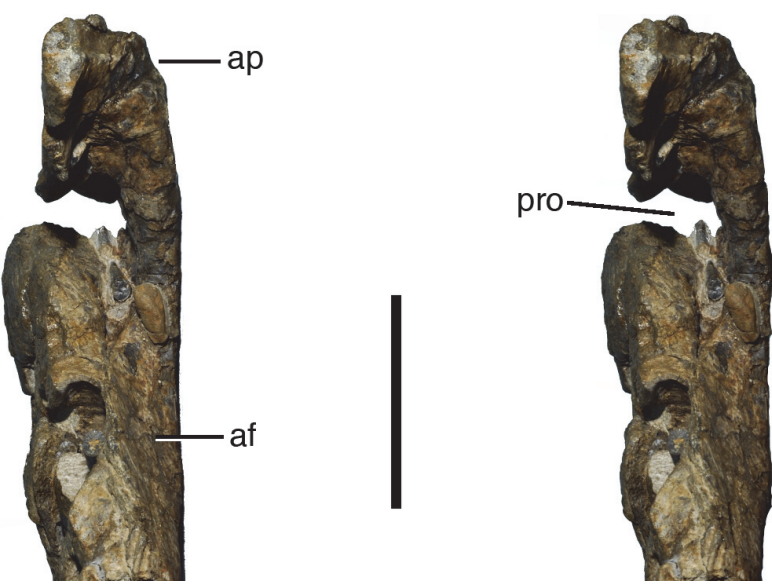

FIGURE 8. Stereophotographs of the promaxillary foramen in the right maxilla of Wiehenvenator albati in posterodorsal view. Abbreviations as in Figure 6. Scale bar equals $50 \mathrm{~mm}$.

gin, the ventral margin flexes ventrally in the area of the contact with the jugal.

The internal antorbital fenestra invaginates the maxilla posteriorly. It was obviously a considerably long, but relatively low opening, being longer than high. The ventral margin of the opening is straight and descends slightly posteroventrally. Thus, the dorsal and ventral margins of the jugal ramus of the maxilla converge somewhat posteriorly, though less notably than in other theropods, such as Ceratosaurus (Gilmore, 1920), Allosaurus (Madsen, 1976a), or Acrocanthosaurus (Eddy and Clarke, 2011). At its anterior end, the jugal ramus is considerably lower $(123 \mathrm{~mm})$ than the anterior ramus of the maxilla. It tapers to a height of $74 \mathrm{~mm}$ at the level of the $11^{\text {th }}$ alveolus, close to the posterior end of the tooth row. Although the posterodorsal end of the jugal ramus is somewhat damaged, it can be said that the margin of the fenestra flexes abruptly ventrally towards the jugal suture posteriorly. Thus, the jugal ramus of the maxilla is remarkably similar to that of Torvosaurus gurneyi (Hendrickx and Mateus, 2014a).

As in the vast majority of non-avian theropods, the antorbital fenestra is surrounded by a maxillary antorbital fossa (Figures 6.1, 7.2). However, in comparison with most tetanuran theropods, this fossa is very small in Wiehenvenator, similar to the situation in Torvosaurus (Britt, 1991), abelisaurids (e.g., Sampson and Witmer, 2007), and derived carcharodontosaurids (e.g., Coria and Currie, 2006). The maximal height of the fossa ventral to the antorbital opening at the anterior end of the jugal ramus is $25 \mathrm{~mm}$, and it gradually tapers posteriorly and disappears at about the level of the $10^{\text {th }}$ alveolus. The fossa is mainly marked as a slightly dorsolaterally inclined surface that is set off from the lateral surface of the maxilla by a low, rounded eminence (Figures 6.1, 7.2, 8). Although the internal wall of the antorbital fossa is somewhat damaged anteriorly, enough is preserved to indicate that the fossa was reduced in the anteroventral end of the antorbital opening. This contrasts with the situation in the vast majority of theropods, in which the maxillary antorbital fossa anterior to the internal antorbital opening accounts for $10 \%$ of the length of the latter or more. The fossa extends onto the posterior surface of the ascending process, where, in the preserved ventral part, its surface faces posterolaterally rather than strictly laterally (Figures 6.1, 7.2). As in other theropods, the anterior margin of the antorbital fossa extends onto the ascending process up to the level of the kink in the dorsal margin, from where on the nasal would have formed the dorsal margin of this fossa.

The lateral surface of the maxilla is largely smooth. It is very slightly convex dorsoventrally in the anterior ramus, but very slightly concave in the jugal ramus. A very slight, triangular depression is present on the lateral surface of the base of the ascending process. The lateral surface is pierced by numerous foramina (Figures 6.1, 7.2). Anterodorsally, there is a large, anteriorly and slightly dorsally facing foramen towards the dorsal margin of the anterior ramus, at about its mid-length. A notable, but shallow depression extends from this foramen anteroventrally onto the dorsal fourth of the anterior end of the anterior ramus. Another very conspicuous foramen is found some $27 \mathrm{~mm}$ from the anterior margin of the maxillary body at about the mid-height of the anterior ramus, approximately at the level of the border between the first and second alveolus. It faces ventrally and very slightly anteriorly and continues as a deep channel anteroventrally up to the break in the anteroventral margin of the bone. Apart from these very conspicuous foramina, numerous large, ventrolaterally opening foramina are present along the tooth row. They are arranged in a zig-zag pattern with alternating lower and higher foramina. The lower foramina are offset from the alveolar margin by minimally $17 \mathrm{~mm}$, whereas the upper foramina extend up to $40 \mathrm{~mm}$ from the alveolar margin. A further foramen, similar in size and morphology to these neurovascular foramina, is present above the fourth alveolus, some $60 \mathrm{~mm}$ above the alveolar margin. The last two foramina are placed above the $8^{\text {th }}$ and $10^{\text {th }}$ alveolus, respectively, and do not follow the zigzag pattern, being placed at approximately the 
same level, some $48 \mathrm{~mm}$ above the alveolar margin.

Only parts of the sutural contacts to other bones are preserved. The premaxillary suture is represented mainly by a small section of its midheight, which forms a transversely convex, anteriorly facing surface. The dorsal surface of the anterior end of the anterior ramus of the maxilla is too strongly weathered to discern any facet for the subnarial process of the premaxilla. More posteriorly, the dorsal surface is better preserved, but no facet for the subnarial process is present, indicating that the maxilla might have separated the subnarial process of the premaxilla and the ventral anterior process of the nasal and thus formed at least a small portion of the ventral margin of the external naris. Towards the base of the ascending process, at about the level of the border between the third and fourth alveolus, the facet for the ventral anterior process of the nasal is developed as an anterodorsally facing depression. The depression is marked by raised lateral and medial margins and tapers anteriorly. On the anterior surface of the ascending process, this facet becomes notably deeper, though this might be due to deformation. Another small facet for the main body of the nasal is present on the dorsolateral surface of the dorsalmost preserved part of the ascending process. This facet narrows slightly anteriorly and extends up to the rim of the antorbital fossa.

Posteriorly, large parts of the suture with the jugal are preserved (Figures 6.1, 7.2). The suture is preserved as an elongate lateral facet bordered ventrally by a laterally flexed shelf of the ventral border of the maxilla. This shelf turns dorsally anteriorly to enclose a narrow, deep furrow for the reception of the anterior end of the jugal, as in Torvosaurus gurneyi (Hendrickx and Mateus, 2014a). Just at the posterior end of the tooth row, the shelf expands rapidly dorsally to form the lateral surface of the maxillary body, but the furrow continues medial to the shelf up to at least the anterior end of the $11^{\text {th }}$ alveolus and becomes shallower anteriorly. Medial to the jugal facet, a shallow, elongate groove is present on the transversely thickened posterior end of the maxilla. This groove faces dorsally and slightly laterally and probably represents the contact for the lacrimal.

As it is usual in averostran theropods, additional pneumatic features are present in the anterior end of the antorbital fossa. Due to the reduction of the fossa noted above, no maxillary fenestra or fossa seems to be present, in contrast to the majority of tetanuran theropods. However, a large promaxillary foramen is present in the anterior end of the fossa and pierces the base of the ascending process, leading anteriorly into a large promaxillary recess within this structure (Figures $6.2,7.1,8)$. The foramen is large and considerably higher (c. $39 \mathrm{~mm}$ ) than wide (c. $21 \mathrm{~mm}$ ). As in many theropods, it is completely concealed in lateral view by the overhanging anterior border of the antorbital fossa (Figures 6.1,7.2). The premaxillary recess associated with this foramen is triangular in outline, tapering anteroventrally and thus occupies the entire base of the ascending process (Figures $6.2,7.1$ ). A small depression is furthermore present dorsal to the promaxillary foramen on the ventral part of the antorbital fossa on the ascending process and is visible in lateral view (Figures 6.1, 7.2). This depression corresponds in relative position to the excavatio pneumatica seen in some theropods (Witmer, 1997) and might thus represent this structure. In accordance with the reduced medial wall of the antorbital fossa, this depression is smaller and slightly more ventrally placed than the excavatio pneumatica in most theropods, in which it is present. It is furthermore bordered medially by a rather robust wall of bone, in contrast to e.g., Sinraptor, in which the excavation pneumatica is only limited by a very thin sheet of bone medially (IVPP V-10600; Currie and Zhao, 1993)

The medial side of the maxilla is poorly preserved, and the medial wall of several alveoli and the anteromedial process are missing (Figures 6.2, 7.1). As in the premaxilla, the alveoli are very high and extend dorsally over almost the entire height of the maxillary body. In accordance with the general shape of the maxillary body, the height of the alveoli increases up to the third alveolus and then gradually decreases again posteriorly. Posterior to the $10^{\text {th }}$ alveolus, the dorsal margin of the maxilla is thickened medially and extends further ventrally, resulting in a notable step in the bone between the $10^{\text {th }}$ and the $11^{\text {th }}$ alveolus. The mesiodistal width of the alveoli increases from approximately $35 \mathrm{~mm}$ in the first alveolus to a maximum of $45 \mathrm{~mm}$ in the third alveolus and then decreases gradually towards the end of the tooth row (see Table 1). Several interdental plates are at least partially preserved. The plates are clearly separated, in contrast to the situation in Torvosaurus (Britt, 1991; Hendrickx and Mateus, 2014a) and allosauroids. The medial surface of the interdental plates is poorly preserved in most elements, but robust dorsoventral striations are discernible in some plates (Figures 6.2, 7.1), as they are also present in some other megalosauroids (Benson, 2010a). A true 
TABLE 1. Anteroposterior width of the maxillary alveoli of Wiehenvenator albati (in $\mathrm{mm}$ ).

\begin{tabular}{|c|c|c|c|c|c|c|c|c|c|c|c|c|c|}
\hline Alveolus & 1 & 2 & 3 & 4 & 5 & 6 & 7 & 8 & 9 & 10 & 11 & 12 & 13 \\
\hline Width & c. 35 & c. 39 & c. 45 & c. 40 & 37 & 35 & 30 & 25 & 23 & c. 18 & c. 20 & 13 & 10 \\
\hline
\end{tabular}

paradental groove ('groove for the dental lamina' of Brusatte et al., 2012; 'nutrient groove' of Hendrickx and Mateus, 2014a), as it is present in many theropods is absent, but there is a notable step separating the interdental plates from the medial wall of the maxillary body dorsal to the plates, here termed the paradental ridge. The paradental ridge is visible in a few places (Figure 6.2); it is placed at about two thirds of the height of the maxillary body and is slightly curved, reaching its highest point at about the third to fourth alveolus and lowering anteriorly, as in many other megalosaurids (Benson, 2010a). An enlarged dental foramen ('nutrient foramen' of Hendrickx and Mateus, 2014a) is present between the second and third alveolus and extends further dorsally than the paradental ridge (Figures 6.2, 7.1), as in Majungasaurus (Sampson and Witmer, 2007), although this might be somewhat exaggerated by erosion (Although we follow Hendrickx and Mateus [2014a] in the terminology of other parts of the maxilla, we prefer the terms 'paradental groove' and 'dental foramen' for these structures associated with the interdental plates, as they are more specific than the terms 'nutrient groove' and 'nutrient foramen' advocated by these authors). Although none of the interdental plates is complete, their ventral border was clearly placed considerably dorsal to the lateral alveolar margin, as in Torvosaurus (Britt, 1991) and Megalosaurus (Benson, 2010a). The anteromedial process is broken off, but its base is placed notably above the interdental plates (Figure 6.2), as in Torvosaurus (Britt, 1991) and Megalosaurus (Benson, 2010a). Posteriorly, some longitudinal striations are present on the dorsomedial side of the thickened posterior end of the maxillary body; these striations probably represent the posterior part of the suture with the palatine. If a large neurovascular opening was present on the dorsomedial margin of the jugal process, as it is the case in Torvosaurus (Hendrickx and Mateus, 2014a) and other basal tetanurans, cannot be said, as this region is poorly preserved (Figures $6,7)$.

The only functional tooth preserved occupies the fourth alveolus, though the crown sits approximately with its half-height still above the alveolar border. Thus, it currently protrudes $47 \mathrm{~mm}$ beyond the alveolar border, but the total height of the crown is approximately $80 \mathrm{~mm}$. Replacement teeth are present in the first, second, third, fourth, and fifth alveolus, in different stages of eruption: Whereas in the second alveolus, the tip of the crown just protrudes beyond the alveolar border, the fourth alveolus shows the upper part of the crown of a new replacement tooth in the upper part of the alveolus lingual to the functioning tooth. The teeth are described in detail below.

Lacrimal. As it is usual in theropods, the lacrimal is an inverted L-shaped element, with a preserved height of approximately $180 \mathrm{~mm}$ (Figure 9). A small portion of the ventral end seems to be missing, but this missing portion should not be more than a few $\mathrm{cm}$. However, in comparison with most taxa, the anterior process is remarkably short and dorsoventrally high; the total length of the dorsal part of the lacrimal $(122 \mathrm{~mm})$ is approximately $68 \%$ of the preserved height of the bone. This abbreviated shape is most probably not due to breakage, as the margins of the process seem to be intact. Furthermore, the anterior process tapers anteriorly to form a broad tip that most probably articulated with the forked posterior end of the ascending process of the maxilla, as in other theropods, so the shape is also consistent with the process being complete. The dorsal margin of the process is convex over its entire length. The ventral margin is slightly concave in the area of contact with the maxilla, and then becomes slightly convex, before it curves in a gradual concave arch into the anterior margin of the ventral process at about half the length of the anterior process. The facet for the articulation with the maxilla on the ventral part of this anterior process is marked by a notable step on the lateral side.

Although a marked lacrimal horn is absent, the posterodorsal margin of the bone is gently convex, and there is a small, rounded dorsal protrusion at the posterodorsal corner (Figure 9.1). The orbital margin of the ventral process is gently concave over its entire length, whereas the anterior margin is slightly concave in its dorsal half and slightly convex in its ventral half. Thus, the ventral end of the ventral process is more markedly expanded posteriorly than anteriorly. The anteroposteriorly shortest part of the ventral process $(28 \mathrm{~mm})$ is found at about its mid-height. Whereas the anterior process forms a robust, but flat, triangular plate of 


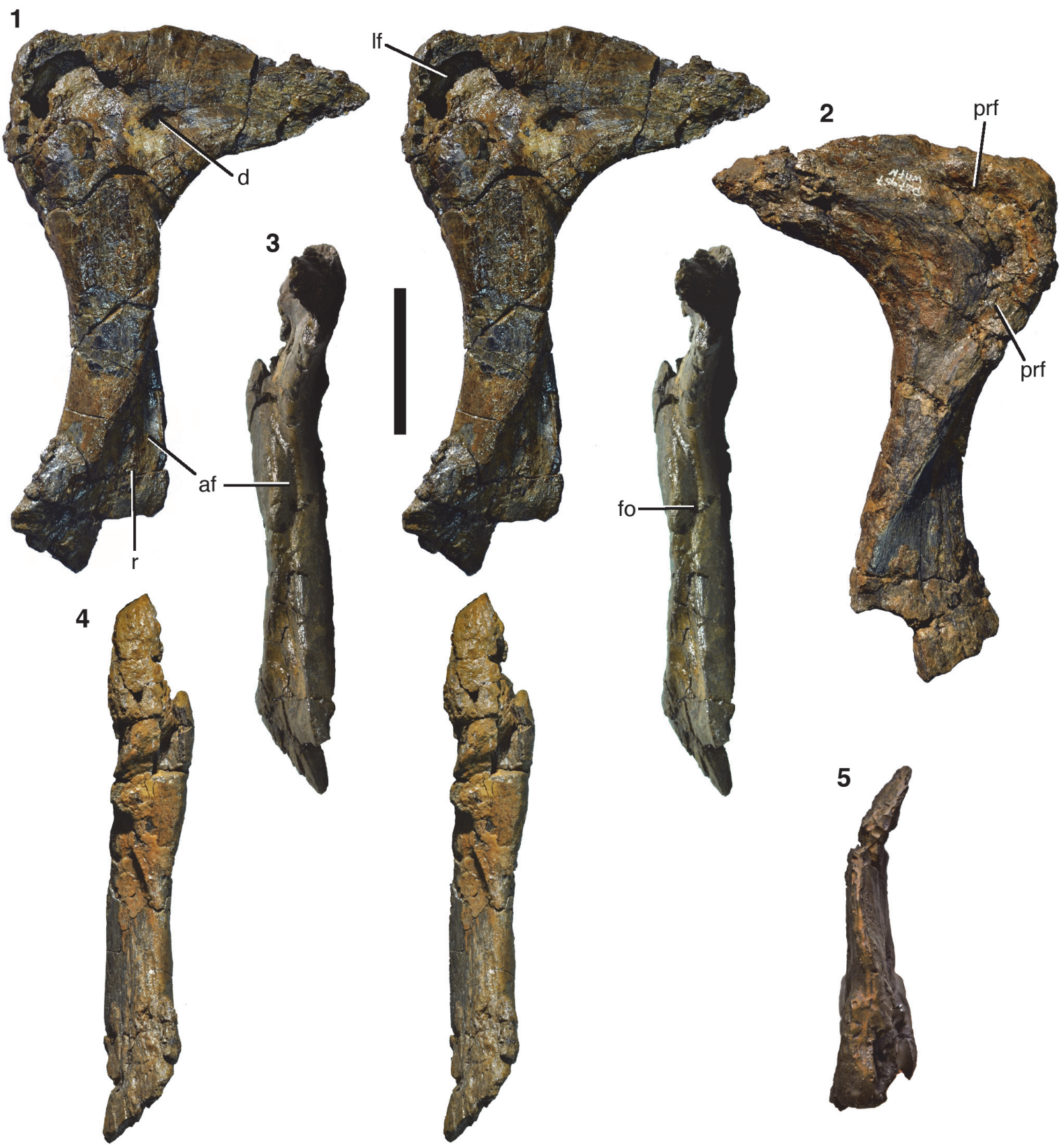

FIGURE 9. Right lacrimal of Wiehenvenator albati in lateral (1; stereophotographs), medial (2), anterior (3; stereophotographs), posterior (4; stereophotographs), and dorsal (5) views. Abbreviations: af, antorbital fossa; d, depression; fo, foramen; If, lacrimal fenestra; prf, facet for prefrontal; r, ridge. Scale bar equals $50 \mathrm{~mm}$.

bone, the ventral process is notably thickened transversely.

The lateral surface of the lacrimal is depressed by the antorbital fossa on its anterodorsal corner and most of the anterior process and on the anterior side of the ventral end of the ventral process (Figure 9.1). Unlike the situation in Torvosaurus (Britt, 1991), spinosaurids (Charig and Milner, 1997; Sues et al., 2002), and Sciurumimus
(Rauhut et al., 2012), but as in most theropods, including Ceratosaurus (Madsen and Welles, 2000), Dubreuillosaurus (Allain, 2002), Afrovenator (Sereno et al., 1994) and allosauroids (Madsen, 1976a), the dorsal and ventral parts of the antorbital fossa are not confluent on the anterior side of the ventral process, but separated by an anteriorly convex margin of the lateral surface of the lacrimal body ('lateral blade' of the lacrimal of Britt, 1991). 
However, whereas the 'lateral blade' protrudes into the antorbital opening in some theropods (e.g., Gilmore, 1920), it only insignificantly overhangs the medial side in Wiehenvenator, similar to the situation in Dubreuillosaurus (Allain, 2002). A shallow groove on the anterior side of the ventral process separates the 'lateral blade' from the medial part and thus connects the dorsal and ventral portions of the antorbital fossa (Figure 9.3). A small foramen in the middle of this groove most probably represents the anterior exit of the lacrimal foramen. The ventral part of the antorbital fossa is triangular in outline and subdivided by a low, almost vertical ridge into an anterior and a posterior concavity (Figure 9.1). The anterior concavity is also separated from the margin of the antorbital fenestra by a very slightly raised edge.

In the posterodorsal corner of the lacrimal, a large lacrimal fenestra expands from the antorbital fossa into the bone. Its lateral wall is broken off, revealing that the lacrimal fenestra led into a single, more or less round pneumatic chamber (Figure 9.1). A small (11 $\mathrm{mm}$ long and $8 \mathrm{~mm}$ high) but deep oval depression is found anterior to the exit of the lacrimal fenestra within the antorbital fossa on the lateral side of the base of the anterior process. Whereas the dorsal margin of the lacrimal is slightly thickened directly in front of the lacrimal fenestra to border the antorbital fossa, this thickening rapidly disappears anteriorly, so that the entire lateral surface of the anterior process is occupied by the fossa, in contrast to Allosaurus (Gilmore, 1920), Torvosaurus (Britt, 1991), and many other theropods.

Medially, the surface of the anterior process is slightly convex dorsoventrally. A shallow depression along the dorsal border of the process becomes more marked in the posterodorsal corner of the bone and then flexes ventrally and slightly anteriorly; this depression marks the contact for the prefrontal (Figure 9.2). The posterodorsal margin of the bone is somewhat thickened (Figure 9.5). From this thickened margin, a notable ridge continues on the ventral process obliquely across the medial surface. The ridge begins at about two thirds of the height of the element at the posterior border and extends anteroventrally until it meets the anterior border towards the ventral end, becoming lower ventrally. The area posterior to the ridge faces more posteriorly than medially in its dorsal part, but gradually twists to face medially in the ventral portion. The posterior border of the bone is more notably thickened than the anterior border. It is flat in its dorsal part, but there is a nota- ble step extending ventrolaterally from the point where the ridge described above begins. This ridge meets the lateral margin of the bone just below the mid-height of the bone and thus borders the posteromedially facing surface described above laterally.

As the ventral end of the bone is damaged, nothing can be said about the exact contacts with the jugal ramus of the maxilla and the jugal.

Postorbital. As with the other cranial elements, the postorbital (Figure 10) is markedly robust. It is a Tshaped element with a long ventral process and short anterior and posterior processes dorsally. The maximal anteroposterior length of the bone across the dorsal processes is $131 \mathrm{~mm}$, whereas the maximal height of the bone is $190 \mathrm{~mm}$. The ventral process is flexed slightly anteriorly, so that its anterior border is gently concave over its entire length and the posterior border is slightly convex. Dorsally, the posterior border flexes posteriorly in a gradual concave arch into the posterior process. The latter is triangular in outline and tapers posteriorly. The anterior process is more robust and rectangular in lateral outline. Its dorsal margin forms a convex margin that is confluent with the dorsal margin of the posterior process, in contrast to Allosaurus (Madsen, 1976a) and many other theropods, in which the dorsal margin of the anterior process is concave, and the margin of the posterior process convex. The two processes are subequal in length, the posterior process being $62 \mathrm{~mm}$ long and the anterior process $69 \mathrm{~mm}$ (both measured from the highest point of the bone, which roughly coincides with the mid-point of the ventral process).

As in many theropods, there is a raised, slightly rugose 'brow' on the lateral side of the anterior process (Figure 10.1). This brow extends approximately onto the half-width of the dorsal end of the ventral process and is bordered posteriorly by a marked depression. This depression starts at approximately the half-height of the ventral process and expands over the confluence of the processes to the base of the posterior process, where the bone becomes flat. The edge between the 'brow' and this depression is curved posterodorsally in its dorsal portion and becomes lower posteriorly.

The ventral process is markedly robust, being thicker transversely (30 $\mathrm{mm}$ at mid-height) than anteroposteriorly $(26 \mathrm{~mm})$. The ventral half of the process is notably convex anteroposteriorly both laterally and medially, whereas the orbital margin is flattened transversely. On the posterior side of the ventral process, a broad, longitudinal groove marks 


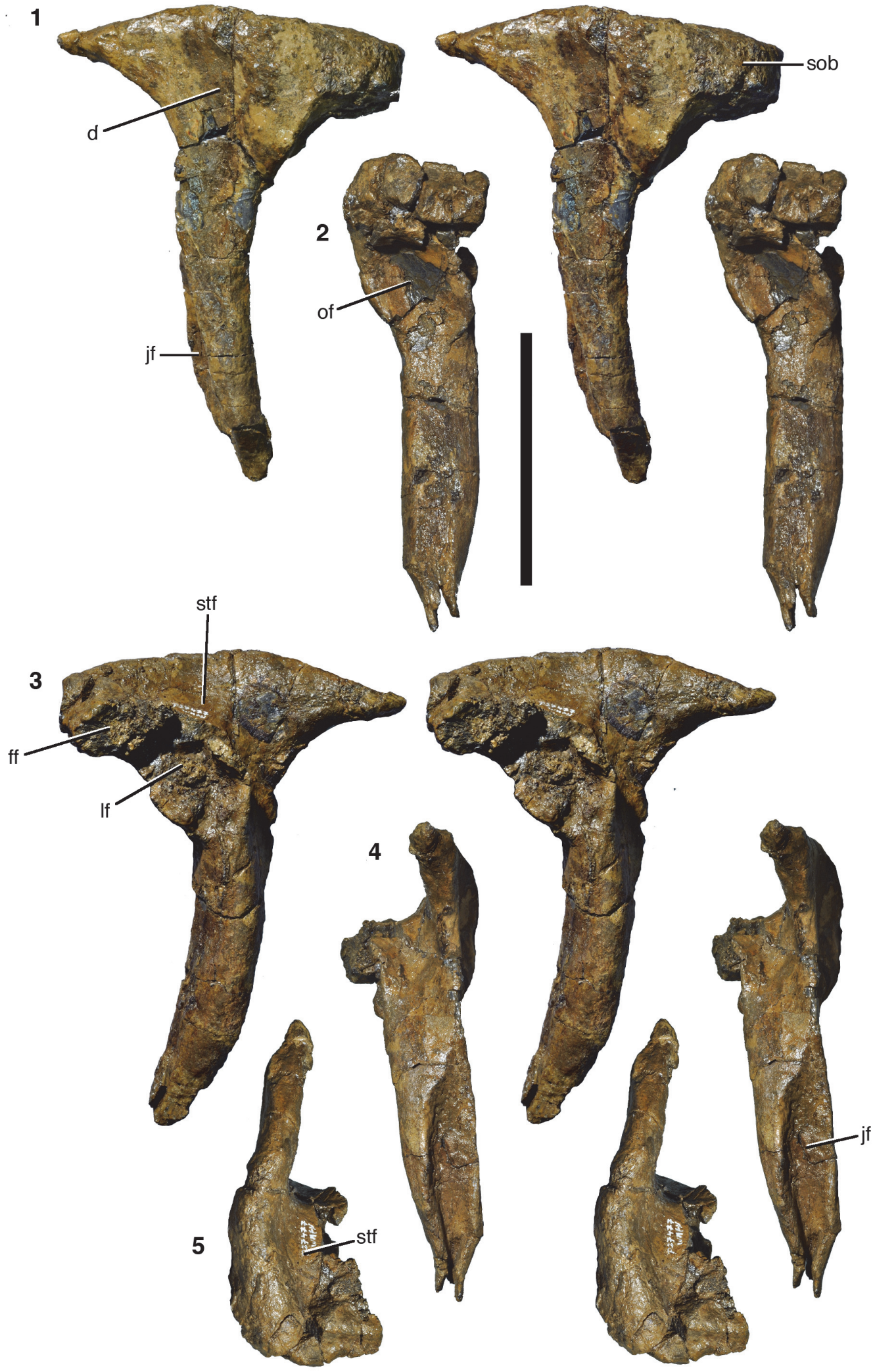

FIGURE 10. Right postorbital of Wiehenvenator albati in lateral (1), anterior (2), medial (3), posterior (4), and dorsal (5) views (all stereophotographs). Abbreviations: d, depression, ff, frontal facet; jf, jugal facet; If, laterosphenoid facet; of, orbital facet; sob, supraorbital brow; stf, supratemporal fossa. Scale bar equals $100 \mathrm{~mm}$. 
the contact with the dorsal process of the jugal (Figure 10.4). The groove is deeper medially than laterally and becomes narrower ventrally. The medial wall of the groove is slightly higher than the lateral wall, so that its edge is visible in lateral view (Figure 10.1). Thus, the suture for the jugal is $U$ shaped in cross-section, as in other megalosaurids (Sereno et al., 1994; Rauhut, 2003). Whereas the lateral edge of the groove is approximately level with the lateral side of the ventral process, the medial wall is slightly offset laterally from the medial side. Dorsally, a low oblique ridge extends from the dorsal end of the medial wall dorsolaterally and meets the lateral edge at about two thirds of the height of the process. From the confluence of these two edges, the posterolateral margin of the bone forms a narrow, but stout ridge connecting the ventral process with the posterior process. Medial to this ridge, the posterior side of the bone becomes markedly concave transversely towards the dorsal supratemporal fossa (Figure 10.4).

The posterior process is considerably more slender transversely than the ventral and anterior process. Its posterior tip is somewhat rounded in cross-section, with the lateral surface being slightly offset from the lateral surface of the main body of the process. A flattened surface for the overlap of the dorsal anterior process of the squamosal is present on the dorsal surface of the process, whereas the ventral facet is slightly convex transversely and faces very slightly medioventrally. Both facets extend anteriorly to approximately the level of the posterior border of the ventral process.

As noted above, the anterior side of the ventral process is flat, but there is an unusual, conspicuous, round facet in the dorsal part of this surface (Figure 10.2). This facet is strongly concave both dorsoventrally and transversely and extends onto the anterior process dorsally. It has markedly raised lateral and medial margins, with the medial side expanding anteromedioventrally, so that it is visible in lateral view anterior to the lateral margin. The margin of this medial expansion forms a sharp ridge, the ventral end of which curves ventrolaterally onto the anterior side of the ventral process, ending some $12 \mathrm{~mm}$ below the lateral margin. The latter is stout and rounded and curves slightly medially in its ventral end, being offset from the anterolateral edge of the ventral process by a small step.

The anterior process is markedly expanded transversely to a maximal width of $57 \mathrm{~mm}$ and houses the anterolateral part of the supratemporal fossa dorsally (Figure 10.5). The fossa is deeply excavated and has a steep lateral margin, with the lateral edge becoming slightly thicker anteriorly. The fossa has a slightly concave lateral margin, but does not extend onto the medial side of the posterior process. Dorsally, the supratemporal fossa has a flat ventral floor anteriorly that abruptly flexes ventrally into the posterior concavity on the dorsal part of the ventral process at about the mid-width of the latter.

The suture with the frontal is largely obscured by erosion and breakage, but there is a large, medially facing facet for the laterosphenoid on the confluence of the anterior and ventral processes (Figure 10.2). This facet is obliquely elongate oval in outline, and seems to have been deeply concave, but has also suffered from erosion, so no details of the articular surface can be made out.

Quadratojugal. A stout, finger-like bone probably represents the anterior (jugal) ramus of the right quadratojugal (Figure 11). The element is preserved over a length of approximately $12 \mathrm{~cm}$, with the posterior end showing signs of erosion, rather than a clear break. It tapers anteriorly, being 37 $\mathrm{mm}$ high at the posterior end, but only $14 \mathrm{~mm}$ at a point c. $10 \mathrm{~mm}$ from the anterior end, from where the anterior end is gently rounded. In lateral view, the anterior portion is very slightly flexed ventrally, in contrast to the situation in many theropods, where the anterior ramus of the quadratojugal is often slightly flexed dorsally (e.g., Currie and Zhao, 1993; Sampson and Witmer, 2007). In dorsal or ventral view (Figure 11.3, 11.4), the bone is slightly curved medially, as it is the case in many theropod quadratojugals. As with all cranial bones of Wiehenvenator, the bone is notably robust, being 14 $\mathrm{mm}$ wide transversely towards the anterior end. Whereas the dorsal margin of the element stays of more or less subequal width over its entire length, the ventral part becomes thinner and the ventral edge has a width of only $6 \mathrm{~mm}$ in its posterior part. At the area of the eroded connection to the dorsal process, the entire bone is again considerably thickened to approximately $14 \mathrm{~mm}$.

The lateral surface is slightly convex dorsoventrally in its anterior portion and the ventral two thirds of the posterior part, but curves medially in the dorsal third in the posterior two-thirds of the process (Figure 11.1), to meet the medial surface in a sharp angle towards the posterior end of the preserved portion. The medial side is both anteroposteriorly and dorsoventrally slightly concave in its ventral part, whereas the dorsal margin forms a stout rib anteriorly and a straight surface towards the posterior end (Figure 11.2). 

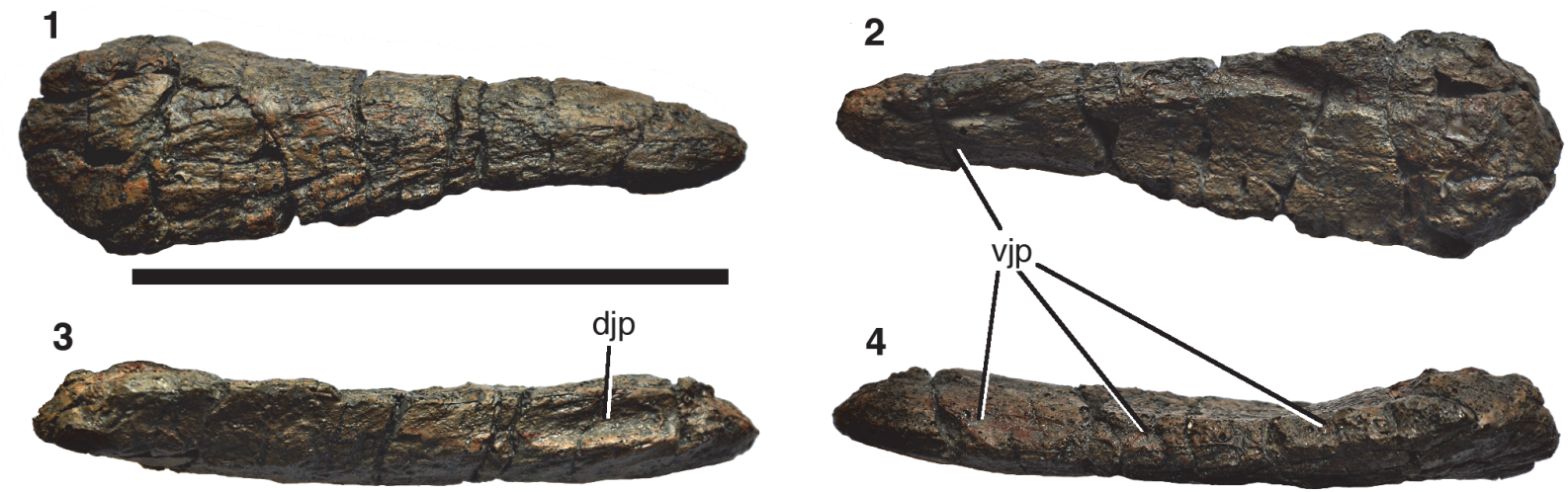

FIGURE 11. Anterior (jugal) process of the right quadratojugal(?) of Wiehenvenator albati in lateral (1), medial (2), dorsal (3), and ventral (4) views. Abbreviations: djp, facet for the dorsal posterior prong of the jugal; vjp, facet for the ventral posterior prong of the jugal. Scale bar equals $100 \mathrm{~mm}$.

The contact facets for the jugal are very similar to those seen in Majungasaurus (Sampson and Witmer, 2007). On the dorsal surface of the anterior end, a well-developed, broad, but rather shallow longitudinal groove represents the facet for the dorsal posterior prong of the jugal (Figure 11.3). This groove begins posterior to the anteriorly rounded tip of the bone and extends for approximately $30 \mathrm{~mm}$ posteriorly before it fades out into a broad, flattened surface, which becomes increasingly inclined laterally posteriorly. Based on the morphology of this facet, the dorsal prong of the jugal overlapped the quadratojugal probably for 50 $60 \mathrm{~mm}$. The contact for the ventral posterior prong of the jugal is developed as a ventromedially facing facet anteriorly that becomes gradually thinner posteriorly and turns onto the ventral edge, where it continues over the entire length of the preserved portion of the quadratojugal as a flattened ventral surface (Figure 11.2, 11.4). Thus, the ventral posterior prong of the jugal was obviously considerably longer than the dorsal prong, as in most theropods. Dentary. The right dentary is present, but very poorly preserved (Figure 12). The bone was found in three pieces, which together account for approximately $485 \mathrm{~mm}$ of its length. Approximately 275 $\mathrm{mm}$ of these represent the tooth-bearing portion of the dentary, whereas the posterior part is only represented by its ventral portion, which does not show any signs of alveoli (Figure 12.3). It is unclear whether any part in between these portions is missing, but if so, it should be a minor part. In the anteriormost preserved part of the main dentigerous portion of the bone, the lateral side flexes slightly medially and the ventral margin starts to curve dorsally, indicating that this part is close to the anterior end of the dentary. A small fragment obviously represents a portion even more anteriorly, with an anteroposteriorly narrow alveolus and an almost entirely anteriorly facing lateral side, but again it cannot be said how much is missing between this fragment and the main section. However, given the proximity of this fragment to the main section of the dentary in the quarry and the indications that the anterior part of the main section is already close to the anterior end, not much seems to be missing, and we assume that the preserved one and one-third alveoli of this piece are continuous with the alveoli of the main section.

At least nine alveoli are present in the preserved parts of the tooth row (Figure 12.3). The first alveolus is considerably smaller (c. $14 \mathrm{~mm}$ anteroposterior length and two-thirds to threefourths of the height of the other alveoli) than the more posterior tooth sockets. The second alveolus cannot be measured with any certainty, as a small part of it might be missing. In the main section of the dentary, the presumably third alveolus is notably larger (35 $\mathrm{mm}$ anteroposterior length) than the more posterior alveoli, which remain of subequal size throughout the preserved portion $(27-28 \mathrm{~mm}$ anteroposterior length). Thus, the alveoli in the dentary are consistently lower and narrower than those in the maxilla, indicating that the dentary teeth might have been somewhat smaller than the corresponding maxillary teeth, as in Dilophosaurus (Welles, 1984), Ceratosaurus (Gilmore, 1920), Dubreuillosaurus (Allain, 2002), Baryonyx (Charig and Milner, 1997), Eustreptospondylus (Sadleir et al., 2008), and probably Torvosaurus (Britt, 1991; though note that the maxilla BYU 9122 does not necessarily represent the same individual as the dentary BYU 2003). The anterior end of the dentary is slightly expanded transversely compared to 


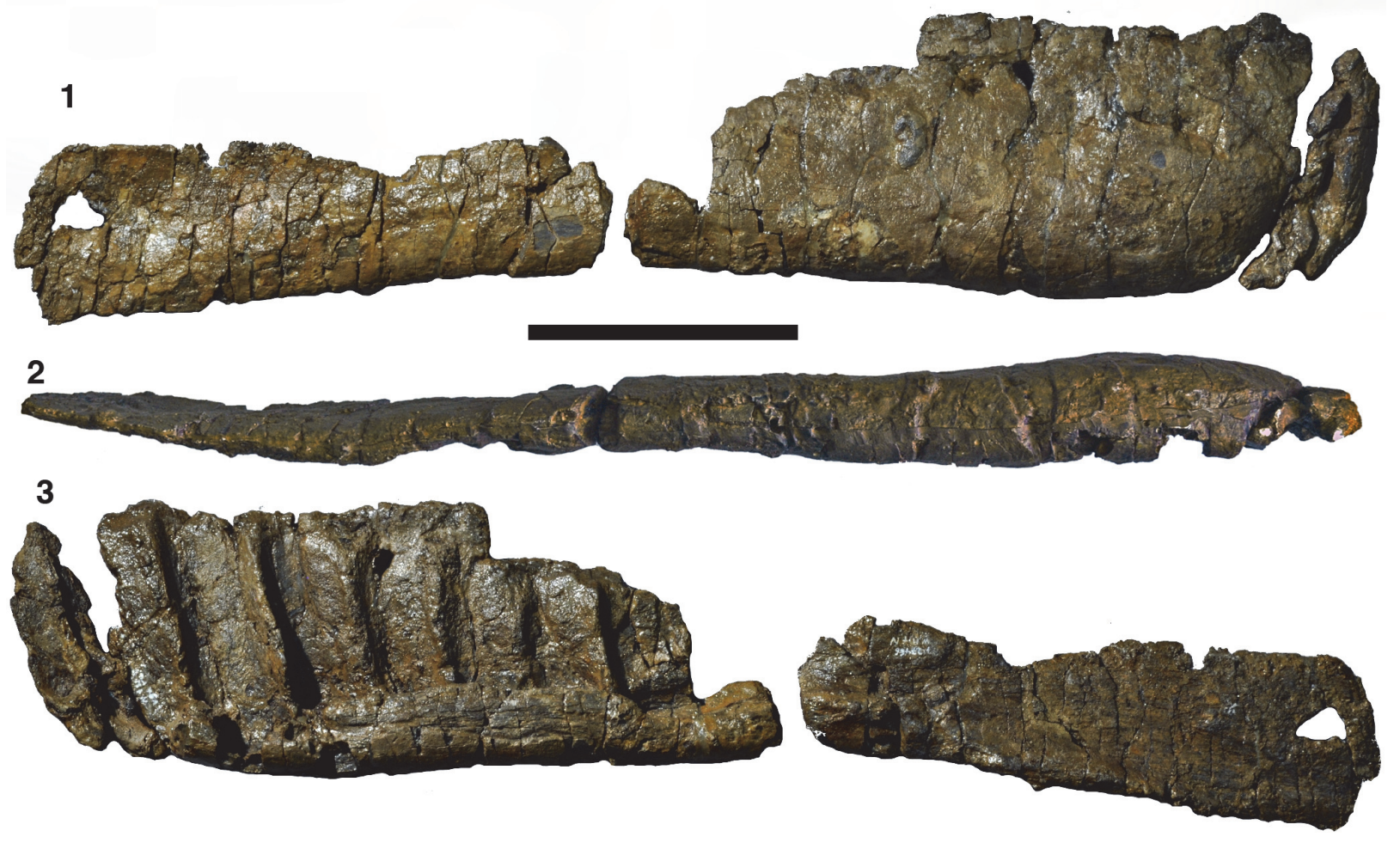

FIGURE 12. Right dentary of Wiehenvenator albati in lateral (1), ventral (2), and medial (3) views. Scale bar equals $100 \mathrm{~mm}$.

the mid-section of the bone (Figure 12.2), which is consistent with the interpretation that one or several of the anterior dentary teeth might have been larger than the other dentary teeth, as in many megalosauroids. However, whereas the enlarged dentary tooth is the third in Eustreptospondylus (Sadleir et al., 2008), as in Wiehenvenator, Megalosaurus has the fourth dentary tooth enlarged (Benson et al., 2008). In Duriavenator (Benson, 2008) and Dubreuillosaurus (Allain, 2002), the third dentary tooth is enlarged, but the fourth is more or less subequal in size, and more distal teeth gradually become smaller. The main section of the tooth row has parallel dorsal and ventral borders and is c. $101 \mathrm{~mm}$ high. The lateral side is flat and unornamented, although a few large lateral foramina seem to be present (Figure 12.1). These foramina are randomly distributed and are not placed in a lateral groove, although it cannot be excluded that such a groove might have been present in a more posterior part of the dentary, as in Dubreuillosaurus (Allain, 2002). Ventrally, the lateral side of the bone flexes gradually into the ventral side, with this flexure being more strongly convex in the anterior part than the posterior part. In the posterior portion pre- served, the ventral margin becomes a sharp edge posteriorly.

In medial view, most of the medial wall, including all interdental plates, are missing (Figure 12.3). As in the premaxilla and maxilla, the teeth in the tooth-bearing portion were deeply rooted, with the alveoli extending almost to the ventral border of the bone. The alveoli are slightly inclined anterodorsally, more so in the anterior part of the tooth row. The ventral margin of the anterior portion of the dentary flexes medially into the ventral part of the medial wall. In the central section of the preserved main part, a slightly depressed and striated area probably indicates the suture for the splenial. The posterior part preserved represents the area of the dentary where the Meckelian groove expands to occupy most of the height of this bone. Consequently, this portion is transversely thin, plate like, and has only a slightly thickened ventral margin in its anterior part. No teeth are preserved in the dentary.

Dentition. Apart from the teeth preserved in the maxilla as noted above (Figure 13.1, 13.2), six isolated teeth of Wiehenvenator are present. All of the isolated teeth have at least parts of their root preserved, and their morphology is consistent with 
those of the teeth in the maxilla, indicating that they are all derived from the skeleton (Figure 13.3-9). One tooth probably comes from the mesial dentition and represents a premaxillary or mesial dentary tooth and is described separately below (Figure 13.10-12).

The lateral maxillary or dentary teeth are strongly flattened transversely and are considerably recurved, so that the tip of the crown is placed distal to the distal margin of the base of the crown. Accordingly, the mesial carina is convex over its entire length and the distal carina slightly concave. Both the mesial and distal carinae show serrations. However, whereas the distal carina extends to the tooth base, the mesial carina is restricted to the apical two-thirds of the crown (Figure 13.4, 13.6), as in all megalosaurids (Hendrickx et al., 2015a) and many other theropods. In contrast to some allosauroids, tyrannosauroids and dromaeosaurids (Hendrickx and Mateus, 2014b), the basal end of the mesial carina is straight and does not curve labially. In the teeth preserved in the maxilla, both carinae are more or less centrally placed, so that the teeth are symmetrical in apical view. However, in several of the isolated teeth (WMN P27483, $27459,27467)$, the distal carina is slightly displaced labially from the midline (Figure 13.4). As at least the teeth WMN P27483 and 27459 are too large to fit in the dentary, this probably indicates some variation in this character in the maxillary teeth. The serrations are poorly preserved in most specimens. However, where they are preserved, the denticles are chisel-shaped and relatively low. There are approximately 15 denticles per $10 \mathrm{~mm}$ on both the mesial and distal carina. No interdenticle sulci or enamel undulations, longitudinal ridges or grooves, flutes or labial and lingual depressions (sensu Hendrickx et al., 2015b) are visible on any of the teeth. However, as the serrations are poorly preserved in all teeth, it cannot be ruled out that interdenticle sulci might have been present in at least some elements and some parts of the serrations, since they are present in the vast majority of megalosaurids (Hendrickx et al., 2015a), and their presence can be variable within a single dentition (Benson, 2010a; Hendrickx et al., 2015a). A rarely reported feature of these teeth is that the serrations are continuous across the tip of the crown (Figure 13.9), as in Acrocanthosaurus (Harris, 1998). The denticles crossing the tip are markedly smaller than those on the central parts of the carinae. If the presence of denticles crossing the tip of the crown is really rare in theropods has to be shown by more detailed studies of complete thero- pod teeth (Hendrickx et al., 2015a; Hendrickx, personal commun., 2016); in Megalosaurus (OUMNH $\mathrm{J}$ 13506), most tooth tips lack serrations, but this might simply be due to wear, since one well-preserved crown of an erupting replacement tooth retains such denticles.

The preserved roots are long and robust. In the most complete tooth, WMN P27483, the crown height is approximately $73 \mathrm{~mm}$, but the root, as preserved, is at least $114 \mathrm{~mm}$ long (Figure 13.4-6). The root is continuous with the base of the crown and not separated by an incision. It remains of subequal mesiodistal width over most of its length, but narrows slightly towards its basal end. In mesial or distal view, the widest part of the root is placed some $20 \mathrm{~mm}$ below the base of the crown; from there on, the root gradually narrows towards the basal end. There is a shallow longitudinal depression on either side of the root that extends over its entire length. The part mesial of this depression is slightly wider labiolingually than the part distal to it. On the lingual side of the root, the longitudinal depression becomes deeper and wider basally, forming the resorption pit (Hendrickx et al., 2015b) to accommodate the developing replacement teeth. In the tooth WMN P27473, the root seems to be slightly angled in relation to the crown, so that the latter projects slightly mesially (Figure 13.8). However, it is unclear if this might not simply be an artifact of preservation, as the basal part of the crown and the root are poorly preserved.

The probable premaxillary or anterior dentary tooth WMN P27456 has parts of the root preserved, but the basal part of the labial side of the crown and this side of the root is missing most of its enamel and dentine (Figure 13.10-12). The tooth is considerably smaller than the larger lateral teeth, with the crown measuring approximately 42 $\mathrm{mm}$ in height, as in ceratosaurs (Rauhut, 2004), tyrannosauroids (Brusatte and Carr, 2016), and other megalosaurids (Hendrickx et al., 2015a). The tooth is furthermore less compressed and less recurved than the lateral teeth, with the tip of the crown being placed only insignificantly distal to the distal base of the crown, so that the distal carina is only slightly concave in its basal part and straight in its apical two thirds. In this tooth, the crown is slightly twisted in respect to the root, so that the mesial carina is displaced lingually and the distal carina slightly labially (Figure 13.10, 13.12). However, in contrast to Allosaurus (Madsen, 1976a) and several other theropods, such as tyrannosauroids and dromaeosaurids, the tooth crown in itself is not asymmetric, but the carinae are placed on 


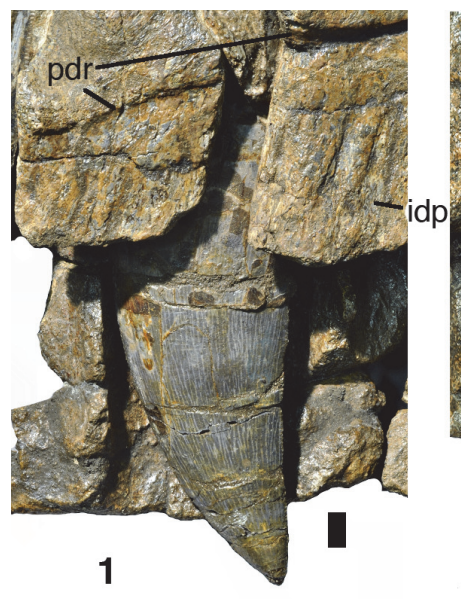

1

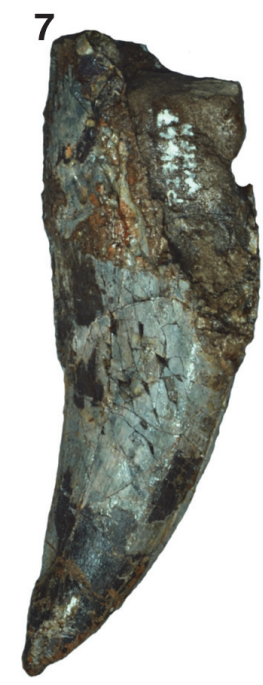

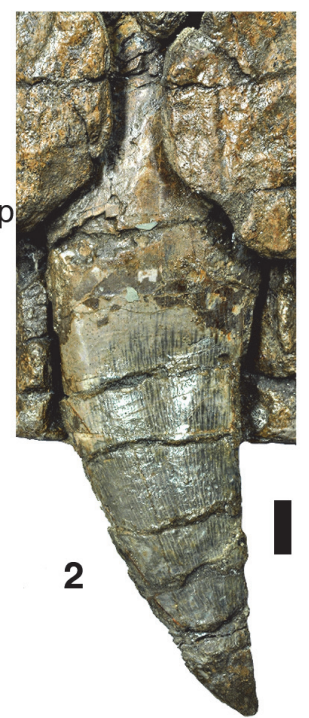

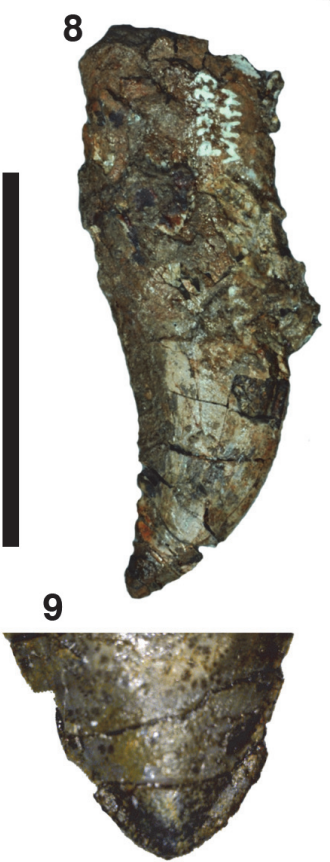

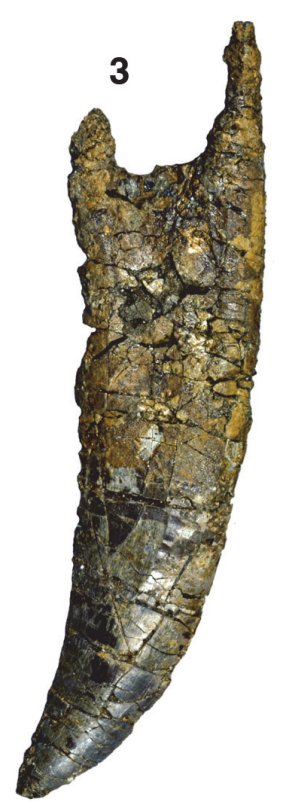
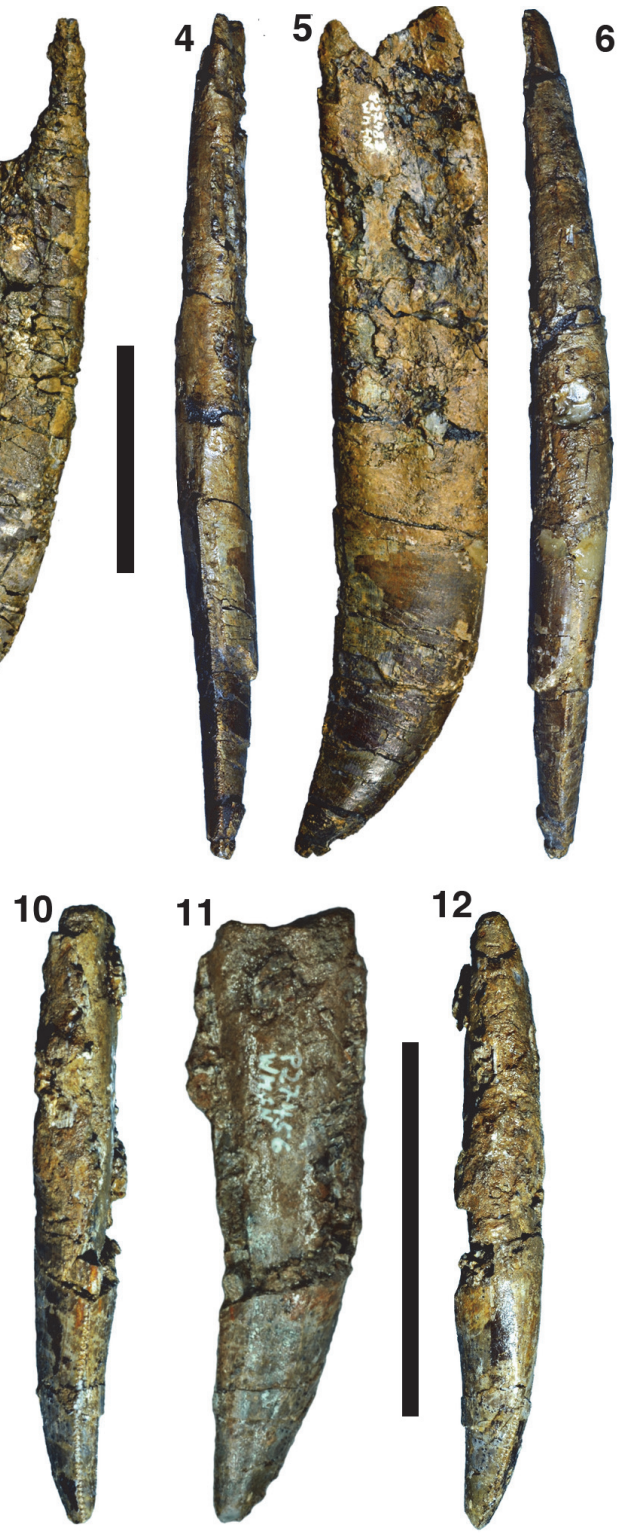

FIGURE 13. Dentition of Wiehenvenator albati. 1, replacement tooth in the 2nd maxillary alveolus; 2 , functional tooth in the 4th maxillary alveolus; 3 , probable maxillary tooth with partially preserved root (WMN P27459) in lingual view; 4-6, probable maxillary tooth with complete root (WMN P27483) in distal (4), lingual (5) and mesial (6) views; 7 , mesial (posterior premaxillary or anterior dentary) tooth (WMN P27467) in labial(?) view; 8, maxillary or dentary tooth (WMN P27473) in labial(?) view; 9, detail of crown apex of WMN P27373, showing the carina that is continuous across the tip (mesial is to the left); 10-12, mesial (probably premaxillary) tooth (WMN P27456) in distal (10), labial (11) and mesial (12) views. Abbreviations: idp, interdental plates; pdl, paradental lamina. Scale bars equal $10 \mathrm{~mm}$ (1, 2) and $50 \mathrm{~mm} \mathrm{(3-12;} \mathrm{not} \mathrm{9).}$

opposing sides, as in other megalosaurids (Hendrickx et al., 2015a). In mesial or distal view, the crown is slightly flexed labially towards its tip. Whereas the distal carina follows the line of this curve, the mesial carina is very slightly sigmoidal, flexing very slightly lingually in the apicalmost part.
Both carinae bear serrations, but they are poorly preserved. There are approximately 16 denticles per $10 \mathrm{~mm}$ on the distal and 14 denticles per $10 \mathrm{~mm}$ on the mesial carina, although these counts should be seen with caution due to the poor preservation. The eroded bases of the denticles of the 
distal carina indicate that these denticles might have been angled very slightly apically; there is no indication for such an inclination in the mesial carina. The tip of the tooth is worn, so it cannot be established if the denticles might have been continuous over the tip.

The preserved part of the root largely corresponds to that of more posterior teeth. The only difference might be that there is no indication of a longitudinal depression on the preserved part of the lingual side.

The tooth WMN P27467 is somewhat intermediate in morphology between this tooth and the more typical lateral teeth (Figure 13.7) and might thus represent a more distal premaxillary or an anterior dentary tooth.

Due to the generally poor preservation of the surfaces of the tooth crowns, the presence and structure of possible enamel texture (see Hendrickx and Mateus, 2014b; Hendrickx et al., 2015a, $2015 \mathrm{~b}$ ) is difficult to establish. The teeth preserved in situ in the maxilla do not show any clear pattern and seem to be largely smooth, although this might be due to erosion. The most complete isolated tooth, WMN P27483, seems to have the braided enamel texture that is typical for megalosaurid teeth (Hendrickx et al., 2015a) in the basal part of the crown, but a rather anastomosed texture (sensu Hendrickx et al., 2015b) in a more apical part. However, it cannot be ruled out that the latter texture simply results from erosion of this part of the tooth enamel.

Vertebrae. Three almost complete and two fragmentary caudal vertebrae of Wiehenvenator are preserved. The most anterior of the more complete elements, WMN P27501, represents an anterior mid-caudal vertebra (Figure 14), whereas the other two vertebrae WMN P27499 and P27500 are somewhat more posterior elements from the midcaudal section (Figures 15, 16). WMN P47417 preserves only the posterior end of an anterior midcaudal, whereas WMN P29131 is a poorly preserved fragment of a more distal caudal vertebra. Measurements for the complete vertebrae are found in Table 2.

The vertebral centrum of MWN P27501 has several breaks in the anterior part and is missing most of the posterior articular end (Figure 14). The centrum is strongly constricted, its minimal width at about mid-length $(50 \mathrm{~mm}$ ) being only about $45 \%$ of the width of the anterior articular surface (c. 113 $\mathrm{mm}$ ). The anterior articular surface is very slightly concave, whereas the posterior surface seems to be flat. The rim of the anterior articular surface is flexed slightly laterally. The articular surface is slightly wider than high and round in outline. Dorsally, the neural canal forms a wide, but low indentation into the articular surface. The ventral surface of the centrum is broad and rounded, without any ventral keel or ventral groove (Figure 14.4). On the lateral side of the centrum, a well-developed, but shallow pleurocentral depression is present on either side just above the mid-height of the centrum (Figure 14.1). This depression becomes slightly deeper posteriorly and is more clearly defined dorsally than ventrally. Similar, large, shallow, but rather well-defined lateral depressions are also present in the caudal vertebrae of Torvosaurus (Britt, 1991) and Megalosaurus (NHMUK R 9672, 97673, 9676, OUMNH J 13578, 13579; Benson, 2010a). The broken posterior part of the centrum shows that there are no internal cavities, in contrast to the situation in Ceratosaurus (Madsen, 1976a) and abelisaurids (Rauhut et al., 2003). On the anterior part of the right side of the centrum, the neurocentral suture is visible. It extends in a gently convex arch from the anterodorsal margin of the centrum posteroventrally for approximately 25-30 $\mathrm{mm}$ and then extends in a straight line across the dorsal part of the centrum. The suture is strongly interdigitating and completely closed, but still visible.

The neural arch is relatively low, but becomes somewhat higher posteriorly. The neural canal is large and has a rounded outline anteriorly (Figure 14.3). Posterior to the anterior opening, the canal incises into the dorsal part of the centrum, so that it becomes inverted teardrop-shaped in outline, which is also the outline of the posterior opening. In the posterior half of the centrum, the floor of the neural canal is slightly convex. Anteriorly, the neural canal widens slightly both transversely and dorsally, so that the centroprezygapophyseal laminae are slightly directed anterolaterally.

Robust transverse processes are present. They are placed on the posterior half of the neural arch, at the level of the roof of this structure (Figure 14.1). The transverse processes are directed laterally and slightly dorsally and posteriorly. The dorsal inclination is approximately $25^{\circ}-30^{\circ}$ from the horizontal. The processes are considerably longer (16 $\mathrm{cm}$ from neural arch to distal end) than the length of the centrum and very slightly expand distally (Figure 14.2). At the base, the anteroposterior width of the processes is approximately $50 \mathrm{~mm}$, whereas the distal end has an estimated width of $\mathrm{c}$. $65 \mathrm{~mm}$. Rudimentary lateral laminae are present in the proximal part of the transverse processes. 


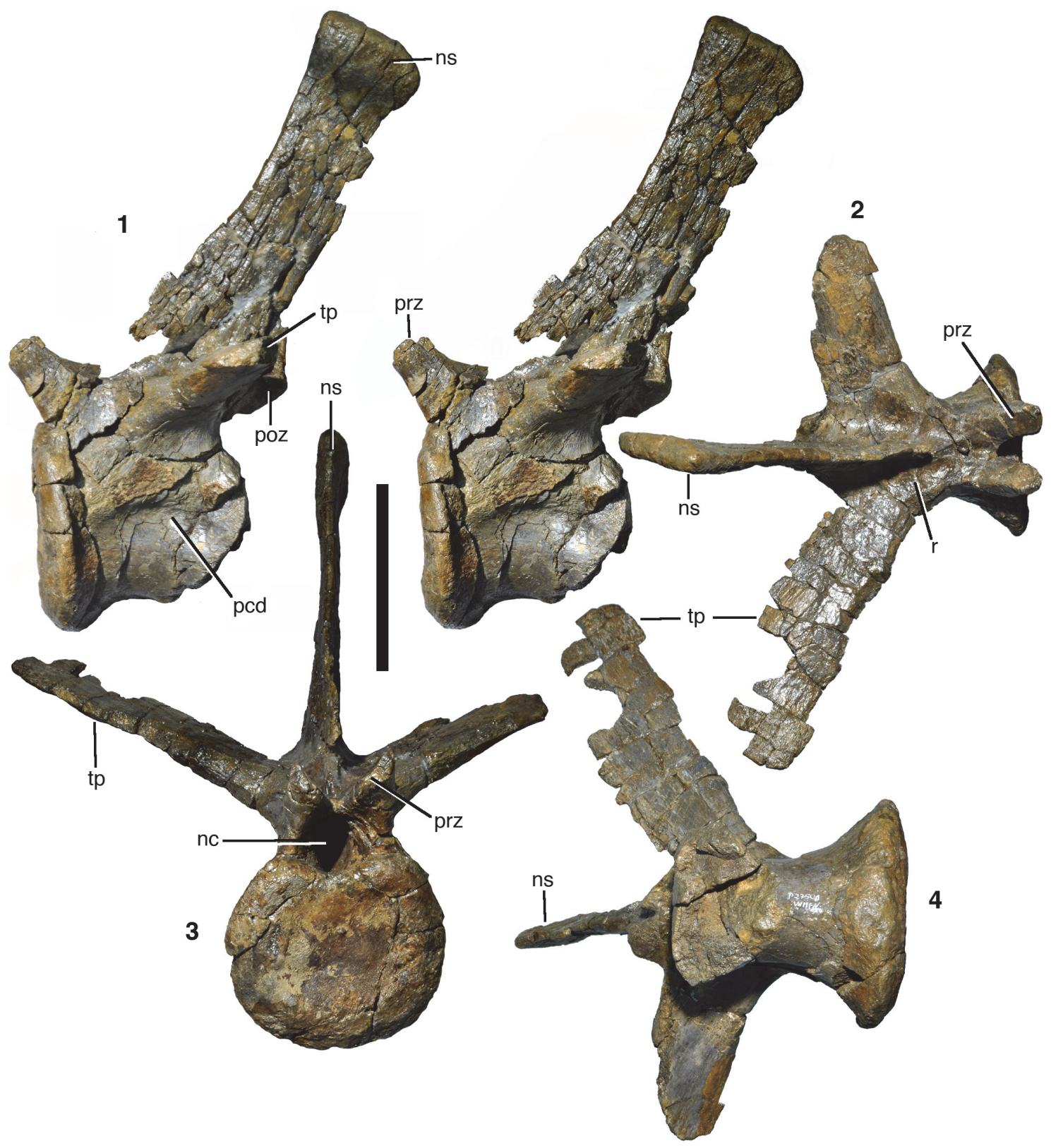

FIGURE 14. Anterior mid-caudal vertebra of Wiehenvenator albati in lateral (1; stereophotographs), dorsal (2), anterior (3), and ventral (4) views. Abbreviations: nc, neural canal; ns, neural spine; pcd, pleurocentral depression; poz, postzygapophysis, prz, prezygapophysis; r, ridge; tp, transverse process. Scale bar equals $100 \mathrm{~mm}$.

However, these rudimentary laminae are less welldeveloped than in abelisaurids (Rauhut et al., 2003), and fossae between the laminae are only indicated by very shallow depressions. Both anterior and posterior centrodiapophyseal lamina are represented by broad, rounded ridges that extend from the dorsal end of the centrum towards the ventral surface of the transverse processes. The prezygadiapophyseal lamina is also represented by a low ridge that extends from the lateral margin of the prezygapophysis to the dorsal margin of the base of the transverse process and thus defines the dorsal rim of a shallow depression on the anterior side of the thick base of the transverse process. The base of the transverse process is thicker dorsoventrally anteriorly than posteriorly, but becomes rapidly more plate-like distally. The processes are slightly twisted distally, so that the dor- 
TABLE 2. Measurements of caudal vertebrae of Wiehenvenator albati (in mm).

\begin{tabular}{|l|c|c|c|}
\hline & WMN P27501 & WMN P27499 & WMN P27500 \\
\hline Centrum length & c. 110 & 114 & 114 \\
\hline Anterior centrum height & 104 & 79 & 85 \\
\hline Anterior centrum width & 113 & c. 82 & $72+$ \\
\hline Posterior centrum height & - & 80 & $74+$ \\
\hline Posterior centrum width & - & 83 & c. 35 \\
\hline Minimal centrum width & 50 & c. 38 & 135 \\
\hline Neural arch length & 143 & $125+$ & $195+$ \\
\hline Total height & c. 320 & 247 & \\
\hline
\end{tabular}

sal surface faces slightly anterodorsally towards the distal end. On the dorsal surface of the neural arch, a low, but well-defined ridge extends from the base of the neural spine on either side anterolaterally towards the anterior margin of the base of the transverse process (Figure 14.2). This ridge separates a smaller, triangular depression anteriorly from a larger posterior concavity on the posterior part of the roof of the neural arch.

The prezygapophyses are placed on short stalks so that they overhang the centrum for approximately the entire length of their articular surfaces. The prezygapophyses are short, diverge very slightly anteriorly and are inclined medially at an angle of approximately $55^{\circ}$ from the horizontal. The lateral side of the prezygapophyses bulges slightly laterally at about the level of the dorsal margin of the neural canal; this bulge becomes lower anterodorsally. The articular surfaces are anteroposteriorly short (c. $15 \mathrm{~mm}$ ) and oval in outline, being wider (c. $19 \mathrm{~mm}$ ) than long. They are connected medially by a very stout intraprezygapophyseal lamina, and there are low, but clearly defined spinoprezygapophyseal laminae extending from about the mid-width of the prezygapophyseal stalks towards the base of the neural spine; together these laminae define a narrow, triangular prespinal fossa.

The postzygapophyses are poorly preserved. They are placed below the base of the neural spine and face lateroventrally at an angle of $45^{\circ}$ from the horizontal. The articular surface seems to have been high oval in outline, but it is damaged posteriorly in the only preserved (left) postzygapophysis. The postzygapophyses are connected to the transverse processes by short, but stout postzygodiapophyseal laminae and to the neural spine by likewise short, but well-defined spinopostzygapophyseal laminae. The intrapostzygapophyseal lamina is short and forms a rounded, V-shaped edge some $5 \mathrm{~mm}$ above the neural canal; a hypo- sphene is absent. The postzygapophyses and the spinopostzygapophyseal laminae define an elongate, narrow, but deep postspinal fossa.

The neural spine is placed on the posterior two thirds of the neural arch. It is posteriorly inclined at about $25^{\circ}-30^{\circ}$ from the vertical and very high, reaching a height of c. $185 \mathrm{~mm}$ above the roof of the neural arch. The spine is transversely flat and anteroposteriorly wide at its base. It narrows dorsally up to approximately its mid-height and then very slightly expands again dorsally (Figure 14.3). Thus, its minimal anteroposterior width is $48 \mathrm{~mm}$, whereas the dorsal width is $57 \mathrm{~mm}$. In anterior view, the basal part has a sharp anterior margin, but this margin becomes wider and rounded dorsally. Towards the dorsal end, the spine slightly expands transversely to a maximal transverse thickness of $16 \mathrm{~mm}$. The dorsal end of the spine is rounded transversely and anteroposteriorly straight over its anterior two thirds, whereas the posterior third flexes posteroventrally. On the posterior side of the spine, a ridge-like postspinal lamina appears at about the mid-height of the spine and continues ventrally between the spinopostzygapophyseal laminae approximately to the base of the neural spine.

In WMN P47417, the posterior articular surface is slightly higher than wide, indicating that this fragment might represent a slightly more anterior caudal vertebra. The surface is slightly concave dorsally, but becomes convex ventrally, where it curves into the poorly defined chevron facets. The ventral surface of the centrum is slightly convex transversely, though less so than in WMN P27501, and lacks any keel or furrow. The posterior end of the lateral pleurocentral depression is preserved on the lateral side of the vertebral fragment.

The other two more complete vertebrae (Figures 15,16$)$ represent more posterior mid-caudal elements, but they do not seem to be consecutive elements. The centra are smaller and relatively 
more elongate than in the vertebra described above. They are also strongly constricted. In the more anterior element WMN P27499, the articular surfaces are parallel (Figure 15), but in the more posterior element WMN P27500, the posterior articular surface is slightly angled posteroventrally in respect to the anterior surface (Figure 16). Both vertebrae are platycoelous, although the exact morphology of the articular surfaces varies between the elements and between the anterior and posterior surface. Thus, in WMN P27499, the anterior articular surface is flat to very slightly convex, whereas the posterior surface is slightly concave and the margins flex notably anteriorly. In WMN P27500, the anterior articular surface is concave with posterior flexed margins and the posterior surface is slightly convex. In the latter element, the posterior articular surface is also notably smaller than the anterior surface, whereas they are of subequal size in the more anterior vertebra. Well-developed chevron facets are present in both elements. However, whereas the facets are only marked by the ventrally flexed posterior articular end in the more posterior vertebra, the more anterior element WMN P27499 shows two clearly defined, concave facets posteroventrally. The ventral sides of the centra are relatively narrower than in WMN P27501, and two diverging ridges are present on the posterior half of the ventral surface (Figure 16.3). These ridges define a longitudinal ventral depression, which is wider in WMN P27499 than in the more posterior element. In both vertebrae, well-defined, elongate oval pleurocentral depressions are present on the lateral side of the centrum, just above its mid-height (Figures 15.2, 16.2). In contrast to the anterior mid-caudal, these depressions are deepest in the middle part and become gradually shallower towards either end, and their dorsal and ventral margins are equally strongly developed.

Of the neurocentral suture, only the posterior ends of the pedicles of the neural arch are marked as slightly offset bulges in the more anterior element. The arches are low and have notably large neural canals, which are very similar in shape and development as in the vertebra described above. As in the latter, the roof of the neural canal slightly raises posteriorly. Both elements show strongly developed transverse processes, which are still placed on the posterior end of the neural arch at the level of the roof of this structure. They show a very similar dorsal and posterior inclination as in the vertebra described above. In the better preserved element WMN P27499, the transverse pro- cess has its anteroposteriorly narrowest part (34 $\mathrm{mm}$ ) in its proximal third and then expands slightly distally to a maximal anteroposterior width of 45 $\mathrm{mm}$ at about three-fourths of its length. At this point, the posterior margin flexes notably anterolaterally. Unfortunately, the distalmost tip is not preserved, but if one extends the distalmost preserved part of the posterior margin, it would have met the gently posterolaterally curving anterior margin in a pointed end. As in the more anterior vertebra, the distal end of the process is slightly twisted to face anterodorsally. The lateral lamination is more weakly developed than in the vertebra described above, but still present. An oblique ridge on the dorsal surface of the base of the process, as described for the more anterior element above, is absent.

The prezygapophyes are missing in WMN P27499, but present in the more posterior element (Figure 16). They are very similar in shape and development to the prezygapophyses of the anterior element described above. However, there are no clearly defined spinoprezygapophyseal laminae and a prespinal fossa is absent.

The postzygapophyses are completely preserved in WMN P27499 (Figure 15). They are placed posteroventrally to the base of the neural spine, with the articular surfaces almost completely overhanging the centrum. The articular surfaces are high oval in outline and inclined to a similar degree as those described above. In posterior view, the postzygapophyses are relatively more widely spaced than in the element described above, and the intrapostzygapophyseal lamina is straight, rather than ventrally pointed. The spinopostzygapophyseal laminae are more weakly developed and the postspinal fossa is marked, but smaller than in the vertebra described above.

Both vertebrae show a small dorsal spur some way anterior to the neural spine (Figures 15, 16). Whereas there is some uncertainty in the more anterior vertebra in how far this spur might have been connected to the base of the spine by a now broken lamina, it is clearly separated in the more posterior element, where it is a small, pointed process (Figure 16.2), as in several other theropods, such as Dubreuillosaurus (Allain, 2005), Allosaurus (Madsen, 1976a), or Lourinhanosaurus (Mateus, 1998). The main neural spine is anteroposteriorly short and placed on the posteriormost third of the neural arch, with the posteriormost part of its base being level or even slightly overhanging the posterior end of the centrum. It is posterodorsally inclined and remains of subequal anteroposterior 


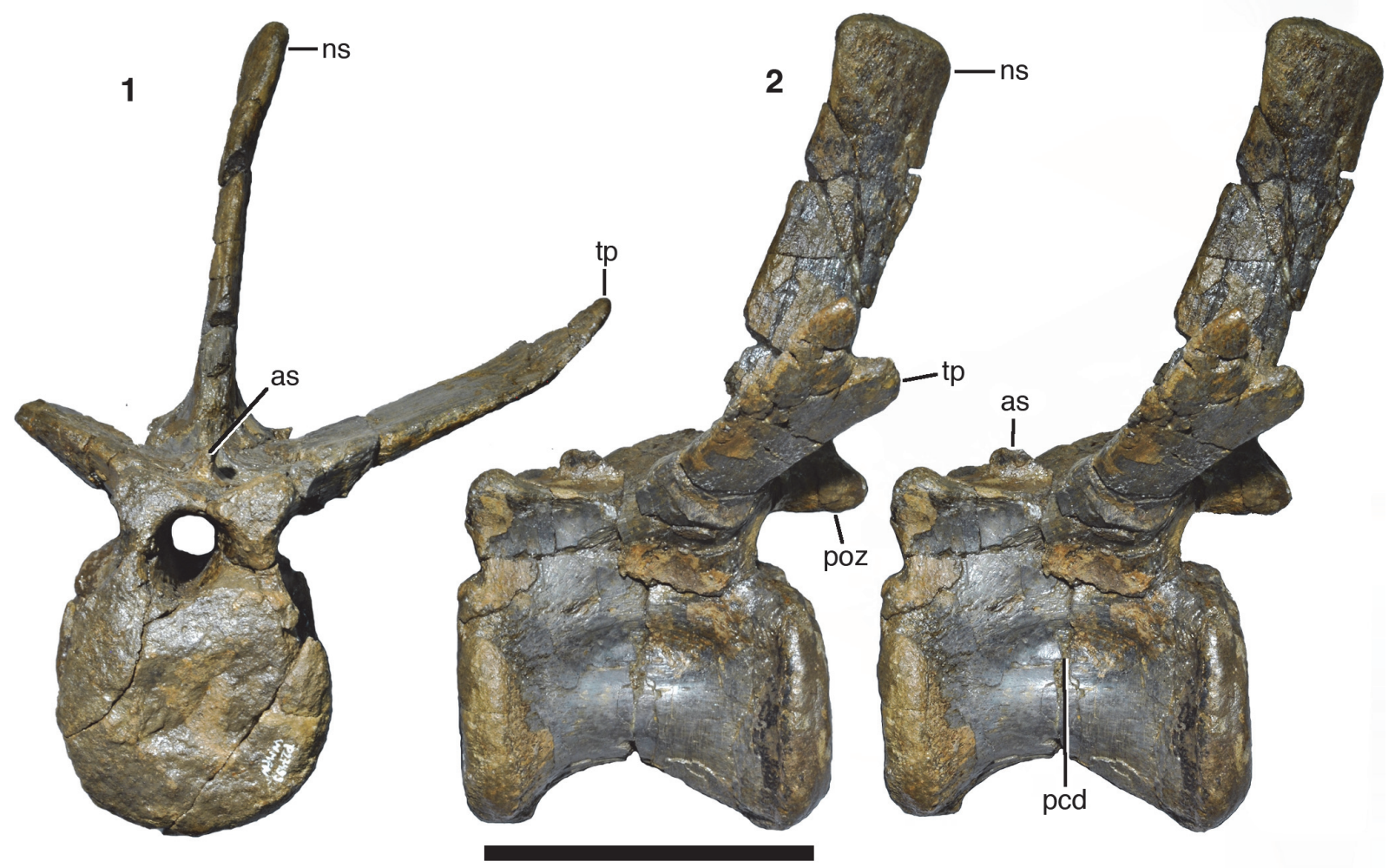

FIGURE 15. Mid-caudal vertebra of Wiehenvenator albati in anterior (1) and lateral (2; stereophotographs) views. Abbreviations as in Figure 14, and: as, anterior spur. Scale bar equals $100 \mathrm{~mm}$.

width over its entire height. The distal end is very slightly expanded transversely in WMN P27499; in the more posterior element, this part seems to be incomplete. The dorsal margin is similar to the more anterior element in WMN P27499. The dorsal part of the neural spine has a sharp posterior, but broad and rounded anterior margin, but the posterior margin becomes broader and flattened ventrally. A very low postspinal ridge is present in the ventral half of the spine.

Ribs. Several rib fragments and two more or less complete dorsal ribs are present. An anterior thoracic rib (Figure 17.1) is $105 \mathrm{~cm}$ long along the outer curve. The proximal two-thirds of the rib are considerably curved, whereas the distal third is almost straight, indicating a broad, oval ribcage for Wiehenvenator. The proximal end is divided into a long, medially directed capitulum and a much shorter tuberculum, which are connected by a robust bony lamina and thus not clearly separated, although this might be partially due to damage of the articular end. Proximally, the rib is thickened both anteriorly and posteriorly on the lateral side, resulting in a T-shaped cross-section of the rib. This thickening disappears at approximately onethird along the length of the element. Distal to this point, the rib shaft gradually tapers, until it reaches a thin, oval outline, which it retains for the distal third of its length. The distal tip is broken, so it cannot be said if a distal thickening, indicating the cartilaginous connection to a sternal rib, was present, as it is found in other theropods.

A posterior, abdominal rib (Figure 17.2) is strongly and gradually curved along its entire length. The rib head has a long medial process for the capitulum and a much shorter, strongly distally displaced posterodorsal process for the tuberculum. Both processes are connected by a thin bony lamina. From the tuberculum, a posteriorly oriented lamina extends along the posterolateral margin of the rib shaft and becomes rapidly lower distally. The rib shaft tapers gradually distally. Its anterior side is flat, whereas the posterior side is broad and convex transversely proximally (distal to the lamina extending from the tuberculum described above), but gets more narrow and thus more strongly convex distally.

Gastralia. A robust, boomerang-shaped element (WMN P27455) represents the gastral basket (Figure 17.3-5). In accordance with the situation in other theropods (Chure, 2000; Allain and Chure, 2002), we interpret this element as the fused 

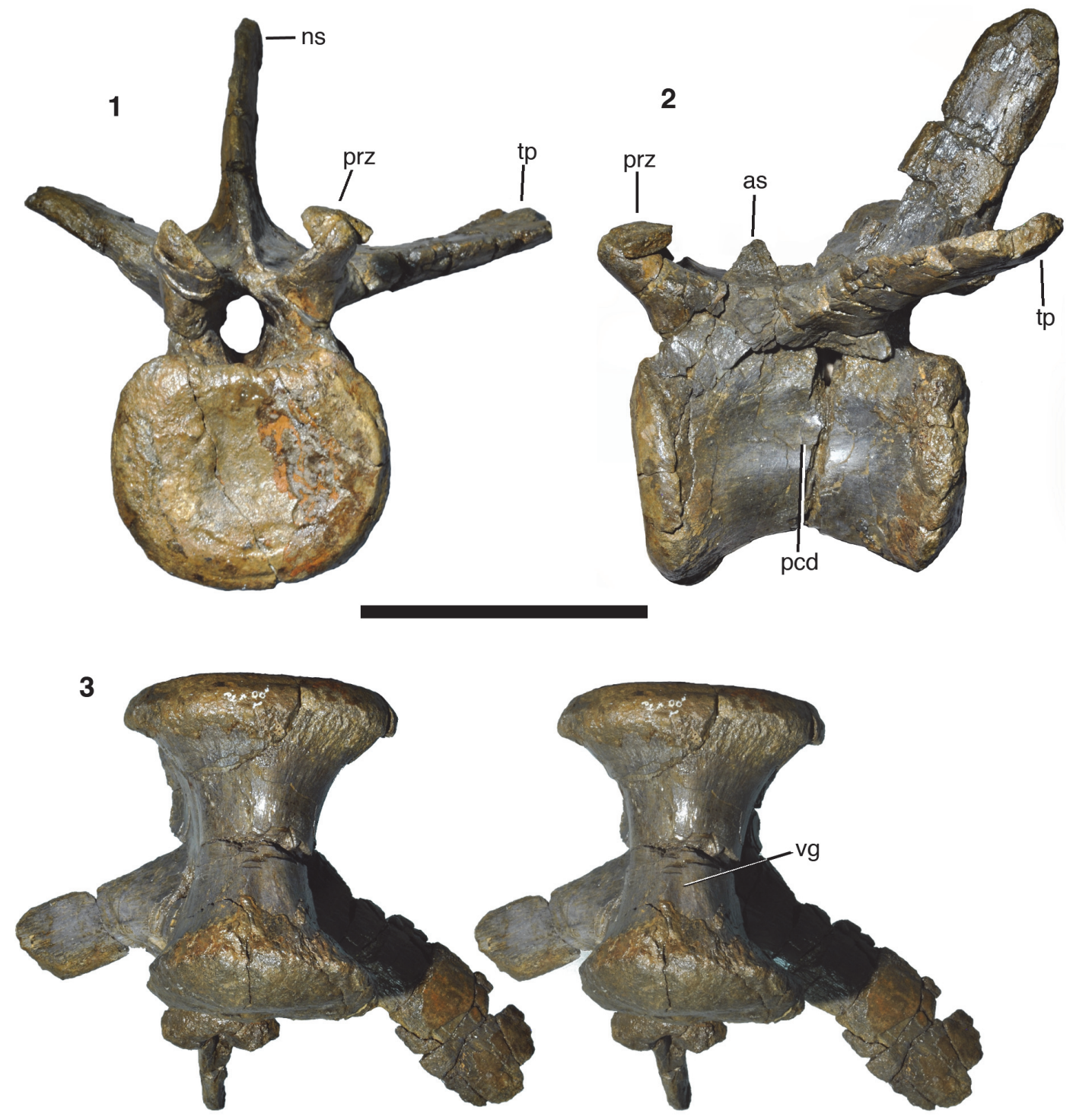

FIGURE 16. Posterior mid-caudal vertebra of Wiehenvenator albati in anterior (1), lateral (2), and ventral (3; stereophotographs) views. Abbreviations as in Figures 14 and 15, and: vg, ventral groove. Scale bar equals $100 \mathrm{~mm}$.

medial rods of a pair of posterior gastralia. The element is dorsoventrally flattened, oval in cross-section, and forms a wide U-shape in dorsal or ventral view, with the angle between the two rami being approximately $100^{\circ}$. The central part is slightly curved ventrally in respect to the left and right ramus and has a thickened anterior margin (Figure 17.5). Just lateral to the central fusion, a notable longitudinal depression is present on the anterior margin of the ventral side on either side (Figure 17.4) for the articulation with the lateral gastral element (Chure, 2000; Allain and Chure, 2002). This depression is open anteriorly, so that the anterior margin of the lateral rami forms a sharp ridge, whereas the posterior margin is more massive and dorsoventrally rounded. The lateral rami become more slender posterolaterally, but their tips are broken.

Forelimb. A single, damaged phalanx probably represents the forelimb of Wiehenvenator (Figure 18). The proximal end of the element is largely missing, so that only the central dorsal part of the proximal articular surface is preserved, and the lateral distal condyle is damaged. The element is rather short and stout, with a length of c. $81 \mathrm{~mm}$ and a minimal width in the shaft of $33 \mathrm{~mm}$. This and 


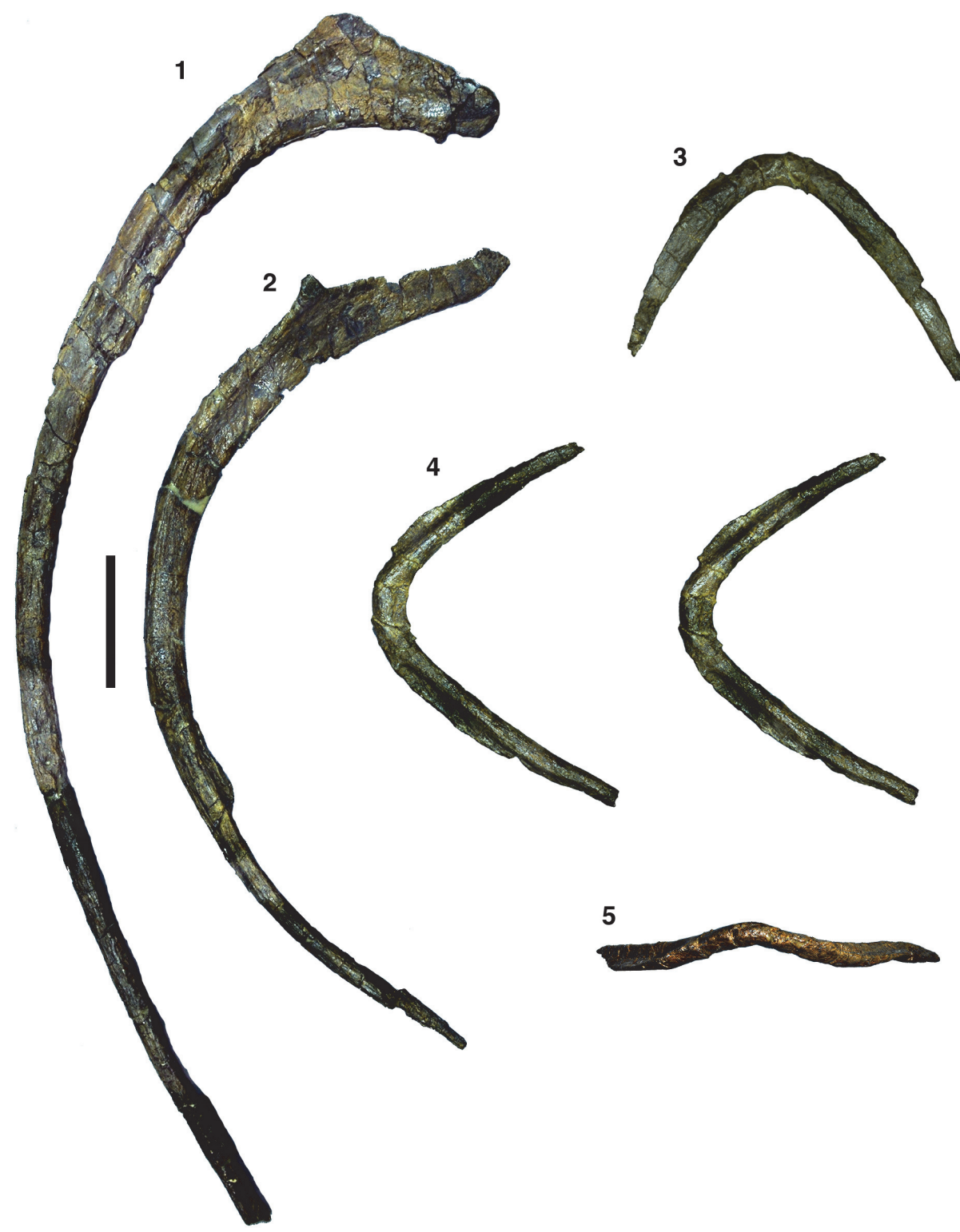

FIGURE 17. Dorsal ribs and gastralia of Wiehenvenator albati. 1, thoracic rib. 2, abdominal rib. 3-5, fused posterior medial gastralia in dorsal (3), ventral (4; stereophotographs), and anterior (5) views. Scale bar equals $100 \mathrm{~mm}$.

the fact that the proximal articular surface lacks a median ridge indicate that it is probably the first phalanx of digit III, most probably of the right manus.

The proximal articular surface was obviously notably concave transversely and extended slightly more distally on the lateral side than on the medial side. As noted above, it lacks a central ridge, indicating that the metapodium proximal to it did not have a ginglymodial distal articulation, which is the case in metacarpal III in tetanurans. The shaft of the bone is only slightly constricted (Figure 18.2), its minimal width being only slightly less than the width of the distal end (c. $38 \mathrm{~mm}$ ). In lateral or medial view (Figure 18.1), the bone gradually narrows towards the distal ginglymus, indicating that the damaged proximal part was dorsoventrally high, as it is usual in the first phalanx of digit III in tetanuran theropods (e.g., Madsen, 1976a; Currie and Carpenter, 2000). A broad, but shallow extensor groove is present on the dorsal side just proximal to the distal ginglymus. The distal articular end is strongly ginglymoidal, with two well-rounded condyles that are separated by a broad, U-shaped furrow (Figure 18.2, 18.3). The articular surface extends considerably further proximally on the ven- 

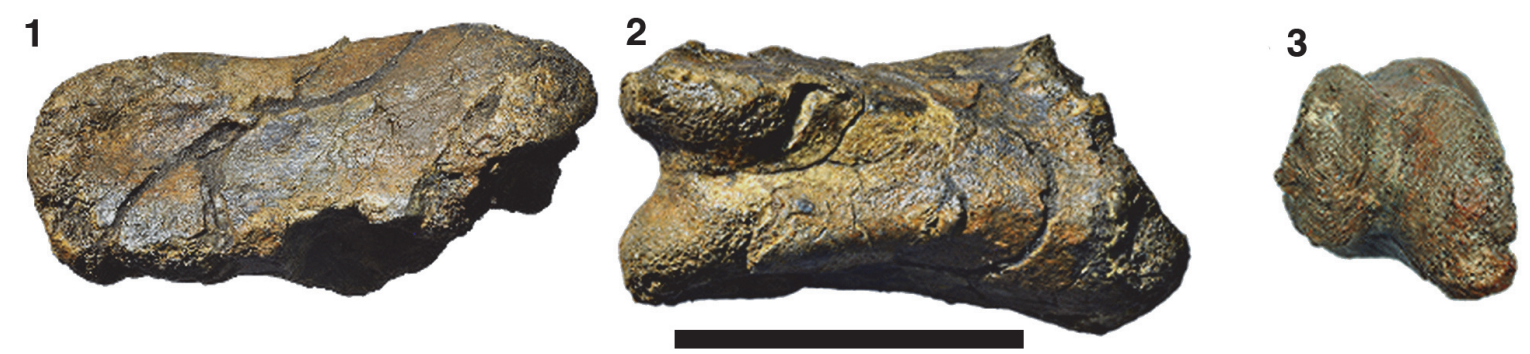

FIGURE 18. Manual phalanx (probably right phalanx III-1) of Wiehenvenator albati in medial (1), dorsal (2) and distal (3) views. Scale bar equals $50 \mathrm{~mm}$.

tral than on the dorsal side, as it is usual in manual phalanges. Collateral ligament grooves are only represented by shallow depressions that are placed slightly dorsal from the midline in the ginglymoidal arch (Figure 18.1). The medial groove is better developed than the lateral one.

Hindlimb. The hindlimb of Wiehenvenator is represented by both fibulae, the right astragalus and a partial right calcaneum.

Fibula. The better preserved left fibula (Figure 19) has suffered from slight deformation, so that the shaft is curved medially, and from minor erosion of the distal end, but is otherwise complete. The bone is notably robust for a theropod fibula, its length being approximately $730 \mathrm{~mm}$, the proximal anteroposterior width $161 \mathrm{~mm}$, and the anteroposterior width at mid-shaft $56 \mathrm{~mm}$. The anteroposterior width of the less damaged distal end of the right fibula is $101 \mathrm{~mm}$, or $180 \%$ of mid-shaft width. The proximal end is not only expanded anteroposteriorly in comparison to the shaft, but also transversely: its maximal transverse width of $75 \mathrm{~mm}$ is more than $250 \%$ of the minimal transverse width of the shaft (c. $29 \mathrm{~mm}$ ). In proximal view (Figure 19.2), the articular surface is comma-shaped, becoming thinner posteriorly and with a medially curved anteromedial edge, as in the fibula of an indeterminate megalosauroid from the Late Jurassic of Tendaguru (Rauhut, 2011). The surface is very slightly inclined proximomedially and slightly concave anteroposteriorly over its anterior twothirds and convex over the posterior third. Although the medial side of the proximal end is slightly concave anteroposteriorly due to the medially curved anteromedial edge, there is no medial depression or fossa (Figure 19.3), in contrast to the situation in many neotheropods, but as in Torvosaurus (Britt, 1991) and other megalosaurians (Benson, 2010a; Carrano et al., 2012).

The lateral surface of the proximal end has a slightly transversely convex anterior side that curves into the almost flat central part of the lateral side. Posteriorly, the lateral side becomes slightly concave, and a short, longitudinal depression is present posterolaterally some $50-60 \mathrm{~mm}$ below the proximal end, as in Afrovenator and some other theropods (see Benson 2010a, p. 918-919). A considerably broader, but less deep and less welldefined fossa is present on the anterior side of the fibula in the same region (Figure 19.4); both depressions fade out some $160-170 \mathrm{~mm}$ below the proximal end, approximately at the level of the beginning of the proximal expansion. Distal to these depressions, the shaft of the fibula is strongly anteroposteriorly convex. There is no marked tubercle or ridge for the insertion of the M. iliofibularis, as in Torvosaurus (Britt, 1991), but at approximately the level where this insertion would have been, the posterior two thirds of the lateral side of the shaft become flattened, so that only the anterior third retains an anteroposterior convexity. At about the mid-length of the bone, the lateral side becomes again gently convex anteroposteriorly, but less so than proximal to the flattened part.

On the medial side there is a marked, rounded tubercle at the anteroproximal edge (Figure 19.3). Further distally, a broad, but low, roughly triangular swelling is present anteriorly just proximal to the level of the beginning of the proximal expansion. Distal to this swelling, the posteromedial margin of the bone becomes sharp-edged and is raised medially (Figure 19.5). Distal to the end of the posterolateral depression described above, this edge turns anteromedially onto the medial surface, where it continues distally as a slightly oblique ridge (Figure 19.5), thus creating a flat and distally widening posteromedial surface and a slight longitudinal concavity on the anterior part of the medial side. A stout but low tubercle is present at the anterior side of this ridge in its proximal part. Distally, the ridge becomes lower and finally flexes anteriorly some $220 \mathrm{~mm}$ distal to the proximal end to 

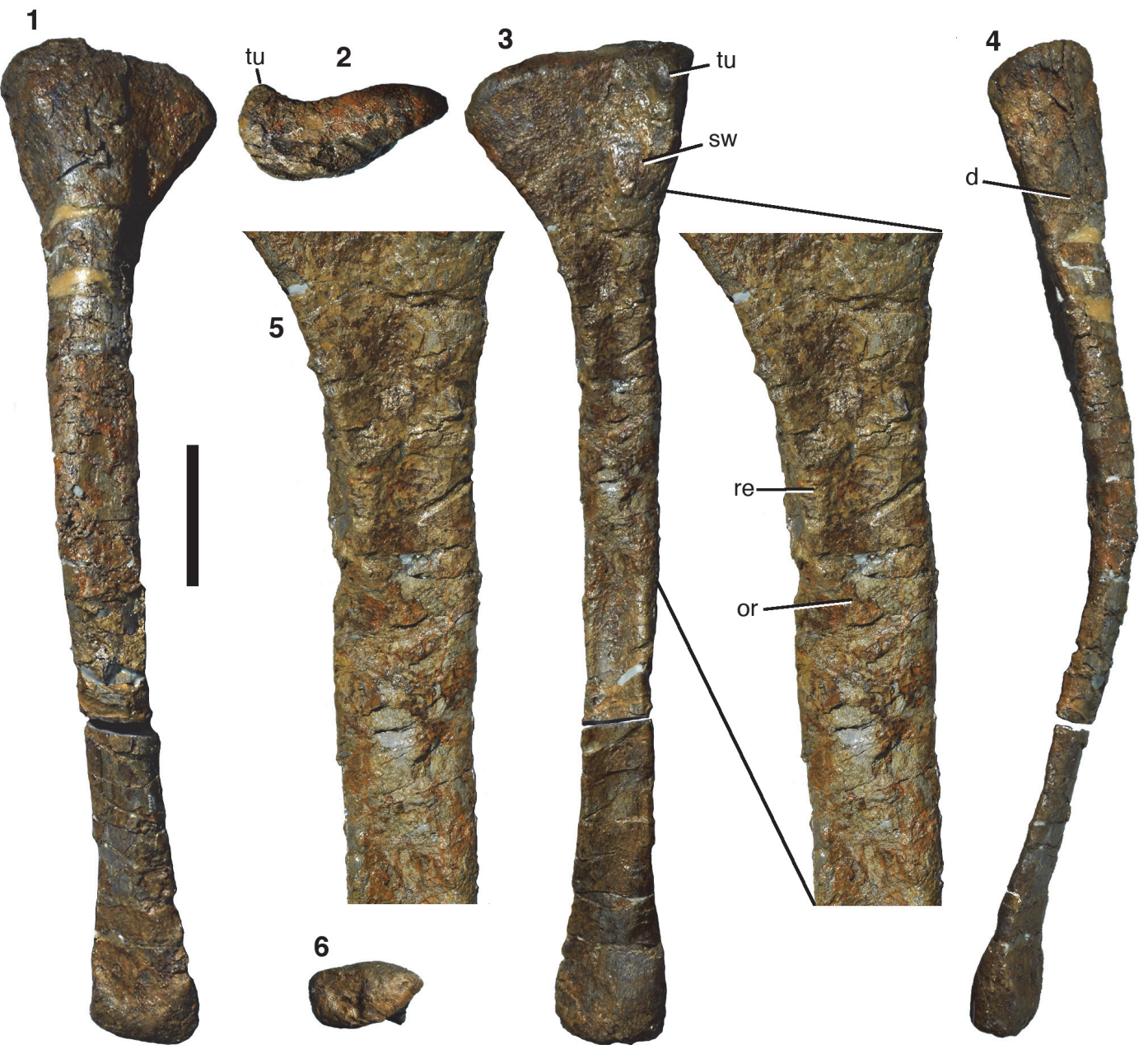

FIGURE 19. Left fibula of Wiehenvenator albati in lateral (1), proximal (2), medial (3), anterior (4), and distal (6) views. 5, detail of proximal shaft of the fibula in medial view (stereophotographs). Abbreviations: d, depression; or, oblique ridge; re, raised edge; sw, swelling; tu, tubercle. Scale bar equals $100 \mathrm{~mm}$ (not for 5).

separate the anteromedial concavity from a small posteromedial depression. Such a ridge has not been described or observed in any other theropod, and we thus interpret it as an autapomorphy of Wiehenvenator, as this morphology is present in both the left and right element. Distally, the ridge fades out, and the medial surface becomes slightly convex anteroposteriorly over a short distance, before a marked longitudinal fossa begins at about the mid-length of the bone and continues to approximately the distalmost fifth of the element, becoming shallower distally.

The distal end is slightly twisted in relation to the proximal end, so that its long axis is oriented somewhat anteromedially-posterolaterally. It is expanded both anteroposteriorly and transversely, reaching a maximal transverse width of $55 \mathrm{~mm}$ in the right element. The anteroposterior expansion starts more proximally on the anterior side, but is more marked on the posterior side, whereas the transverse expansion is mainly marked laterally. The lateral side of the bone becomes flattened towards the distal end and has a slight concavity on its anterior two-thirds distally, mainly defined by a ridge that curves from the anterior margin of the bone posterodistally towards the distal end, thus separating the widening anterior side from the lateral side.

The posterior margin becomes a sharp edge where the distal expansion begins. Distally, it flexes slightly laterally, resulting in a small, posteromedially directed surface. The medial side of the distal end is anteroposteriorly convex anteriorly, but shows a large, triangular fossa posteriorly; this morphology is more obvious in the right fibula than in the distally more poorly preserved left element, 
in which the posterior part is flat rather than depressed. However, in both elements, there is a distinction between a more anteromedially oriented anterior part and a larger, more posteromedially facing posterior portion, separated by a faint, oblique ridge that extends from the distal end anteroproximally. The distal articular surface is oval in outline (Figure 19.6), becoming notably more slender posteriorly. The posterior two-thirds of the surface are gently convex anteroposteriorly, but there is a notable fossa anteromedially.

Astragalus. The right astragalus is almost complete, being only damaged on the posterolateral side and showing signs of erosion anterodistally (Figure 20). The element is massive, being 193 $\mathrm{mm}$ wide transversely and maximally $113 \mathrm{~mm}$ anteroposteriorly on the medial side. As is usual in theropod astragali, the bone narrows laterally, so that its lateral anteroposterior width is $80 \mathrm{~mm}$. As in all tetanuran theropods, the astragalar body is strongly expanded anteroproximally (Figure 20.1, 20.2), so that the distal condyles face anterodistally (Sereno et al., 1994). The anteroproximal expansion is notably high, its medial height of c. $57 \mathrm{~mm}$ above the articular facet for the tibia being more than the height of the astragalar body below this facet $(49 \mathrm{~mm})$. This anteroproximal expansion is anteroposteriorly widest distally and gradually narrows proximally. In medial view (Figure 20.2), the astragalar body is thus L-shaped, with the proximal surface for the articulation with the distal end of the tibia forming an almost flat, only very slightly anteroposteriorly concave shelf that stands at an angle of c. $45^{\circ}$ to the posterior surface of the anteroproximal expansion and at $90^{\circ}-100^{\circ}$ towards the anterior side of the latter. The facet for the articulation with the tibia becomes more notably concave and narrower laterally (Figure 20.3). Furthermore, from approximately the level of the medial margin of the ascending process of the astragalus, it extends further distally, so that the astragalar body below the tibia is less deep laterally than medially (Figure 20.4).

As in all averostran theropods, the ascending process of the astragalus is laminar and was placed anterior to the distal end of the tibia. However, in contrast to the situation in most coelurosaurs, in which the process forms a thin bony lamina, it is rather robust, with a minimal thickness of $17 \mathrm{~mm}$ and up to $23 \mathrm{~mm}$ (Figure 20.2, 20.3), similar to the situation in Torvosaurus (Britt, 1991). As in non-coelurosaurian theropods generally, the process is placed on the lateral side of the astragalar body (Figure 20.1). Medially, it arises from the anterior border of the astragalar body at about onefourth of the transverse width of the bone and then rises gradually proximolaterally at an angle of $30^{\circ}$ $35^{\circ}$ in respect to the transverse axis of the bone. The medial margin of the ascending process shows a flattened, medially and slightly posteriorly facing facet (Figure 20.3), presumably for the contact with the oblique ridge that braces the ascending process of the astragalus on the anterior side of the tibia in basal tetanurans (Rauhut, 2003). This facet is broadest basally, but becomes slightly narrower towards the apex of the ascending process. The lateral margin of the ascending process is almost vertical in its distal two-thirds. Proximally, there is an unusual tab-like process that points proximolaterally and thus creates a kink in the lateral margin (Figure 20.1, 20.4), proximal to which the margin continues for $14 \mathrm{~mm}$ at an angle of approximately $65^{\circ}-70^{\circ}$ in respect to the distal part of the lateral margin of the ascending process. The apex of this tab-like process is placed at about its mid-width and represents the proximalmost point of the ascending process. Lateral to it, there is a proximolaterally facing, anteroposteriorly thickened, elongate oval to kidney-shaped facet that is notably convex anteroposteriorly and less so lateromedially (Figure 20.3). Such a tabular process on the ascending process of the astragalus, with a thickened proximolateral margin and a notable kink in the lateral margin of the ascending process is not found in any other theropod and thus represents an autapomorphy of Wiehenvenator. In general shape and orientation, as well as in a slight proximal thickening of its margin, the ascending process of the astragalus of Streptospondylus is similar to this process (MNHN 8608; Allain, 2001), but it lacks the marked kink in the lateral margin and is generally lower. Likewise, an astragalus referred to Torvosaurus tanneri (BYU VP 5029) is similar in a lateral inclination of the ascending process and a slight thickening of its proximolateral margin, resulting in an elongate oval, lateroproximally facing facet, but it lacks the notable lateral kink. Furthermore, Britt (1991, p. 45) noted that at least part of the lateral orientation of the ascending process in this element might be due to deformation.

The maximal height of the ascending process is c. $75 \mathrm{~mm}$, which is slightly less than the maximal height of the astragalar body (c. $99 \mathrm{~mm}$, including the anteroproximal expansion). Anteriorly, the process is offset from the astragalar body in that its anterior surface is slightly depressed in relation to the anterior margin of the body. This depression becomes more marked laterally, where it finally 


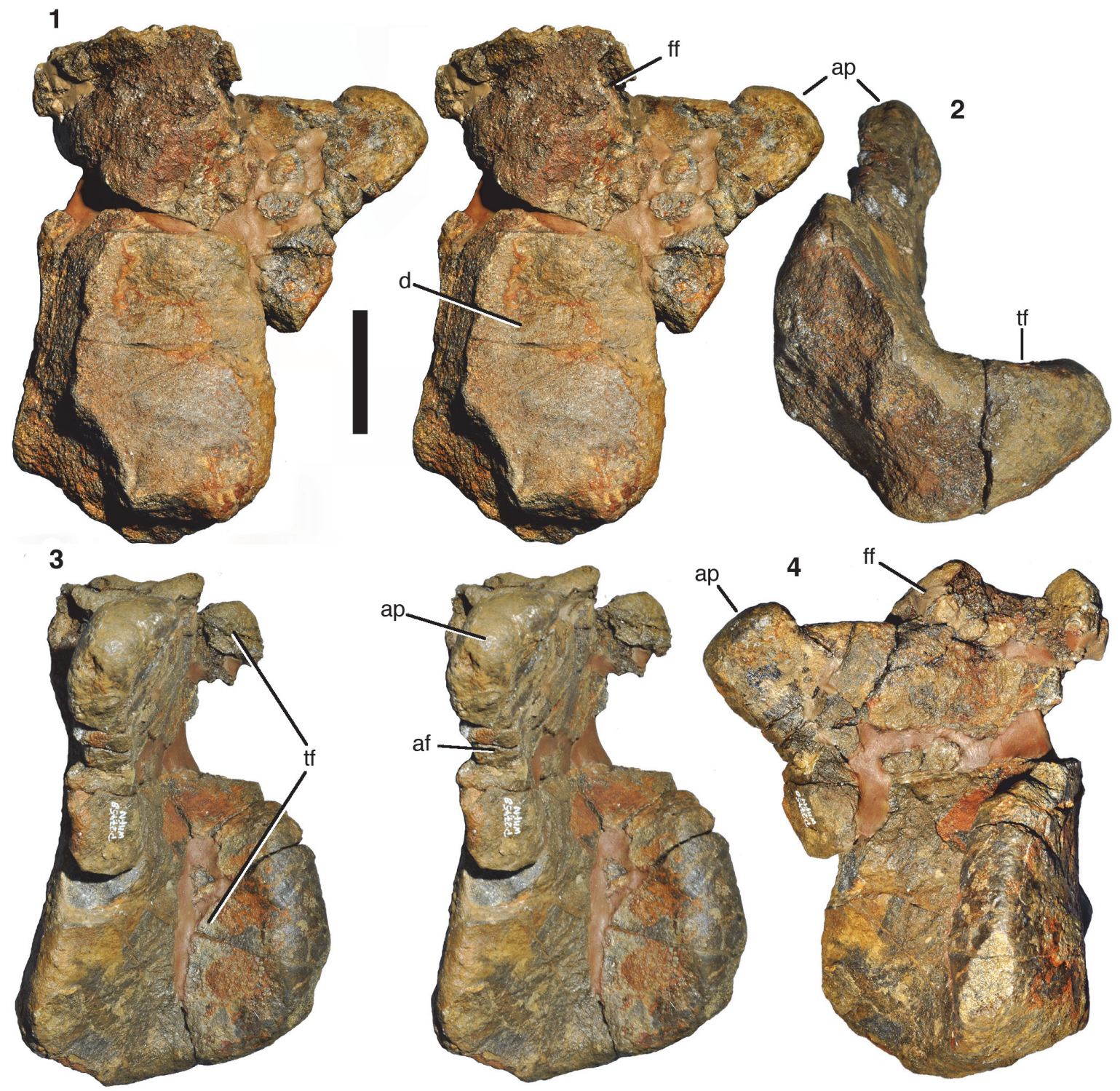

FIGURE 20. Right astragalus of Wiehenvenator albati in anterior (1; stereophotographs), medial (2), proximal (3; stereophotographs), and posterior (4) views. Abbreviations: af, articular facet for ridge on anterior side of tibia; ap, ascending process; d, depression; ff, fibular facet; tf, facet for articulation with tibia. Scale bar equals $50 \mathrm{~mm}$.

leads to the anterior shelf that widens laterally for the facet for the fibula (Figures 20.1, 20.4, 21). At the medial margin of this facet, at about one-fourth of the width of the astragalus as seen from the lateral side, a large $(7-8 \mathrm{~mm})$, round foramen is present and opens proximally and slightly anteriorly (Figure 21). Lateral to this foramen, the fibular facet is triangular in outline, widening laterally, and seems to be facing mainly proximally, but it is damaged and not much can be said about its detailed morphology, due to breakage. The posterior side of the base of the ascending process is damaged, so it is unclear if any foramina might have been present in this area. However, a large, rounded depression, as it is present in Allosaurus (e.g., USNM V 7336), is certainly absent.

The distal condyles of the astragalus were clearly strongly convex anteroposteriorly, but are damaged distally. Anteriorly, a large, marked depression is present distally in the central part of the astragalar condyles (Figure 20.1). However, a well-developed horizontal groove across the con- 


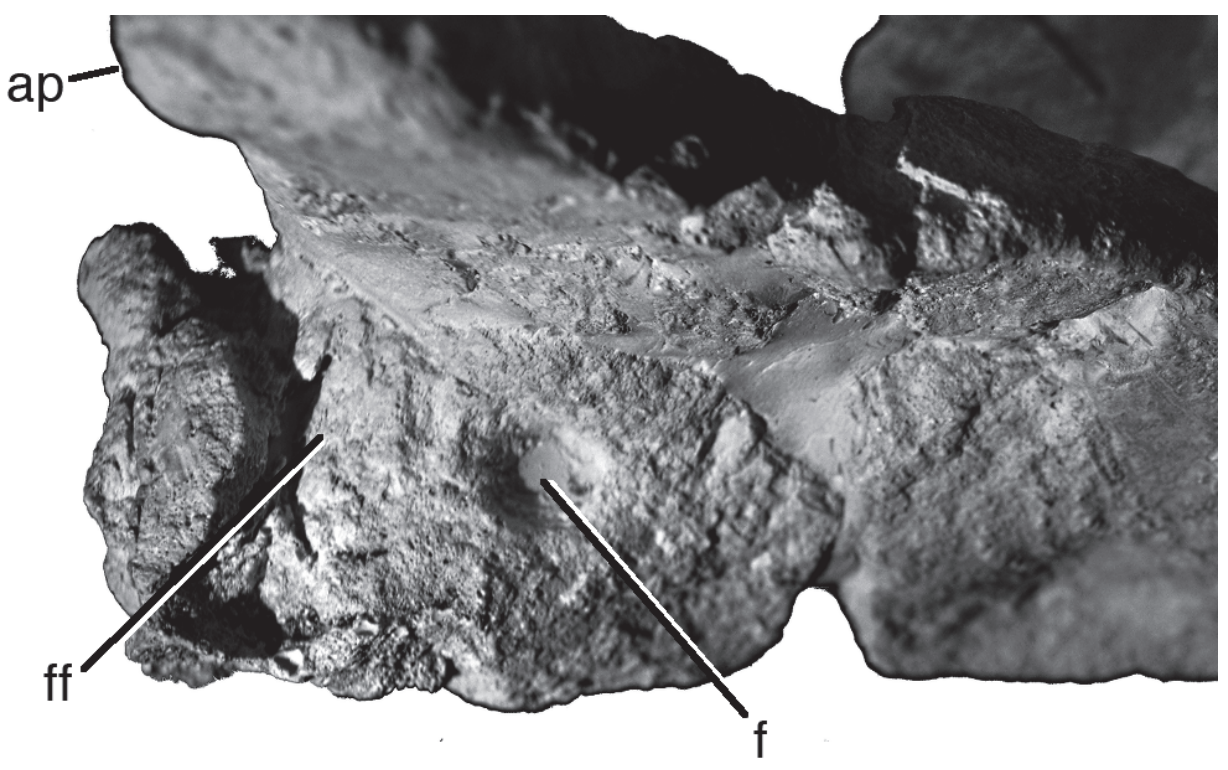

FIGURE 21. Detail of the right astragalus of Wiehenvenator albati: Base of the ascending process and fibular facet in anteroproximal view, showing large foramen anterior to the ascending process. Abbreviations as in Figure 20, and: $f$, foramen.

dyles, as it is present in many basal tetanurans, seems to be absent at least medially, where this groove is especially marked in Torvosaurus (Britt, 1991); the lateral side of the condyles is too poorly preserved to say anything about its morphology. Likewise, the articular surface for the calcaneum is poorly preserved, but it seems to have been rather simple, without the peg-in-socket articulation found in Allosaurus (Welles and Long, 1974).

Calcaneum. The right calcaneum (Figure 22) was found in close proximity to the astragalus. Unfortunately, however, it is poorly preserved and little can be said about its morphology. The bone was obviously rather massive and had an anteroposteriorly strongly convex distal condyle. The facet for the tibia was large and reached the lateral side of the calcaneum, as in tetanurans generally. The lateral side of the bone is flattened, with slightly raised anterodistal and posterodistal margins.

Histology. The cross section of the left fibula WMN P27479 is semilunate in outline with an anteroposterior length of $50 \mathrm{~mm}$ and a mediolateral width of $20 \mathrm{~mm}$ (Figure 23). A marrow cavity is almost absent, similar to e.g., Tyrannosaurus (Horner and Padian, 2004; Horner personal commun., 2015, to TH), Mei (Gao et al., 2012), and Ornithomimus (Cullen et al., 2014), and is only represented by an elongated area with larger secondary osteons in the centre of the cross section. Most of the cross section consists of dense haversian tissue with at least two generations of secondary osteons. Primary bone tissue is still present at the anterior and posterior corners, where it represents about $10 \mathrm{~mm}$ of the outer cortex (Figure 23). The tissue between primary osteons and simple vascular canals mainly houses osteocyte lacunae of circular to irregular shape and arrangement of canaliculi. They are usually widely scattered, but some dense clusters are present as well. Under polarized light, the tissue shows only weak birefringence. Following the definitions of Prondvai et al. (2014), the primary bone tissue is therefore of the woven-fibered complex type. The primary osteons are mostly longitudinally orientated with occasional anastomoses, which is similar to the ulna of Allosaurus (Bybee et al., 2006, figure 1d), the third metatarsal of Troodon (Varricchio, 1993, figure 3), and the fibula of Tyrannosaurus (Horner and Padian, 2004) and Acrocanthosaurus (D'Emic et al., 2012). The abundance of vascular canals in general decreases significantly towards the periphery.

Four lines of arrested growth (LAGs) are visible in the anterior corner of the bone and up to seven in the posterior margin (Figure 23). An additional outermost line can be seen by following the course of the other LAGs from the posterior corner laterally. Most of the LAGs are accompanied by annuli or thick, laminated bands of lamellar bone, sometimes undulating around or incorporating small primary osteons or simple vascular canals. 


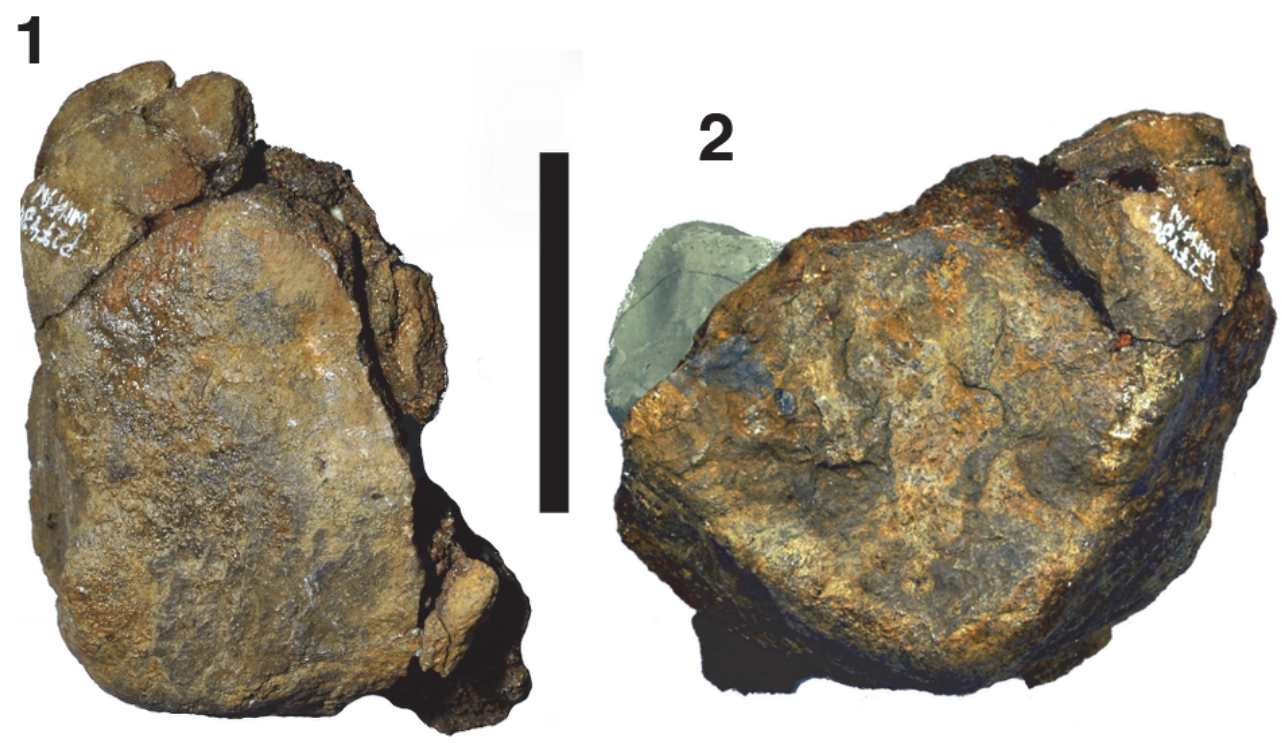

FIGURE 22. Right calcaneum of Wiehenvenator albati in anterior (1) and lateral (2) views. Scale bar equals $50 \mathrm{~mm}$.

This is similar to the pattern seen in a metatarsal of Troodon (Varricchio, 1993: figure 3). However, the osteocyte lacunae in these annular bands are still irregular in shape and not spindle-like as expected, although they are rarer in number than in the growth zones. The thickness of these zones decreases consistently towards the periphery. The size and density of primary osteons also decrease significantly, but an external fundamental system (EFS) as a sign of skeletal maturity is absent.

\section{DISCUSSION}

\section{Histological Analysis}

Fibulae are the only preserved long bones of Wiehenvenator. Fibulae are not ideal bones to reconstruct maximum growth rates in a dinosaur, because they are much smaller in terms of circumference and thickness than femora or tibiae, and they are less involved in weight bearing than the tibiae. Thus, fibular periosteal growth rates are lower, which is indicated by the rather simple longitudinal orientation of primary osteons in the cortex, which is also visible in other theropods (Horner and Padian, 2004; Zanno et al., 2011; D'Emic et al., 2012). Bone histology studies of other dinosaurs known from more complete appendicular skeletons demonstrate the relationship between size and degree of utilization (Hübner, 2012) of skeletal elements and their relative growth rates, such as in Tyrannosaurus (Horner and Padian, 2004), Allosaurus (Bybee et al., 2006), Plateosaurus (Klein and Sander, 2007), Dysalotosaurus (Hübner,
2012), Tenontosaurus (Werning, 2012), and Ornithomimus (Cullen et al., 2014).

However, fibulae are well suited to study the completeness of the growth record, at least in theropods (Erickson et al., 2004). Accordingly, the holotype of Wiehenvenator albati was at least in its ninth year of life at the time of death. However, with respect to the intense secondary remodeling, which might have obscured several earlier growth marks, the age at death might have been well over 10 years. The absence of an EFS indicates that the animal was still actively growing, but the narrow growth zones and the patchiness of small primary osteons close to the periosteal surface demonstrates that the skeletal growth rate was already slowing down. Thus, the growth stage of Wiehenvenator fits best to that of a large subadult individual.

Concerning the size of Wiehenvenator, the maxilla is c. $82 \%$ of the size of that of Torvosaurus gurneyi, which was estimated to be approximately the size of Gorgosaurus or Daspletosaurus (c. 10 $m$ in length and 4 to 5 tons in weight) by Hendrickx and Mateus (2014a). On the other hand, the caudal vertebrae are closely comparable in size to elements from a similar position in Torvosaurus tanneri, and the fibulae are even slightly longer than those referred to the latter taxon (Britt, 1991); this taxon was estimated to be approximately $9 \mathrm{~m}$ in body length by Britt (1991). Thus, Wiehenvenator is one of the largest theropods found so far in Europe and might only have been slightly smaller than Torvosaurus gurneyi. 


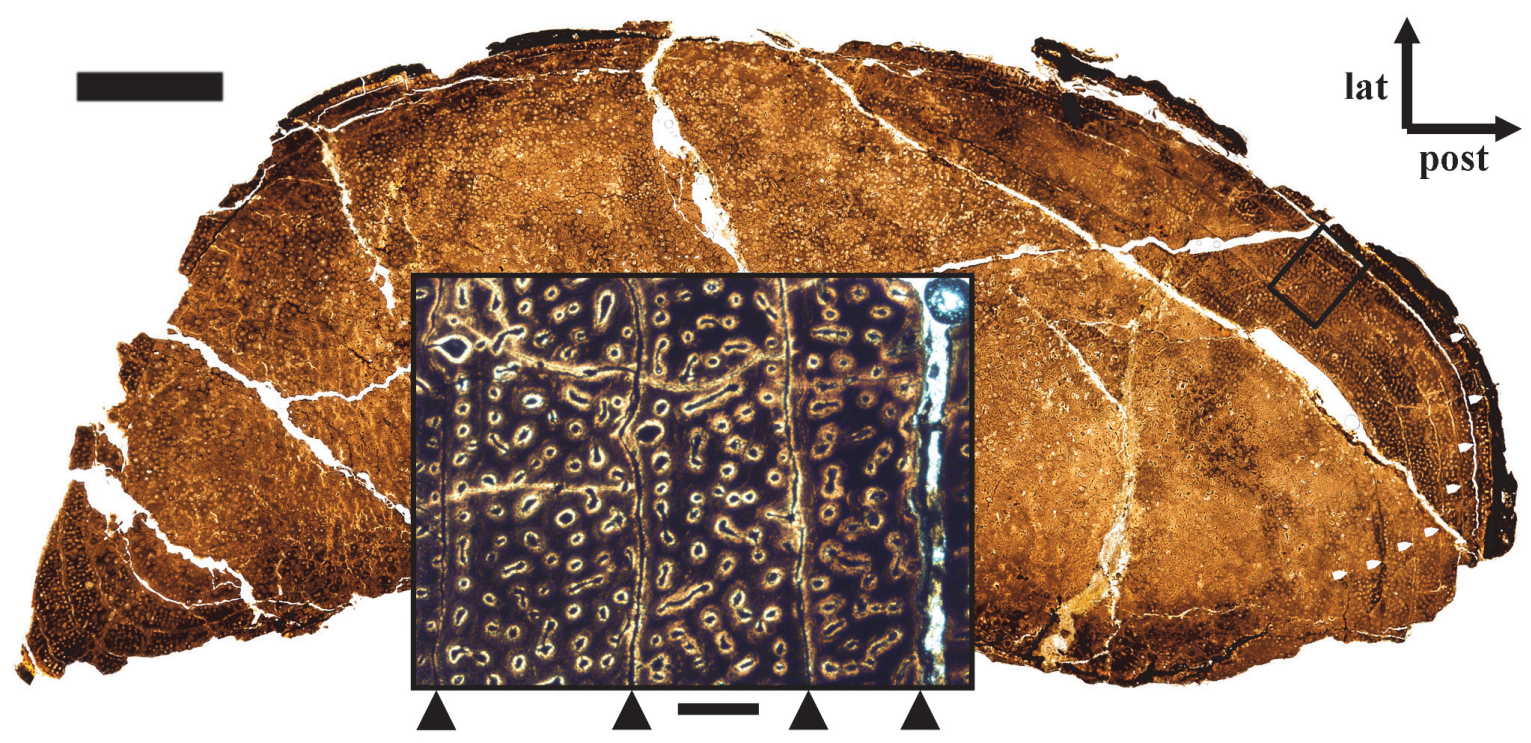

FIGURE 23. Overview of transverse thin section of the left fibula of Wiehenvenator albati. Most of the primary tissue is secondarily remodelled, but growth marks are still preserved anteriorly and posteriorly (white arrows). Abbreviations: lat, lateral; post, posterior. Scale bar equals $5 \mathrm{~mm}$. Inset: Slightly clockwise rotated and magnified image of the posterior outer bone cortex (see frame in overview image). Growth marks are marked by black arrows. Scale bar equals $400 \mu \mathrm{m}$.

\section{Systematic Position}

The phylogenetic analysis recovered 500 equally parsimonious trees with a length of 1096 steps $(\mathrm{Cl} 0.4$, RI 0.67, RC 0.27). The strict consensus tree shows a reasonable resolution (Figure 24.1), recognizing most major clades present in recent analyses, including Coelophysoidea, Ceratosauria, Megalosauroidea, Allosauroidea, and Coelurosauria. However, the tree shows several differences from that obtained by Carrano et al. (2012). In basal theropods, the Early Jurassic North American taxon Dilophosaurus was found to be more closely related to averostrans than to coelophysids, and the Early Jurassic taxa Cryolophosaurus and Sinosaurus were recovered a successively closer outgroups to Averostra. Although the interrelationships of basal theropods were not the objective of the current analysis, and the results should be seen with caution, due to rather poor taxon and character sampling in this part of the tree, some comments on the latter taxa will be offered. Cryolophosaurus and Sinosaurus were found to be basal tetanurans by Carrano et al. (2012) and thus as the oldest representatives of this clade, with far reaching consequences for our understanding of the evolutionary and biogeographic origin of tetanurans. In the current analysis, Cryolophosaurus is placed outside Averostra due to the lack of several synapomorphies of the latter clade: presence of a lacrimal fenestra, reduction of the prefrontal exposure on the orbit, a parietal that overlaps the supraoccipital, a short and blunt retroarticular process, an expanded lateral malleolus of the tibia that backs the distal end of the fibula posteriorly, a laminar ascending process of the astragalus, the presence of an enlarged fossa at the base of the ascending process of the astragalus, and the reduction of the articular surface for the fibula on the astragalus. Likewise, Sinosaurus lacks the following averostran synapomorphies: presence of a lacrimal fenestra, a transversely expanded dorsal end of the axial neural spine, elongate axial epipophyses, the presence of a pleurocoel in the axis, a reduced expansion of the distal scapula, a slender scapular blade (length/width ratio of more than 7.5), a laterally exposed proximal part of the medial brevis shelf, a distinct lesser trochanter and attachment bulge on the femur, a laminar ascending process of the astragalus, and the reduction of the articular surface for the fibula on the astragalus. A placement of Cryolophosaurus at the base of Tetanurae requires seven additional steps, whereas four more steps are needed to move Sinosaurus to that position. 


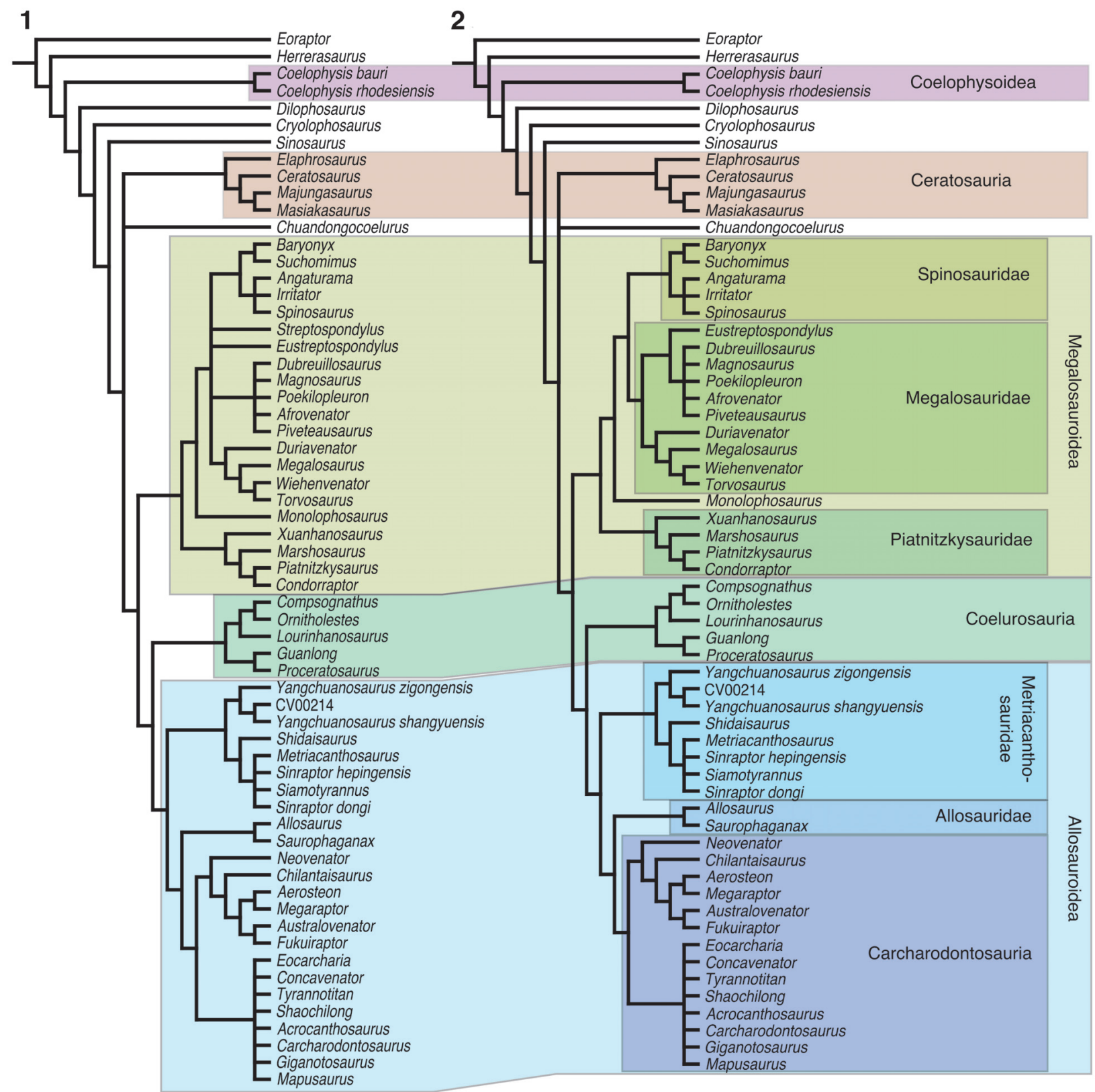

FIGURE 24. Phylogenetic position of Wiehenvenator albati, based on an analysis of 62 taxa and 351 characters (see text for details). 1, strict consensus tree. 2, reduced consensus tree after the a posteriori exclusion of Streptospondylus.

Within tetanurans, the main changes concern the taxa Monolophosaurus and Xuanhanosaurus. Whereas the former was found to be a basal tetanuran outside Orionides (Megalosauroidea + Avetheropoda) and the latter to be a metriacanthosaurid allosauroid by Carrano et al. (2012), both are placed in the Megalosauroidea in the current analysis, thus mirroring the results of Benson (2010a). Xuanhanosaurus was thus found as the most basal member of the Piatnitzkysauridae, and Monolopho- saurus was recovered as sister taxon to Megalosauria within the Megalosauroidea. Xuanhanosaurus is based on very fragmentary material (mainly an almost complete forelimb; Dong, 1984), with the added complication that some of the elements preserved (e.g., manus) are otherwise poorly represented in basal tetanurans. Thus, it is not surprising that the systematic position of this taxon remains uncertain; placement of Xuanhanosaurus as a basal metriacanthosaurid 
requires only one additional step. As for Monolophosaurus, the inclusion of this taxon in the Megalosauroidea is better supported in the current analysis. Moving this taxon outside Orionides (as found by Carrano et al., 2012) requires five extra steps, and a placement within Allosauroidea, as found e.g., by Sereno et al. (1996), Holtz (2000), and Rauhut (2003), even results in trees that are at least eight steps longer than the most parsimonious trees.

Within Megalosauria, the analysis found a polytomy that included the clades Spinosauridae, Megalosaurinae, and Afrovenatorinae (sensu Carrano et al., 2012), together with the genera Eustreptospondylus and Streptospondylus. A posteriori removal of Streptospondylus resulted in the recovery of a monophyletic Megalosauridae, including Megalosaurinae and a second monophyletic subclade, with Eustreptospondylus being placed as the most basal taxon in the latter (Figure 24.2). As the name Eustreptospondylinae is available for this clade (Holtz et al., 2004) and has priority over Afrovenatorinae, this name is used here.

Wiehenvenator was consistently found to be a megalosaurine megalosaurid. Within this clade, it represents the sister taxon of Torvosaurus, with Megalosaurus and Duriavenator representing successively more distant taxa. However, Bremer and Bootstrap support are low for any clade within Megalosauria (with the exception of Spinosauridae), which is to be expected, as four (Duriavenator, Magnosaurus, Piveteausaurus, Poekilopleuron) of the 10 taxa within the Megalosauridae have more than $85 \%$ of missing data, and only three taxa (Afrovenator, Eustreptospondylus, Torvosaurus) could be coded for more than $50 \%$ of the characters. Wiehenvenator itself could only be coded for slightly more than $20 \%$ of the characters. Thus, character support for the position within megalosaurine megalosaurids for this taxon is also poor. However, Wiehenvenator shows the following synapomorphies of megalosaurids or subclades thereof: palatal process of the maxilla offset dorsally from interdental plates (synapomorphy of megalosaurines), ventral margin of the interdental plates placed considerably dorsal to the lateral alveolar margin (synapomorphy of the clade containing Megalosaurus, Torvosaurus, and Wiehenvenator), presence of a deep and broad posteriorly facing groove on the jugal process of the postorbital (synapomorphy of megalosaurids, convergently present in Marshosaurus; CM 21704), supratemporal fossa extends onto the posterior process of the postorbital (synapomorphy of mega- losaurids or megalosaurians), presence of a welldeveloped supraorbital brow on the anterior process of the postorbital (present in Torvosaurus, but unknown in Duriavenator and Megalosaurus; absent in eustreptospondylines and convergently present in many allosauroids), a blunt and unexpanded anterior end of the dentary (synapomorphy of the clade containing Megalosaurus, Torvosaurus and Wiehenvenator, reversal of a megalosauroid synapomorphy), and presence of a large, pronounced pleurocentral fossa on the lateral side of the caudal vertebral centra (possible synapomorphy of megalosaurines, unknown in Duriavenator; convergently present in several carcharodontosaurids). Moving Wiehenvenator outside megalosaurines requires four additional steps, whereas a placement outside megalosaurids results in three (placement as sister taxon to spinosaurids) or five (sister taxon to megalosaurians) additional steps, and placing this taxon outside megalosauroids requires even nine additional steps. Given that only 71 of the 351 characters could be coded for Wiehenvenator, this relatively high number of additional steps necessary indicates that megalosauroid relationships are rather well supported for this taxon by the available evidence.

\section{Implications for the Early Radiation of Tetanurans}

The identification of Wiehenvenator as a megalosaurid theropod adds to the already diverse assemblage of taxa within this group in the Middle Jurassic. With the recovery of the Early Jurassic Cryolophosaurus and Sinosaurus outside Tetanurae, the oldest known representatives of the latter clade are early Middle Jurassic in age (see also Benson, 2010b). As noted by Benson (2010b), the presence of the basal ceratosaur Berberosaurus in the Toarcian of northern Africa (Allain et al., 2007) indicates that tetanurans originated at that time at the latest. Earlier records are currently unknown, although there are a number of pre-Toarcian Early Jurassic dinosaurs faunas known that also include theropods (see. e.g., Weishampel et al., 2004; Rauhut and López-Arbarello, 2008). The oldest certain tetanurans are the basal megalosauroids Piatnitzkysaurus and Condorraptor (Figure 25) from the probably Aalenian-Bajocian of the Cañadón Asfalto Formation of Argentina (Bonaparte, 1979, 1986; Rauhut, 2005; Cúneo et al., 2013), but true megalosaurids appear already in the Bajocian of Europe, with the eustreptospondyline Magnosaurus (Benson, 2010b) and the megalosaurine Duriavenator (Benson, 2008). Given the 
sister group relationship between megalosaurids and spinosaurids, the latter lineage must thus also already have been established at that time. Likewise, the sister group relationship between megalosauroids and Orionides indicates that the latter was also present by the beginning of the Middle Jurassic. Indeed, the earliest allosauroids, Yangchuanosaurus zigongensis and, possibly, Shidaisaurus are of probable Bajocian age as well (Gao, 1993; Wu et al., 2009; Li et al., 2011, Carrano et al., 2012). As these taxa are representatives of the metriacanthosaurids within allosauroids, their relationships indicate that at least two further lineages of tetanurans must have been present by this time, the coelurosaurs and the Allosauria. Given a possible Toarcian origin and certainly not a pre-Toarcian radiation of tetanurans (based on the available fossil record), the early diversification and radiation of this clade happened rapidly within the 10-14 million years from the Toarcian to the end of the Bajocian. This is mirrored by the second important lineage of theropods, the ceratosaurs: the presence of the basal abelisaurid Eoabelisaurus in the AalenianBajocian of South America (Pol and Rauhut, 2012) and the identification of some Middle and Late Jurassic taxa as noasaurids (Rauhut and Carrano, 2016) indicate that at least three important lineages of this clade (Ceratosauridae, Noasauridae, and Abelisauridae) were already established at that time (Figure 26).

The appearance of black shales in the Early Toarcian (such as the famous Posidonienschiefer of Germany) has been known for a long time, and an oceanic anoxic event has been inferred to have produced these deposits (e.g., Jenkyns, 1988), which are known to be associated with a secondorder extinction event (e.g., Hallam, 1986; Harries and Little, 1999). In recent decades, increased volcanism in southern Gondwana (in the Karoo-Ferrar igneous province) has come into focus as one of the main drivers behind this event (e.g., Pálfy and Smith, 2000), resulting in a volcanic greenhouse effect (Wignall, 2005). Although the effects of this extinction event on marine organisms has been rather well studied (e.g., Hallam, 1987; Harries and Little, 1999; Aberhan and Baumiller, 2003; Wignall et al., 2005; Dera et al., 2010; Caruthers et al., 2014), consequences for terrestrial ecosystems and biota are much more poorly known.

Allain and Läng (2009) suggested that the Pliensbachian-Toarcian extinction event played an important role in the evolution of saurischian dinosaurs. Indeed, whereas a lot of emphasis has been laid on the role of extinctions during the Late Trias- sic or the Triassic-Jurassic extinction event for the success of dinosaurs in recent decades (e.g., Benton, 1983, 1990, 2004; Olsen et al., 1987, 2002, 2011; Brusatte et al., 2010b; Langer et al., 2010; Benton et al., 2014), from a phylogenetic point of view, there is not much difference in saurischian faunal composition (though probably abundance of different groups; Brusatte et al., 2010b) between the Late Triassic and the pre-Toarcian Early Jurassic. In sauropodomorphs, a range of basal, nonsauropodan taxa are known from the Late Triassic, including several distinct clades, such as plateosaurids, massospondylids, and sauropodiforms (see McPhee et al., 2015; Otero et al., 2015). Apart from plateosaurids, these clades thrive also in the Early Jurassic, but no basal, non-sauropodan sauropodomorph has securely been reported from rocks that are younger than Toarcian, whereas sauropods are already diverse in the Middle Jurassic (see Rauhut and López-Arbarello, 2008). Likewise, in theropods, the most common Late Triassic clade are the coelophysoids (e.g., Rauhut and Hungerbühler, 2000; Nesbitt and Ezcurra, 2015), which are also still diverse in the Early Jurassic (see Ezcurra, 2012; You et al., 2014; Martill et al., 2016). The sister taxon to Coelophysoidea, the lineage leading towards Averostra, must have originated at the same time; its probably oldest known representative being the Norian Zupaysaurus (Ezcurra, 2012; Langer et al., 2014). The stem lineage of Averostra might have included yet another distinct clade, the dilophosaurids (Smith et al., 2007; Ezcurra, 2012; Holtz, 2012; Langer et al., 2014), the monophyly of which is debated (see Brusatte et al., 2010a, 2010b). If these taxa indeed form a clade, all of the constituent taxa are known from Lower Jurassic rocks, but the stratigraphic position of the immediate outgroup taxon of Averostra, Tachiraptor, at the base of the Jurassic indicates that the origin of this clade also reaches back to the Triassic (Figure 26; Langer et al., 2014). Thus, latest Triassic and Early Jurassic theropod faunas seem to have not been dramatically different in overall faunal composition. However, both coelophysoids and dilophosaurids (or non-averostran theropods) disappear towards the end of the Early Jurassic, and are completely replaced by the diverse lineages of averostrans found at the beginning of the Middle Jurassic noted above. Thus, the Pliensbachian-Toarcian extinction event seems to have played a major role in the evolution of theropods and the radiation of averostrans. Indeed, the explosive radiation of the latter (Figure 26) is reminiscent of the rapid radia- 


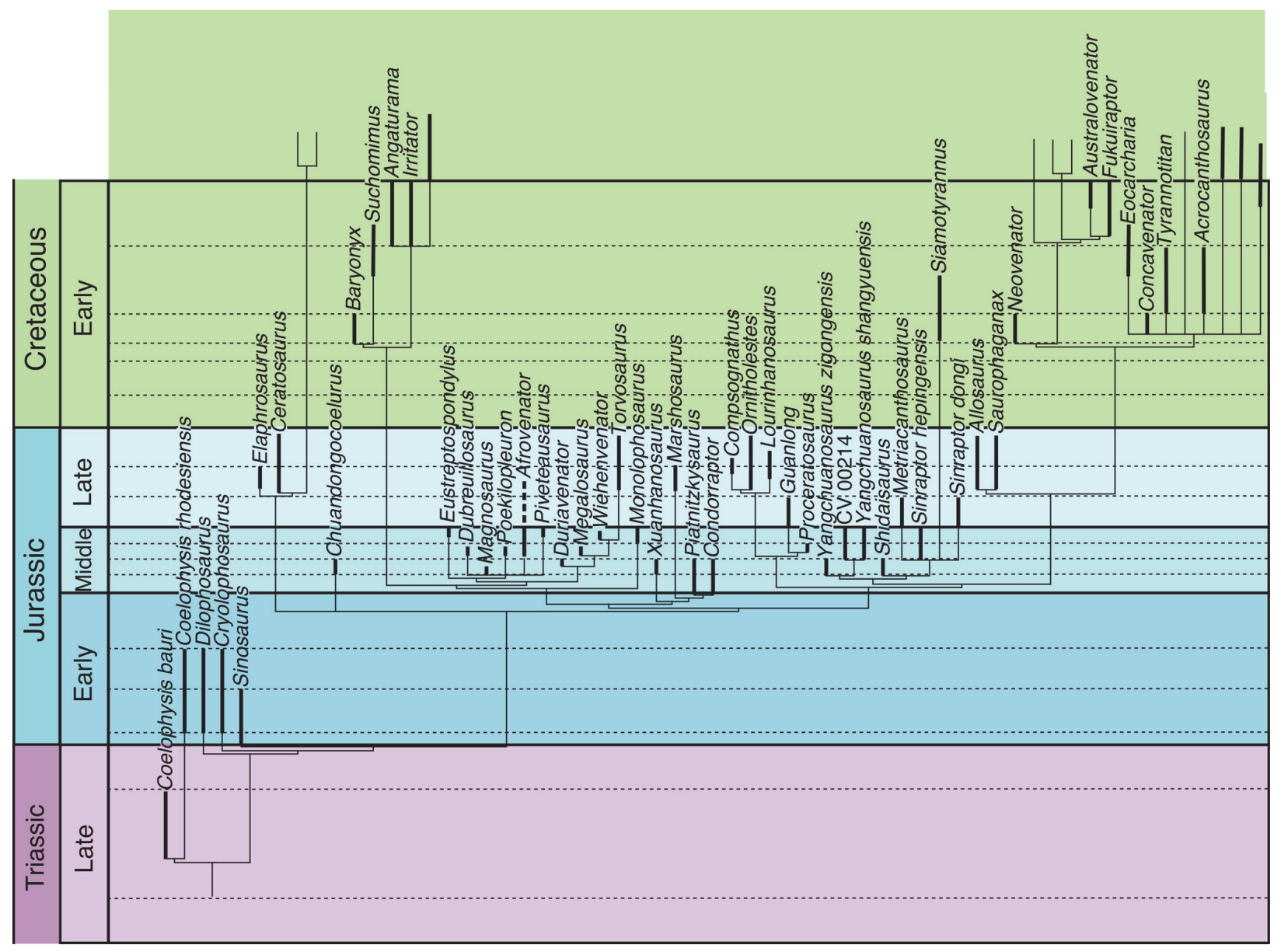

FIGURE 25. Time-calibrated cladogram of early tetanuran relationships, showing the earliest records of the distinct clades, and the rapid evolution of tetanurans in the early Middle Jurassic.

tion of surviving clades following the infamous Cretaceous-Palaeogene boundary (Jarvis et al., 2014; Claramunt and Cracraft, 2015; Halliday and Goswami, 2015; Halliday et al., 2015), indicating at least a thorough reorganization of the niches of larger predatory vertebrates at that time.

As noted above, megalosauroids originated in the Aalenian at the latest, and rapidly diversified into a number of subclades. By the Bajocian, megalosauroids had split into its major constituent clades, including piatnitzkysaurids, megalosaurine megalosaurids, eustreptospondyline megalosaurids, and spinosaurids. Whereas the first three of these clades are well represented in the Middle Jurassic, the first certain spinosaurids appear in the Barremian (Charig and Milner 1986, 1997; Buffetaut, 2007), although Buffetaut $(2008,2011)$ considered an isolated tooth from the Tithonian Tendaguru Formation of Tanzania to represent the oldest known spinosaurid (but see Rauhut, 2011), and Allain et al. (2012) suggested that a large ungual from the Kimmeridgian-Tithonian Morrison Formation of Colorado, originally referred to Torvosaurus by Galton and Jensen (1979) might also belong to this group. However that may be, the sister-group relationship between megalosaurids and spinosaurids indicates that the latter linage must have been established by the Bajocian at the latest.

The topology of taxa within megalosaurines is in perfect accordance with the stratigraphic appearance of the taxa that constitute this clade (Figure 25). The most basal taxon, Duriavenator, is also the stratigraphically oldest representative, being Bajocian in age (Waldman, 1974; Benson, 2008). This is followed by the Bathonian Megalosaurus and the Callovian Wiehenvenator. Finally, the sister taxon to Wiehenvenator, the genus Torvosaurus, is known from the Kimmeridgian-Tithonian of North America (Galton and Jensen, 1979) 


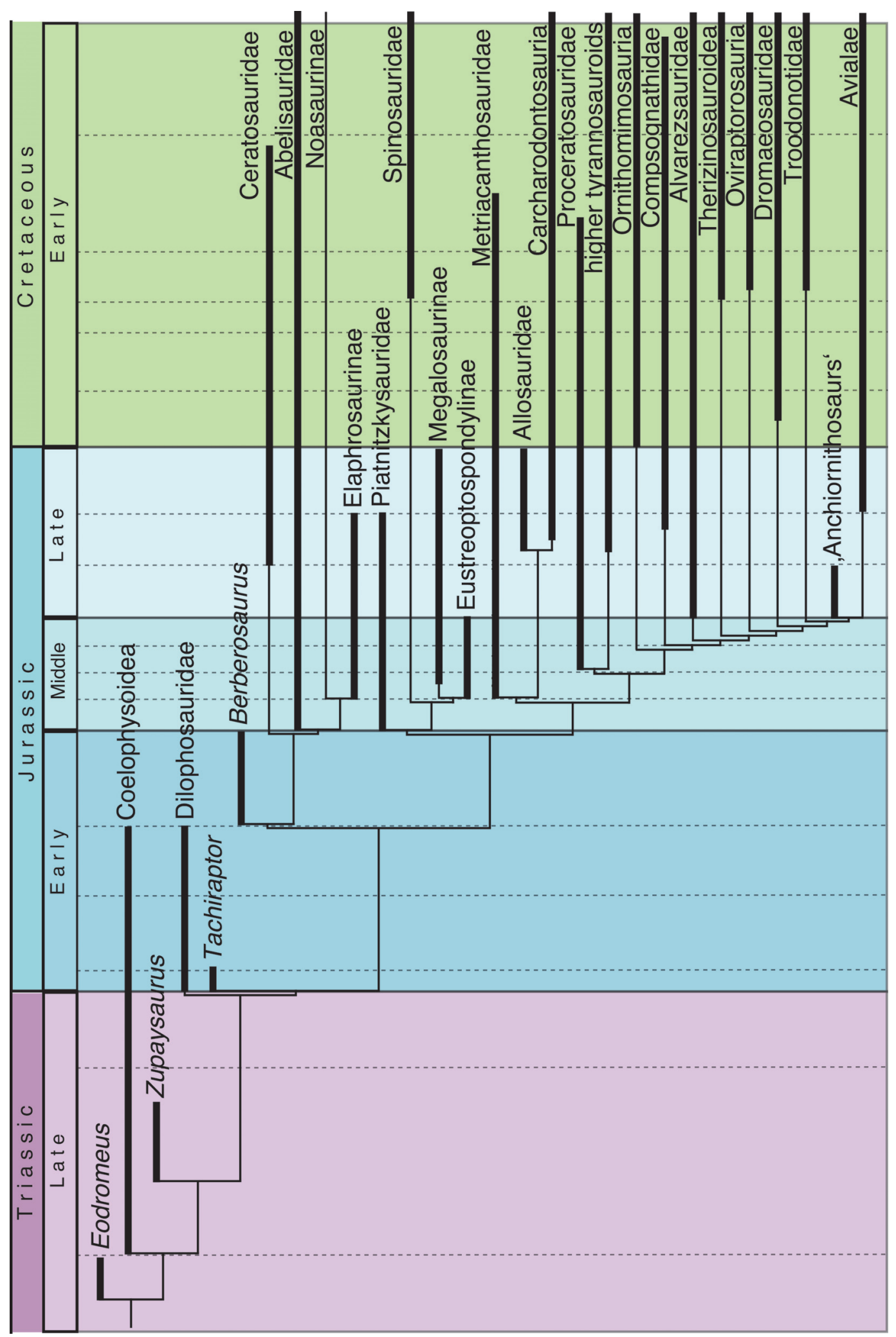

FIGURE 26. Time-calibrated informal supertree of theropod relationships, showing the explosive radiation of the clade in the latest Early and Middle Jurassic. Theropod interrelationships are based on Ezcurra (2012) and Langer et al. (2014) for non-averostran taxa, Rauhut and Carrano (2016) for Ceratosauria, the present study for basal tetanurans, Brusatte and Carr (2016) for tyrannosauroids, and Brusatte et al. (2014) and Foth et al. (2014) for other coelurosaurs. 
and the Kimmeridgian of Europe (Hendrickx and Mateus, 2014a), and thus represents probably the only megalosaurid that survived the Middle Jurassic. The only other megalosaurid taxon that has been considered to be younger than Middle Jurassic is Afrovenator (Sereno et al., 1994), but the age of this taxon is unclear, and it might be considerably older than originally suggested (Rauhut and López-Arbarello, 2009; see below).

\section{Theropod Faunal Changes from the Middle to the Late Jurassic}

Benson (2010a, p. 930-931) suggested that there was a faunal turnover from megalosauroids to allosauroids from the Middle to the Late Jurassic, at least in respect to large theropods, representing the apex predators in their respective ecosystems. One problem with trying to analyse changes in theropod faunal composition in the course of the Middle to Late Jurassic, however, is the uncertain stratigraphic age and range of several theropod-bearing formations. Especially problematic in respect to the Middle-Late Jurassic transition are two units in China, the Tiaojishan Formation and the Shaximiao Formation. The former has been constrained by radiometric dates, but ages obtained still range between the uppermost Bathonian and the lowermost Kimmeridgian (Sullivan et al., 2014). However, although many researchers give the age range of the fossils as Callovian-Oxfordian (e.g., Xu et al., 2015), Liu et al. (2012) dated the layers where the small theropod Anchiornis comes from at $160-161 \mathrm{Ma}$, which places these layers in the Lower Oxfordian. They furthermore gave an upper age constraint for the fossiliferous layers at $158.5 \mathrm{Ma}$, representing the Upper Oxfordian. Thus, we consider the fossils from the Tiaojishan Formation to be Oxfordian in age.

The other problematic unit has been subdivided into two units in the more recent Chinese literature, the Xiashaximiao Formation (= lower Shaximiao Formation) and the Shangshaximiao Formation (= upper Shaximiao Formation; e.g., Peng et al., 2005). The Xiashaximiao Formation is generally considered to be Middle Jurassic in age, although the exact dating of the unit is still controversial, with ages ranging from the Bajocian to the Callovian. The Shangshaximiao Formation has often been said to be Late Jurassic (e.g., Peng et al., 2005), mainly based on the vertebrate fauna. However, after carefully re-evaluating the available evidence, Li et al. (2011) argued that the two units should only be regarded as members within a sin- gle formation, the Shaximiao Formation, which is entirely Middle Jurassic in age. Thus, these authors assume a probably Bajocian age for the lower member, and a Bathonian-Callovian age for the upper member. This view is followed here.

Another unit of uncertain age is the Tiouraren Formation of Niger, from where the megalosaurid Afrovenator and a small ceratosaur have been reported (Sereno et al., 1994, 2004). The latter specimen (MNN Tig6) was referred to the species Spinostropheus gautieri by Sereno et al. (2004), but shows numerous differences to the original material of this taxon described by de Lapparent (1960), and thus should be regarded as a separate taxon. The Tiouraren Formation has traditionally been regarded as Early Cretaceous (e.g., de Lapparent, 1960; Moody and Sutcliffe, 1991; Sereno et al., 1994, 2004), but Rauhut and López-Arbarello (2009) argued that it is considerably older, and probably Middle to earliest Late Jurassic in age. This assignment has been widely accepted since (e.g., Remes et al., 2009; Mudroch et al., 2011; Serrano-Martínez et al., 2015; van Damme et al., 2015), with most authors favouring a late Middle Jurassic age. This is the age assumed here as well.

Taking a taxonomic approach to faunal changes between Middle and Late Jurassic faunas (Figure 27), we thus regard a total of 63 theropod species from the Middle to Late Jurassic as valid, of which 25 come from the Middle and 38 from the Late Jurassic (Table 3). For the Middle Jurassic, representatives of the Megalosauroidea account for at least $14(56 \%)$ of the recorded taxa, whereas only four ( $16 \%$ of described taxa) are allosauroids, all of which have been found in eastern Asia (Figure 27.1). Within megalosauroids, the most basal clade, the piatnitzkysaurids, seems to represent the first successful radiation, with three species being recorded in the early Middle Jurassic (Aalenian-Bajocian). The group has not been recorded in the later stages of the Middle Jurassic, but must have been present during that time, as the youngest member, Marshosaurus, is KimmeridgianTithonian in age. True megalosaurids are first recorded in the Bajocian, but dominate the later Middle Jurassic (Bathonian-Callovian), representing eight $(53 \%)$ of the 15 recorded taxa for this time. The first coelurosaurs, the proceratosaurids Proceratosaurus and Kileskus, appear in the Bathonian in the fossil record, but their classification as a subclade of tyrannosauroids (Averianov et al., 2010; Rauhut et al., 2010, Brusatte and Carr, 2016) indicates that a first radiation of coelurosaurs 
Middle Jurassic L L Late Jurassic
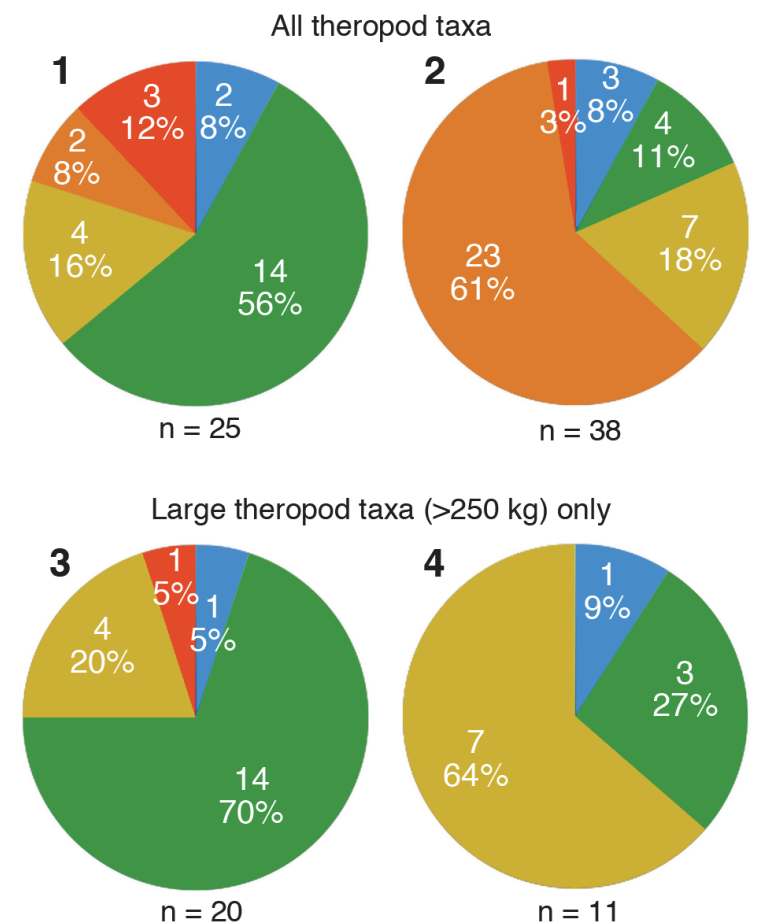

- Ceratosauria Megalosauroidea Allosauroidea - Coelurosauria Incertae sedis

FIGURE 27. Representation of different clades of Middle (1) and Late Jurassic (2) nominal theropod taxa. Figures 3 and 4 show the same for large theropod taxa (body weight $>200 \mathrm{~kg}$ ) only.

must already have happened by that time. In the Late Jurassic, megalosauroids account for only four $(10.5 \%)$ of the taxa described, whereas seven $(18.4 \%)$ are allosauroids (Figure 27.2). The most important radiation, however, seems to be that of coelurosaurs, which already account for $60.5 \%$ (23 taxa) of the formally named theropod taxa. Ceratosaurs are recorded from both the Middle and Late Jurassic, but play only a minor role, accounting for $8 \%$ and $7.9 \%$ of the theropod taxa, respectively.

Looking only at large theropod taxa (>250 kg body mass), a change from megalosauroid-dominated Middle Jurassic to allosauroid-dominated Late Jurassic faunas becomes more obvious (Figure 27.3, 27.4). In the Middle Jurassic, megalosauroids account for $14(70 \%)$ of the 20 described large theropod taxa, whereas only four $(20 \%)$ are allosauroids. In the Late Jurassic, these proportions are basically inverted, with megalosauroids representing three $(27.3 \%)$ of the 13 recorded large theropods, and allosauroids accounting for seven $(63.6 \%)$ of these taxa.
Another way of looking at these faunal changes is not counting named taxa, but considering the distribution of the different clades in theropod-bearing localities. Looking at the percentage of theropod localities, in which megalosauroid and allosauroid remains are found, a similar picture as that for large theropods emerges (Figure 28). In the Middle Jurassic, megalosauroids are found in $69.2 \%$ of the localities with identifiable remains, but only in $15.8 \%$ of the Late Jurassic localities. In contrast, allosauroids are only found in $11.5 \%$ of the Middle Jurassic localities, but in $65.1 \%$ of the Late Jurassic localities. Coelurosaurs more gradually increase their share in these counts, from $9.6 \%$ in the Middle Jurassic to $25.7 \%$ in the Late Jurassic. As with the taxonomic data, ceratosaurs appear in approximately equal proportion in the Middle and Late Jurassic, with $15.4 \%$ and $17.8 \%$, respectively.

Both the taxonomic data as well as the available fossil record thus seem to support a change from megalosauroid-dominated Middle Jurassic theropod faunas to allosauroid-dominated Late Jurassic theropod faunas, with a notable radiation of coelurosaurs during that time. However, some limitations of these analyses are worth mentioning. First of all, both numbers of taxa as well as localities are rather low for the separate stages of the Middle and Upper Jurassic, which, taken together with the uncertain stratigraphic assignment of many localities and taxa on the stage level make a more detailed perspective of the faunal changes impossible at the moment.

More importantly, even the rather rough categories of Middle and Late Jurassic theropod faunas show some notable biases. One is the dominance of a single geological unit, the Morrison Formation, in the locality data for the Late Jurassic. Indeed, this unit accounts for 95 (62.5\%) of the 152 localities with identifiable theropod remains for the Late Jurassic. It is well-known that the genus Allosaurus is notably dominant in theropod faunas of this unit (see Foster, 2003, 2007). The overabundance of this genus is certainly further increased by a positive feedback loop in the identification of theropod remains from the Morrison Formation: As the presence of Allosaurus is expected in Morrison localities, isolated remains of larger theropods (e.g., teeth) are often tentatively identified as Allosaurus, and appear as such in the faunal lists, even though they might indeed not be diagnostic. Although we have tried to exclude localities for which we had information that the identification of taxa was based on such questionable remains, the Morrison Formation accounts for a large percentage of local- 
TABLE 3. Theropod taxa from the Middle and Late Jurassic that are regarded as valid. Abbreviations: Allos, Allosauroidea; Cerat, Ceratosauria; Coel, Coelurosauria; Incert, Incertae sedis; Megal, Megalosauroidea.

\begin{tabular}{|c|c|c|c|c|}
\hline Name & Clade & Unit & Country & Age \\
\hline Condorraptor currumili & Megal. & Cañadón Asfalto Fm. & Argentina & Aalenian-Bajocian \\
\hline Piatnitzkysaurus floresi & Megal. & Cañadón Asfalto Fm. & Argentina & Aalenian-Bajocian \\
\hline Eoabelisaurus mefi & Cerat. & Cañadón Asfalto Fm. & Argentina & Aalenian-Bajocian \\
\hline Shidaisaurus jinae & Allos. & Upper Lufeng Fm. & China & Aalenian-Bajocian \\
\hline Duriavenator hesperis & Megal. & Inferior Oolite Fm. & UK & Bajocian \\
\hline Magnosaurus nethercombensis & Megal. & Inferior Oolite Fm. & UK & Bajocian \\
\hline Yangchuanosaurus zigongensis & Allos. & Xiashaximiao Fm. & China & Bajocian \\
\hline Gasosaurus constructus & Incert. & Xiashaximiao Fm. & China & Bajocian \\
\hline Xuanhanosaurus qilixiaensis & Megal. & Xiashaximiao Fm. & China & Bajocian \\
\hline Chuandongocoelurus primitivus & Incert. & Xiashaximiao Fm. & China & Bajocian \\
\hline Dubreuillosaurus valesdunensis & Megal. & Calcaires de Caen & France & Bathonian \\
\hline Poekilopleuron bucklandii & Megal. & Calcaires de Caen & France & Bathonian \\
\hline Cruxicheiros newmanorum & Incert. & Chipping Norton Limestone & UK & Bathonian \\
\hline Megalosaurus bucklandii & Megal. & Great Oolite & UK & Bathonian \\
\hline Proceratosaurus bradleyi & Coel. & Great Oolite & UK & Bathonian \\
\hline Kileskus aristocraticus & Coel. & Itat Fm. & Russia & Bathonian \\
\hline $\begin{array}{l}\text { Yangchuanosaurus } \\
\text { shangyouensis }\end{array}$ & Allos. & Shangshaximiao Fm. & China & Bathonian-Callovian \\
\hline Sinraptor hepingensis & Allos. & Shangshaximiao Fm. & China & Bathonian-Callovian \\
\hline Afrovenator abakensis & Megal. & Tiouraren Fm. & Niger & ?Bathonian-?Oxfordian \\
\hline MNN Tig6 (,Spinostropheus') & Cerat. & Tiouraren Fm. & Niger & ?Bathonian-?Oxfordian \\
\hline Piveteausaurus divesensis & Megal. & Marnes de Dives & France & Callovian \\
\hline Eustreptospondylus oxoniensis & Megal. & Oxford Clay & UK & Callovian \\
\hline Monolophosaurus jiangl & Megal. & Shishugou Fm. & China & Callovian \\
\hline Wiehenvenator albati & Megal. & Ornatenton & Germany & Callovian \\
\hline Streptospondylus altdorfensis & Megal. & Marnes à Deltoideum delta & France & Callovian-Oxfordian \\
\hline Aurornis xui & Coel. & Tiaojishan Fm. & China & Oxfordian \\
\hline Eosinopteryx brevipenna & Coel. & Tiaojishan Fm. & China & Oxfordian \\
\hline Anchiornis huxleyi & Coel. & Tiaojishan Fm. & China & Oxfordian \\
\hline Epidexipteryx hui & Coel. & Tiaojishan Fm. & China & Oxfordian \\
\hline $\begin{array}{l}\text { Epidendrosaurus } \\
\text { ningchengensis }\end{array}$ & Coel. & Tiaojishan Fm. & China & Oxfordian \\
\hline Pedopenna daohugouensis & Coel. & Tiaojishan Fm. & China & Oxfordian \\
\hline Yiqi & Coel. & Tiaojishan Fm. & China & Oxfordian \\
\hline Metriacanthosaurus parkeri & Allos. & Oxford Clay & UK & Oxfordian \\
\hline Sinraptor dongi & Allos. & Shishugou Fm. & China & Oxfordian \\
\hline
\end{tabular}

ities with allosauroid remains in the Late Jurassic (Figure 29). If one assumes that this might reflect a particularity of this unit, rather than a global trend and thus excludes the Morrison Formation from the data for the Late Jurassic, 57 localities with identifiable theropod specimens remain. The dominance of allosauroids in these localities is much less obvious; this clade is found in $26.3 \%$ of this reduced dataset, whereas megalosauroids are present in
$19.3 \%$. Dominant in the reduced dataset are coelurosaurs, which are found in $40.4 \%$ of the localities, and ceratosaurs are more abundant than in the entire dataset, with occurrences in $26.3 \%$ of the localities.

Potentially related to the Morrison Formation bias is a possible biogeographic bias in the data. The geographic distribution of Middle and Late Jurassic localities is notably different (Figure 30.1, 
TABLE 3 (continued).

\begin{tabular}{|c|c|c|c|c|}
\hline Name & Clade & Unit & Country & Age \\
\hline Guanlong wucaii & Coel. & Shishugou Fm. & China & Oxfordian \\
\hline Limusaurus inextricabilis & Cerat. & Shishugou Fm. & China & Oxfordian \\
\hline Zuolong salleei & Coel. & Shishugou Fm. & China & Oxfordian \\
\hline Haplocheirus sollers & Coel. & Shishugou Fm. & China & Oxfordian \\
\hline Allosaurus europaeus & Allos. & Lourinhã Fm. & Portugal & Kimmeridgian \\
\hline Aviatyrannis jurassica & Coel. & Alcobaça Fm. & Portugal & Kimmeridgian \\
\hline Juravenator starki & Coel. & Painten Fm. & Germany & Kimmeridgian \\
\hline Sciurumimus albersdoerferi & Megal. & Painten Fm. & Germany & Kimmeridgian \\
\hline Elaphrosaurus bambergi & Cerat. & Tendaguru Fm. & Tanzania & Kimmeridgian \\
\hline Veterupristisaurus milneri & Allos. & Tendaguru Fm. & Tanzania & Kimmeridgian \\
\hline Lourinhanosaurus antunesi & Coel. & Lourinhã Fm. & Portugal & Kimmeridgian-Tithonian \\
\hline Torvosaurus gurneyi & Megal. & Lourinhã Fm. & Portugal & Kimmeridgian-Tithonian \\
\hline Allosaurus fragilis & Allos. & Morrison Fm. & USA & Kimmeridgian-Tithonian \\
\hline Allosaurus ,jimmadseni` & Allos. & Morrison Fm. & USA & Kimmeridgian-Tithonian \\
\hline Ceratosaurus nasicornis & Cerat. & Morrison Fm. & USA & Kimmeridgian-Tithonian \\
\hline Torvosaurus tanneri & Megal. & Morrison Fm. & USA & Kimmeridgian-Tithonian \\
\hline Ornitholestes hermanni & Coel. & Morrison Fm. & USA & Kimmeridgian-Tithonian \\
\hline Coelurus fragilis & Coel. & Morrison Fm. & USA & Kimmeridgian-Tithonian \\
\hline Marshosaurus bicentesimus & Megal. & Morrison Fm. & USA & Kimmeridgian-Tithonian \\
\hline Stokesosaurus clevelandi & Coel. & Morrison Fm. & USA & Kimmeridgian-Tithonian \\
\hline Tanycolagreus topwilsoni & Coel. & Morrison Fm. & USA & Kimmeridgian-Tithonian \\
\hline Saurophaganax maximus & Allos. & Morrison Fm. & USA & Kimmeridgian-Tithonian \\
\hline Compsognathus longipes & Coel. & Painten or Solnhofen Fm. & Germany & Kimmeridgian-Tithonian \\
\hline Compsognathus corallestris & Coel. & Calcaires blancs de Provence Fm. & France & Tithonian \\
\hline Juratyrant langhami & Coel. & Kimmeridge Clay & UK & Tithonian \\
\hline Archaeopteryx lithographica & Coel. & Solnhofen Fm. & Germany & Tithonian \\
\hline Archaeopteryx siemensii & Coel. & Solnhofen Fm. & Germany & Tithonian \\
\hline Archaeopteryx recurva & Coel. & Solnhofen Fm. & Germany & Tithonian \\
\hline Chilesaurus diegosuarezi & Incert. & Toqui Fm. & Chile & Tithonian \\
\hline
\end{tabular}

30.2), with the most striking difference being the complete absence of Middle Jurassic theropodbearing localities from North America (the continent with the highest number of Late Jurassic localities). Thus, in the Middle Jurassic, most theropod localities with identifiable remains are found in Europe (59.6\%), followed by Asia (21.2\%). In the Late Jurassic, North America accounts for the majority of such localities $(62.5 \%)$, followed by Europe $(21.7 \%)$ and Asia (8.6\%). As Europe is the best-represented continent for both epochs, we also looked at faunal changes only in this continent. In the Middle Jurassic, megalosauroids appear in the vast majority, 30 out of $31(96.8 \%)$ of the localities, and allosauroids are unknown. In the
Late Jurassic, allosauroids are present in 6 $(18.2 \%)$ of the 33 localities with identifiable remains, but megalosauroids are still better represented, with $10(30.3 \%)$ occurrences. The greatest increase is shown by coelurosaurs, which are present in $3(9.7 \%)$ Middle Jurassic, but $16(48.5 \%)$ of the Late Jurassic localities. Thus, there is little evidence for a drastic faunal turnover in large theropods from megalosauroids to allosauroids in Europe. It should be mentioned, however, that Europe was an archipelago of many islands of different sizes during the Jurassic (e.g., Smith et al., 1994), and can thus not be regarded as a homogenous biogeographic province. However, further evidence for geographic differences might come from 


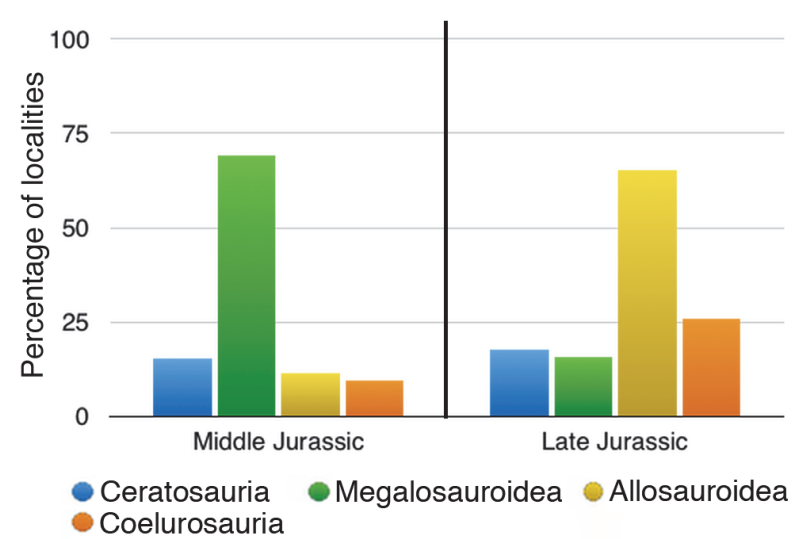

FIGURE 28. Composition of Middle and Late Jurassic theropod faunas, as percentage of localities in which certain clades have been recorded.

Asia, where allosauroids are far better represented in the Middle Jurassic than in other areas. Thus, in eastern Asia, this clade is found in six (54\%) out of 11 localities, whereas megalosauroids are only reported from three $(27 \%)$ sites. Thus, it cannot be ruled out that the apparent change from megalosauroid to allosauroid faunas is due to different geographic regions being sampled for the Middle and Late Jurassic, respectively. As the total numbers are certainly too low to be of statistical significance for many regions, more data is needed.

This leads to another, again potentially related bias in the data, the possible environmental preferences of different theropods. Testing for environmental preferences in the rough categories of inland terrestrial and nearshore environments for all four clades, a strong signal for different preferences of megalosauroids and allosauroids were found: whereas megalosauroids seem to have pre-

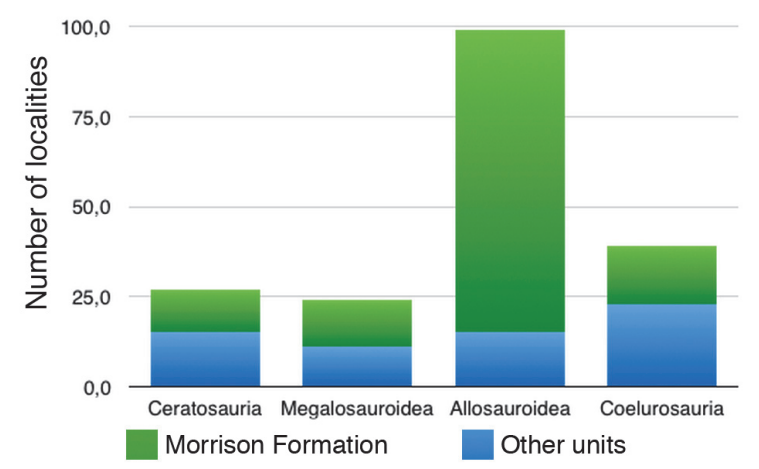

FIGURE 29. Number of Late Jurassic localities in which theropods have been recorded. The green portion of the column indicates how many of these occurrences are accounted for by the Morrison Formation.
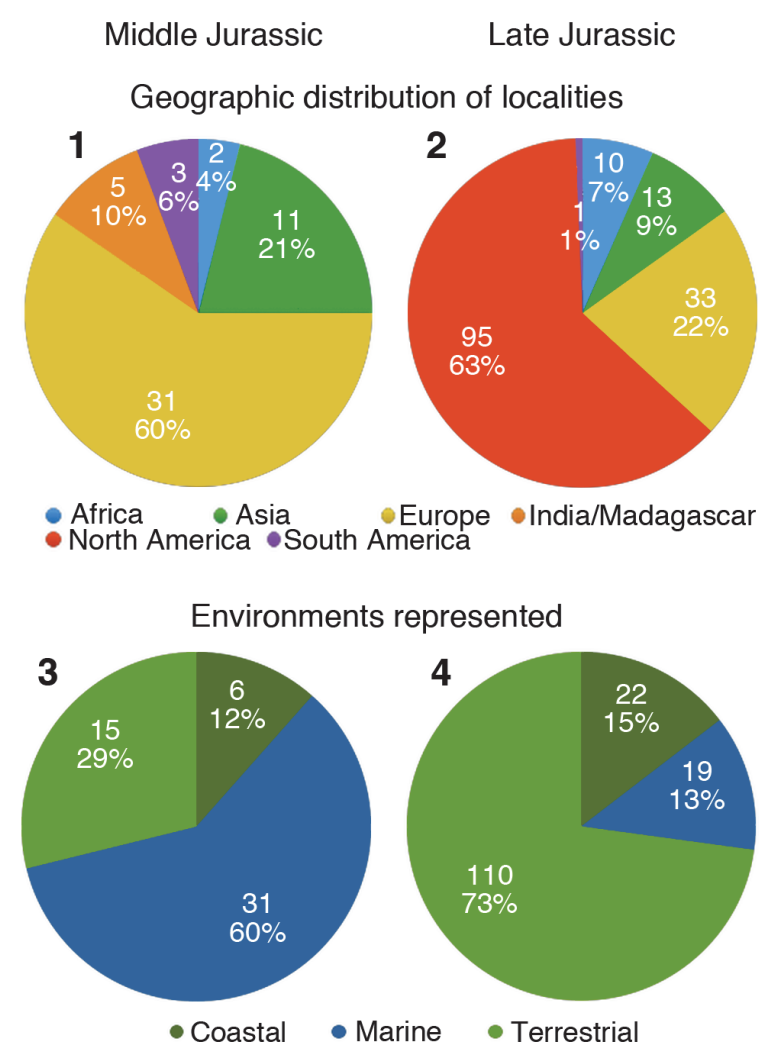

FIGURE 30. Possible biases that influence interpretations of the Jurassic theropod fossil record. Geographic distribution of Middle (1) and Late Jurassic (2) localities with identifiable theropod remains, and environments represented by Middle (3) and Late Jurassic (4) theropod localities.

ferred nearshore environments, allosauroids are rather found in inland terrestrial sites, with both results showing statistical significance at $p=0.005$. As marine and coastal environments (= nearshore environments in our analysis; see methods) dominate the sample for the Middle Jurassic (accounting for $59.6 \%$ and $11.5 \%$, respectively, of the sampled localities), but inland terrestrial environments represent the majority $(72.8 \%)$ of Late Jurassic localities (Figure 30.3, 30.4), these differences in environmental preferences might also explain the apparent differences in theropod faunal composition. Ceratosaurs and coelurosaurs did not show any significant deviation from the expected values for the different environments.

Despite the highly significant $p$-values, caution in interpreting these results is advisable. First, it cannot be excluded that these seemingly significant associations with certain environments are also correlated with other aspects, such as the geographic bias noted above. For example, the high abundance of megalosauroids in the Middle 
Jurassic of Europe, which accounts for 30 of the 36 megalosauroid occurrences for this epoch, all of which in marine deposits, might simply reflect a regional pattern due to island speciation in the European archipelago. Likewise, as noted above, the Late Jurassic data is dominated by the Morrison Formation, which also accounts for the highest amount of allosauroid occurrences recorded, the vast majority of which pertain to a single genus, Allosaurus. Thus, a possible regional pattern created by a single taxon might here also have a notable influence on the results of the analysis. Likewise, the environmental categories used might not be too meaningful, as both inland and nearshore regions might have housed a number of different habitats, and other aspects, such as latitude or regional climatic regime, might also have played important roles (e.g., Noto and Grossman, 2010; Mannion et al., 2012).

Apart from this, artifacts of fossil identification might also have some influence on these results. As noted above, numbers of occurrences of Allosaurus (and, potentially, allosauroids in general) might be inflated by the tendency to identify fragmentary remains as taxa known from a given geological unit, and the same might be true for isolated theropod remains from the marine Middle Jurassic of Europe, which, by default, might be identified as megalosaurid, as mainly megalosaurids are recorded by more complete material. Finally, with diverse clades, such as megalosauroids and allosauroids, evolving over $30 \mathrm{Myr}$ and radiating into several major subclades (piatnitzkysaurids, spinosaurids, megalosaurids, metriacanthosaurids, allosaurids, carcharodontosaurs) during that time, it is questionable if there were no changes in environmental preferences within any of these clades. Indeed, within megalosauroids, piatnitzkysaurids, for example, are so far only recorded from inland environments, with the genera Piatnitzkysaurus and Condorraptor from the Cañadón Asfalto Formation, Xuanhanosaurus from the Shaximiao Formation, and Marshosaurus from the Morrison Formation. In contrast, the oldest carcharodontosaurians, Veterupristisaurus and isolated carcharodontosaurian elements from the Tendaguru Formation (Rauhut, 2011; Carrano et al., 2012), come from nearshore, tidal environments (Bussert et al., 2009).

\section{CONCLUSIONS}

A partial skeleton of a new megalosaurid theropod, Wiehenvenator albati, from the Callovian marine Ornatenton of northern Germany adds to the diverse association of megalosaurid theropods from the Middle Jurassic of Europe. The new taxon is a derived megalosaurine megalosaurid closely related to Torvosaurus, which might be the only megalosaurid taxon to survive into the Late Jurassic. The available evidence supports a rapid radiation of averostran theropods within probably less than $15 \mathrm{Myr}$ during the latest Early and early Middle Jurassic, during which at least nine important lineages were established: Ceratosauridae, Noasauridae, Abelisauridae, Piatnitzkysauridae, Megalosauridae, Spinosauridae, Metriacanthosauridae, Allosauria, and Coelurosauria. Theropod faunal composition seems to show marked changes during the Jurassic with mainly megalosauroid taxa being reported from the Middle Jurassic, whereas allosauroids and, especially, coelurosaurs gained increasing importance in the Late Jurassic. Ceratosaurs seem to have been rare components of both Middle and Late Jurassic theropod faunas, although this might partially reflect geographic patterns, as some clades might have radiated first in southern Gondwana, a region that is poorly represented in the fossil record in post-Bajocian localities. Both geographical distribution and environments sampled during different times of the Jurassic might have an important impact on our views of theropod faunal composition at different times.

\section{NOTE ADDED IN PROOF}

In our Table 3, the latest Middle to earliest Late Jurassic basal coelurosaur Aorun zhaoi was overlooked (Choiniere et al. 2014). This taxon adds to the increasing coelurosaur diversity towards the Middle / Late Jurassic boundary and thus underlines the important radiation this group experienced at that time.

\section{ACKNOWLEDGEMENTS}

We especially like to thank F. Albat, who found the type specimen and brought it to the attention of the LWL Museum für Naturkunde. We also thank M. Böckmann, M. Ludorf, and M. Schlösser for excavating the specimens and for their excellent preparation of the material. We furthermore thank R. Benson, A. López-Arbarello, C. Foth, and Adam Yates for discussions. Many colleagues have granted access to material under their care for comparison; for this we thank R. Allain, B. Britt, M. Carrano, S. Chapman, E. Howlett, M. Lamanna, Li K., M. Richter, P. Sereno, C. Sullivan, and Xu X. G. Schreiber is thanked for his skilled work in produc- 
ing the thin sections of the fibula of Wiehenvenator and $\mathrm{C}$. Steinweg for taking the photo of the complete thin sections. The paper greatly benefited from critical reviews by Christophe Hendrickx and an anonymous reviewer. This paper is a contribution to VW Foundation project I/84 640 and was supported by project RA 1012/18-1 (both to OWMR) and the Landschaftsverband WestfalenLippe (LWL).

\section{REFERENCES}

Aberhan, M. and Baumiller, T.K. 2003. Selective extinction among Early Jurassic bivalves: A consequence of anoxia. Geology, 31:1077-1080.

Allain, R. 2001. Redescription de Streptospondylus altdorfensis, le dinosaure théropode de Cuvier, du Jurassique de Normandie. Geodiversitas, 23:349367. (In French)

Allain, R. 2002. Discovery of megalosaur (Dinosauria, Theropoda) in the Middle Bathonian of Normandy (France) and its implications for the phylogeny of basal Tetanurae. Journal of Vertebrate Paleontology, 22:548-563.

Allain, R. 2005. The postcranial anatomy of the megalosaur Dubreuillosaurus valesdunensis (Dinosauria Theropoda) from the Middle Jurassic of Normandy, France. Journal of Vertebrate Paleontology, 25:850858.

Allain, R. and Chure, D.J. 2002. Poekilopleuron bucklandii, the theropod dinosaur from the Middle Jurassic (Bathonian) of Normandy. Palaeontology, 45:11071121.

Allain, R. and Läng, É. 2009. Origine et évolution des saurischiens. Comptes Rendus Palevol, 8:243-256. (In French)

Allain, R., Tykoski, E., Aquesbi, N., Jalil, N.-E., Monbaron, M., Russell, D., and Taquet, P. 2007. An abelisauroid (Dinosauria: Theropoda) from the Early Jurassic of the High Atlas mountains, Morocco, and the radiation of ceratosaurs. Journal of Vertebrate Paleontology, 27:610-624.

Allain, R., Xaisanavong, T., Richir, P., and Khentavong, B. 2012. The first definitive Asian spinosaurid (Dinosauria: Theropoda) from the early Cretaceous of Laos. Naturwissenschaften. 99(5):369-377.

Averianov, A.O., Krasnolutskii, S.A., and Ivantsov, S.V. 2010. A new basal coelurosaur (Dinosauria: Theropoda) from the Middle Jurassic of Siberia. Proceedings of the Zoological Institute, 314:42-57.

Benson, R.B.J. 2008. A redescription of ,Megalosaurus' hesperis (Dinosauria, Theropoda) from the Inferior Oolite (Bajocian, Middle Jurassic) of Dorset, United Kingdom. Zootaxa, 1931:57-67.

Benson, R.B.J. 2009. An assessment of variability in dinosaur remains from the Bathonian (Middle Jurassic) of Stonesfield and New Park Quarry, UK and taxonomic implications for Megalosaurus bucklandii and Iliosuchus incognitus. Palaeontology, 54:857-877.
Benson, R.B.J. 2010a. A description of Megalosaurus bucklandii (Dinosauria: Theropoda) from the Bathonian of the United Kingdom and the relationships of Middle Jurassic theropods. Zoological Journal of the Linnean Society, 158:882-935.

Benson, R.B.J. 2010b. The osteology of Magnosaurus nethercombensis (Dinosauria, Theropoda) from the Bajocian (Middle Jurassic) of the United Kingdom and a reexamination of the oldest records of tetanurans. Journal of Systematic Palaeontology, 8:131146.

Benson, R.B.J., Barrett, P.M., Powell, H.P., and Norman, D.B. 2008. The taxonomic status of Megalosaurus bucklandii (Dinosauria, Theropoda) from the Middle Jurassic of Oxfordshire, UK. Palaeontology, 51:419424.

Benson, R.B.J. and Radley, J.D. 2010. A new large-bodied theropod dinosaur from the Middle Jurassic of Warwickshire, United Kingdom. Acta Palaeontologica Polonica, 55:35-42.

Benton, M.J. 1983. Dinosaur success in the Triassic: a noncompetitive ecological model. The Quarterly Review of Biology, 58:29-55.

Benton, M.J. 1990. Origin and interrelationships of dinosaurs, pp. 11-30. In Weishampel, D.B., Dodson, P., and Osmólska, H. (eds.), The Dinosauria. University of California Press, Berkeley.

Benton, M.J. 2004. Origin and relationships of Dinosauria, pp. 7-24, In Weishampel, D.B., Dodson, P., Osmólska, H. (eds.), The Dinosauria, 2nd edition. University of California Press, Berkeley.

Benton, M.J., Forth, J., and Langer, M.C. 2014. Models for the rise of the dinosaurs. Current Biology, 24(2):R87-R95.

Bonaparte, J.F. 1979. Dinosaurs: a Jurassic assemblage from Patagonia. Science, 205:1377-1378.

Bonaparte, J.F. 1986. Les dinosaures (Carnosaures, Allosauridés, Sauropodes, Cétiosauridés) du Jurassique Moyen de Cerro Cóndor (Chubut, Argentina). Annales de Paléontologie (Vert.-Invert.), 72:247-289. (In French)

Bonaparte, J.F, Novas, F.E., and Coria, R.A. 1990. Carnotaurus sastrei Bonaparte, the horned, lightly built carnosaur from the Middle Cretaceous of Patagonia. Contributions in Science, 416:1-42.

Britt, B.B. 1991. Theropods of Dry Mesa Quarry (Morrison Formation, Late Jurassic), Colorado, with emphasis on the osteology of Torvosaurus tanneri. BYU Geology Studies, 37:1-72.

Brochu, C.A. 2002. Osteology of Tyrannosaurus rex: insights from a nearly complete skeleton and highresolution computed tomographic analysis of the skull. Society of Vertebrate Paleontology, Memoir, 7:1-138.

Brusatte, S.L., Benson, R.B.J., Zhao, X.-J., and Currie, P.J. 2010a. The skull of Monolophosaurus jiangi (Dinosauria: Theropoda) and its implications for early theropod phylogeny and evolution. Zoological Journal of the Linnean Society, 158:573-607. 
Brusatte, S.L. and Carr, T.D. 2016. The phylogeny and evolutionary history of tyrannosauroid dinosaurs. Scientific Reports, 6:20252.

Brusatte, S.L., Carr, T.D., and Norell, M.A. 2012. The osteology of Alioramus, a gracile and long-snouted tyrannosaurid (Dinosauria: Theropoda) from the Late Cretaceous of Mongolia. Bulletin of the American Museum of Natural History, 366:1-197.

Brusatte, S.L., Lloyd, G.T., Wang, S.C., and Norell, M.A. 2014. Gradual assembly of avian body plan culminated in rapid rates of evolution across the dinosaurbird transition. Current Biology, 24:2386-2392.

Brusatte, S.L., Nesbitt, S.J., Irmis, R.B., Butler, R.J., Benton, M.J., and Norell, M.A. 2010b. The origin and early radiation of dinosaurs. Earth Science Reviews, 101:68-100.

Buckland, W. 1824. Notice on the Megalosaurus or great fossil lizard of Stonesfield. Transactions of the Geological Society of London, Series 2, 1:390-396.

Buffetaut, E. 2007. The spinosaurid dinosaur Baryonyx (Saurischia, Theropoda) in the Early Cretaceous of Portugal. Geological Magazine, 144:1021-1025.

Buffetaut, E. 2008. Spinosaurid teeth from the Late Jurassic of Tendaguru, Tanzania, with remarks on the evolutionary and biogeographical history of the Spinosauridae. Documents des Laboratoires de Géologie de Lyon, 164:26-28.

Buffetaut, E. 2011. An early spinosaurid dinosaur from the Late Jurassic of Tendaguru (Tanzania) and the evolution of the spinosaurid dentition. Oryctos, 10:18.

Bussert, R., Heinrich, W.-D., and Aberhan, M. 2009. The Tendaguru Formation (Late Jurassic to Early Cretaceous, southern Tanzania): definition, palaeoenvironments, and sequence stratigraphy. Fossil Record, 12:141-174

Butler, R.J. and Barrett, P.M. 2008. Paleoenvironmental controls on the distribution of Cretaceous herbivorous dinosaurs. Naturwissenschaften, 95:1027-1032.

Bybee, P.J, Lee, A.H., and Lamm, E.-T. 2006. Sizing the Jurassic theropod dinosaur Allosaurus: assessing growth strategy and evolution of ontogenetic scaling of limbs. Journal of Morphology, 267 (3):347-359.

Carrano, M.T., Benson, R.B.J., and Sampson, S.D. 2012. The phylogeny of Tetanurae (Dinosauria: Theropoda). Journal of Systematic Palaeontology, 10:211-300.

Caruthers, A.H., Smith, P.L., and Gröcke, D.R. 2014. The Pliensbachian-Toarcian (Early Jurassic) extinction: A North American perspective. The Geological Society of America, Special Paper, 505:225-243.

Charig, A.J. and Milner, A.C. 1986. Baryonyx, a remarkable new theropod dinosaur. Nature, 324:359-361.

Charig, A.J. and Milner, A.C. 1997. Baryonyx walkeri, a fish-eating dinosaur from the Wealden of Surrey. Bulletin of the Natural History Museum, Geology Series, 53:11-70.

Choiniere, J.N., Clark, J.M., Forster, C.A., Norell, M.A., Eberth, D.A., Erickson, G.M., Chu, H., and Xu, X.
2014. A juvenile specimen of a new coelurosaur (Dinosauria: Theropoda) from the Middle-Late Jurassic Shishugou Formation of Xinjiang, People's Republic of China. Journal of Systematic Palaeontology, 12:177-215.

Chure, D.J. 2000. Observations on the morphology and pathology of the gastral basket of Allosaurus, based on a new specimen from Dinosaur National Monument. Oryctos, 3:29-37.

Claramunt, S. and Cracraft, J. 2015. A new time tree reveals Earth history's imprint on the evolution of modern birds. Science Advances, 1:e1501005.

Coria, R.A. and Currie, P.J. 2006. A new carcharodontosaurid (Dinosauria, Theropoda) from the Upper Cretaceous of Argentina. Geodiversitas, 28:71-118.

Cullen, T.M., Evans, D.C., Ryan, M.J., Currie, P.J., and Kobayashi, Y. 2014. Osteohistological variation in growth marks and osteocyte lacunar density in a theropod dinosaur (Coelurosauria: Ornithomimidae). BMC Evolutionary Biology, 14:231-244.

Cúneo, R., Ramezani, J., Scasso, R.A., Pol, D., Escapa, I.H., Zavattieri, A.M., and Bowring, S.A. 2013. Highprecision $\mathrm{U}-\mathrm{Pb}$ geochronology and a new chronostratigraphy for the Cañadón Asfalto Basin, Chubut, central Patagonia: implications for terrestrial faunal and floral evolution in Jurassic. Gondwana Research, 24:1267-1275.

Currie, P.J. and Carpenter, K. 2000. A new specimen of Acrocanthosaurus atokensis (Theropoda, Dinosauria) from the Lower Cretaceous Antlers Formation (Lower Cretaceous, Aptian) of Oklahoma, USA. Geodiversitas, 22:207-246.

Currie, P.J. and Zhao, X.-J. 1993. A new carnosaur (Dinosauria, Theropoda) from the Jurassic of Xinjiang, People's Republic of China. Canadian Journal of Earth Sciences, 30:2037-2081.

D'Emic, M.D., Melstrom, K.M., and Eddy, D.R. 2012. Paleobiology and geographic range of the large-bodied Cretaceous theropod dinosaur Acrocanthosaurus atokensis. Palaeogeography, Palaeoclimatology, Palaeoecology, 333-334:13-23.

Day, J.J. and Barrett, P.M. 2004. Material referred to Megalosaurus (Dinosauria: Theropoda) from the Middle Jurassic of Stonesfield, Oxfordshire, England: one taxon or two? Proceedings of the Geologists' Association, 115:359-366.

de Lapparent, A.F. 1960. Les dinosauriens du "Continental Intercalaire" du Sahara central. Mémoires de la Societé Géologique de France, nouvelle série, 88A:1-57. (In French)

del Corro, G. 1974. Un nuevo Megalosaurio (Carnosaurio) del Crétacico de Chubut (Argentina). Communicaciones del Museo Argentino de Ciencias Naturales "Bernardino Rivadavia" e Institutio Nacional de Investigacion de las Ciencias Naturales: Paleontología, 1:37-44. (In Spanish)

Dera, G., Neige, P., Dommergues, J.-L., Fara, E., Laffont, R., and Pellenard, P. 2010. High-resolution dynamics of Early Jurassic marine extinctions: The case of 
Pliensbachian-Toarcian ammonites (Cephalopoda). Journal of the Geological Society, 167:21-33.

Dong, Z. 1984. A new theropod dinosaur from the Middle Jurassic of Sichuan Basin. Vertebrata PalAsiatica, 22:213-218. (In Chinese)

Eddy, D.R. and Clarke, J.A. 2011. New information on the cranial anatomy of Acrocanthosaurus atokensis and its implications for the phylogeny of Allosauroidea (Dinosauria: Theropoda). PLOS ONE, 6:e17932.

Erickson, G.M., Makovicky, P.J., Currie, P.J., Norell, M.A., Yerby, S.A., and Brochu, C.A. 2004. Gigantism and comparative life-history parameters of tyrannosaurid dinosaurs. Nature, 430:772-775.

Eudes-Deslongchamps, J.A. 1837. Mémoire sur le Poekilopleuron bucklandi, grand saurien fossile, intermédiaire entre les crocodiles et les lézards, découvert dans les carrières de la Maladrerie, près Caen, au mois de juillet 1835. Mémoires de la Société Linnéenne du Normandie, 6:1-114. (In French)

Ezcurra, M.D. 2012. Sistemática, Biogeografía y Patrones Macroevolutivos de los dinosaurios terópodos del Triásico Tardío y Jurásico Temprano. Unpublished Licenciatura thesis, Universidad de Buenos Aires, Buenos Aires, Argentina. (In Spanish)

Fitzinger, L. 1843. Systema Reptilium. Fasciculus Primus. Amblyglossae. Apud Braumüller and Seidel Bibliopolas, Vienna. (In Latin)

Foster, J.R. 2003. Paleoecological analysis of the vertebrate fauna of the Morrison Formation (Upper Jurassic), Rocky Mountain Region, USA. New Mexico Museum of Natural History and Science Bulletin, 23:2-100.

Foster, J.R. 2007. Jurassic West: The Dinosaurs of the Morrison Formation and Their World. Indiana University Press, Bloomington and Indianapolis, USA.

Foth, C., Tischlinger, H., and Rauhut, O.W.M. 2014. New specimen of Archaeopteryx provides insights into the evolution of pennaceous feathers. Nature, 511:79-82.

Galton, P.M. and Jensen, J.A. 1979. A new large theropod dinosaur from the Upper Jurassic of Colorado. BYU Geology Studies, 26:1-12.

Gao, C., Morschhauser, E.M., Varricchio, D.J., Liu, J., and Zhao, B. 2012. A second soundly sleeping dragon: new anatomical details of the Chinese troodontid Mei long with implications for phylogeny and taphonomy. PLoS ONE, 7(9):e45203.

Gao, Y. 1993. A new species of Szechuanosaurus from the Middle Jurassic of Dashanpu, Zigong, Sichuan. Vertebrata PalAsiatica, 31:308-314. (In Chinese)

Gilmore, C.W. 1920. Osteology of the carnivorous Dinosauria in the United States National Museum, with special reference to the genera Antrodemus (Allosaurus) and Ceratosaurus. Bulletin of the United States National Museum, 110:1-154.

Goloboff, P.A., Farris, J.S., and Nixon, K. 2008a. TNT, a free program for phylogenetic analysis. Cladistics, 24:774-786.
Goloboff, P.A., Farris, J.S., and Nixon, K. 2008b. TNT: tree analysis using new technologies. Program and documentation available from the authors and at www.zmuc.dk/public/phylogeny

Hallam, A. 1986. The Pliensbachian and Tithonian extinction events. Nature, 319:765-768.

Hallam, A. 1987. Radiations and extinctions in relation to environmental change in the marine Jurassic of north west Europe. Paleobiology, 13:152-168.

Halliday, T.J.D. and Goswami, A. 2015. Eutherian morphological disparity across the end-Cretaceous mass extinction. Biological Journal of the Linnean Society, Early View. doi: 10.1111/bij.12731

Halliday, T.J.D., Upchurch, P., and Goswami, A. 2015. Resolving the relationships of Paleocene placental mammals. Biological Reviews, Early View. doi: $10.1111 /$ brv. 12242

Hammer, Ø. and Harper, D.A.T. 2006. Paleontological Data Analysis. Blackwell, Oxford.

Harries, P.J. and Little, C.T.S. 1999. The early Toarcian (Early Jurassic) and the Cenomanian-Turonian (Late Cretaceous) mass extinctions: Similarities and contrasts. Palaeogeography, Palaeoclimatology, Palaeoecology, 154:39-66.

Harris, J.D. 1998. A reanalysis of Acrocanthosaurus atokensis, its phylogenetic status, and paleobiogeographic implications, based on a new specimen from Texas. New Mexico Museum of Natural History and Science Bulletin, 13:1-75.

Hendrickx, C. and Mateus, O. 2014a. Torvosaurus gurneyi $\mathrm{n}$. sp., the largest terrestrial predator from Europe, and a proposed terminology of the maxilla anatomy in nonavian theropods. PLOS ONE, 9(3):e88905.

Hendrickx, C. and Mateus, O. 2014b. Abelisauridae (Dinosauria: Theropoda) from the Late Jurassic of Portugal and dentition-based phylogeny as a contribution for the identification of isolated theropod teeth. Zootaxa, 3759:1-74.

Hendrickx, C., Mateus, O., and Araújo, R. 2015a. The dentition of megalosaurid theropods. Acta Palaeontologica Polonica, 60:627-642.

Hendrickx, C., Mateus, O., and Araújo, R. 2015b. A proposed terminology of theropod teeth (Dinosauria, Saurischia). Journal of Vertebrate Paleontology, 35:e982797.

Holtz, T.R., Jr. 2000. A new phylogeny of the carnivorous dinosaurs. GAIA, 15:5-61.

Holtz, T.R., Jr. 2012. Theropods, pp. 347-378. In BrettSurman, M.K., Holtz, T.R.Jr., and Farlow, J.O. (eds.), The Complete Dinosaur [Second Edition]. Indiana University Press, Bloomington.

Holtz, T.R., Jr., Molnar, R.E., and Currie, P.J. 2004. Basal Tetanurae, pp. 71-110. In Weishampel, D.B., Dodson, P., and Osmólska, H. (eds.), The Dinosauria. Second edition. University of California Press, Berkeley. 
Horner, J.R. and Padian, K. 2004. Age and growth dynamics of Tyrannosaurus rex. Proceedings of the Royal Society London B, 271:1875-1880.

Hübner, T.R. 2012. Bone histology in Dysalotosaurus lettowvorbecki (Ornithischia: Iguanodontia) - variation, growth, and implications. PLoS ONE, 7(1):e29958.

Jarvis, E.D., Mirarab, S., Aberer, A.J., Li, B., Houde, P., Li, C., Ho, S.Y.W., Faircloth, B.C., Nabholz, B., Howard, J.T., Suh, A., Weber, C.C., da Fonseca, R.R., Li, J., Zhang, F., Li, H., Zhou, L., Narula, N., Liu, L., Ganapathy, G., Boussau, B., Bayzid, M.S., Zavidovych, V., Subramanian, S., Gabaldón, T., CapellaGutiérrez, S., Huerta-Cepas, J., Rakepalli, B., Munch, K., Schierup, M., Lindow, B., Warren, W.C., Ray, D., Green, R.E., Bruford, M.W.,Zhan, X., Dixon, A., Li, S., Li, N., Huang, Y., Derryberry, E.P., Bertelsen, M.F., Sheldon, F.H., Brumfield, R.T., Mello, C.V., Lovell, P.V., Wirthlin, M., Cruz Schneider, M.P., Prosdocimi, F., Samaniego, J.,A., Vargas Velazquez, A.M., Alfaro-Nuñez, A., Campos, P.F., Petersen, B., Sicheritz-Ponten, T., Pas, A., Bailey, T., Scofield, P., Bunce, M., Lambert, D.M., Zhou, Q., Perelman, P., Driskell, A.C., Shapiro, B., Xiong, Z., Zeng, Y., Liu, S., Li, Z., Liu, B., Wu, K., Xiao, J., Yinqi, X., Zheng, Q., Zhang, Y., Yang, H., Wang, J., Smeds, L., Rheindt, F.E., Braun, M., Fjeldsa, J., Orlando, L., Barker, F.K., Jønsson, K.A., Johnson, W., Koepfli, K.-P., O'Brien, S., Haussler, D., Ryder, O.A., Rahbek, C., Willerslev, E, Graves, G.R., Glenn, T.C., McCormack, J., Burt, D., Ellegren, H., Alström, P., Edwards, S.V., Stamatakis, A., Mindell, D.P., Cracraft, J., Braun, E.L., Warnow, T., Jun, W., Gilbert, M.T.P. and Zhang, G. 2014. Whole-genome analyses resolve early branches in the tree of life of modern birds. Science, 346:1320-1331.

Jenkyns, H.C. 1988. The early Toarcian (Jurassic) event: Stratigraphy, sedimentary and geochemical evidence. American Journal of Science, 288:101-151.

Klassen, H. 1984. Geologie des Osnabrücker Berglandes XVI. Naturwissenschaftliches Museum, Osnabrück. (In German)

Klein, N. and Sander, P.M. 2007. Bone histology and growth of the prosauropod dinosaur Plateosaurus engelhardti (von Meyer, 1837) from the Norian bonebeds of Trossingen (Germany) and Frick (Switzerland). Special Papers in Palaeontology, 77:169206.

Lange, W. 1973. Ammoniten und Ostreen (Biostratigraphie, Ökologie, Zoogeographie) des Calloviums Oxfordium Grenzbereichs im Wiehengebirge. Münstersche Forschungen Geologie und Paläontologie, 27:1-209. (In German)

Langer, M.C., Ezcurra, M.D., Bittencourt, J.S., and Novas, F.E. 2010. The origin and early evolution of dinosaurs. Biological Reviews, 85:55-110.

Langer, M.C., Rincón, A.D., Ramezani, J., Solórzano, A., and Rauhut, O.W.M. 2014. New dinosaur (Theropoda, stem-Averostra) from the earliest Jurassic of the
La Quinta Formation, Venezuelan Andes. Royal Society Open Science, 1:140184.

de Lapparent, A.F. 1960. Les dinosauriens du "Continental Intercalaire" du Sahara central. Mémoires de la Societé Géologique de France, nouvelle série, 88A:1-57. (In French)

Li, F., Peng, G., Yong, Y., Jiang, S., and Huang, D. 2009. A new carnosaur from the Late Jurassic of Qianwei, Sichuan, China. Acta Geologica Sinica, 83:12031210. (In Chinese)

Li, K., Liu, J., Yang, C., and Hu, F. 2011. Dinosaur assemblages from the Middle Jurassic Shaximiao Formation and Chuanjie Formation in the SichuanYunnan Basin, China. Volumina Jurassica, 9:21-42.

Liston, J. 2010. The occurrence of the Middle Jurassic pachycormid fish Leedsichthys. Oryctos 9:1-36.

Liu, Y.-Q., Kuang, H.-W., Jiang, X.-J., Peng, N., Xu, H., and Sun, H.-Y. 2012. Timing of the earliest known feathered dinosaurs and transitional pterosaurs older than the Jehol Biota. Palaeogeography, Palaeoclimatology, Palaeoecology, 323-325:1-12.

Maddison, W.P. and Maddison, D.R. 2015. Mesquite: a modular system for evolutionary analysis. Version 3.04. http://mesquiteproject.org

Madsen, J.H., Jr. 1976a. Allosaurus fragilis: a revised osteology. Utah Geological and Mineral Survey Bulletin, 109:1-163.

Madsen, J.H., Jr. 1976b. A second new theropod dinosaur from the Late Jurassic of east central Utah. Utah Geology, 3:51-60.

Mannion, P.D., Benson, R.J.B., Upchurch, P., Butler, R.J., Carrano, M.T., and Barrett, P.M. 2012. A temperate palaeodiversity peak in Mesozoic dinosaurs and evidence for Late Cretaceous geographical partitioning. Global Ecology and Biogeography, 21:898908.

Mantell, G.A. 1827. Illustrations of the Geology of Sussex: A General View of the Geological Relations of the South-Eastern Part of England, with Figures and Descriptions of the Fossils of Tilgate Forest. Lupton Relfe, London.

Marsh, O.C. 1881. Principal characters of American Jurassic dinosaurs. Part V. American Journal of Science (Series 3), 21:417-423.

Martill, D.M., Vidovic, S.U., Howells, C., and Nudds, J.R. 2016. The oldest Jurassic dinosaur: a basal neotheropod from the Hettangian of Great Britain. PLoS ONE, 11(1):e0145713.

Mateus, O. 1998. Lourinhanosaurus antunesi, a new Upper Jurassic allosauroid (Dinosauria: Theropoda) from Lourinhã, Portugal. Memórias da Academia de Ciências de Lisboa, 37:111-124.

McPhee, B.W., Bonnan, M.F., Yates, A.M., Neveling, J., and Choiniere, J.N. 2015. A new basal sauropod from the pre-Toarcian Jurassic of South Africa: evidence of niche-partitioning at the sauropodomorphsauropod boundary? Scientific Reports, 5:13224.

Michelis, J., Sander, P.M., Metzdorf, R., and Breitkreutz, H. 1996. Die Vertebratenfauna des Calloviums (Mit- 
tlerer Jura) aus dem Steinbruch Störmer (Wallücke, Wiehengebirge). Geologie und Paläontologie in Westfalen, 44:5-66. (In German)

Mönnig, E. 1993. Die Ornatenton-Formation in NW Deutschland. Newsletter in Stratigraphy, 28(2/3):131150. (In German)

Molnar, R.E. 1991. The cranial morphology of Tyrannosaurus rex. Palaeontographica A, 217:137-176.

Molnar, R.E., Kurzanov, S.M., and Dong, Z. 1990. Carnosauria, pp. 169-209. In Weishampel, D.B., Dodson, P., and Osmólska, H. (eds.), The Dinosauria. University of California Press, Berkeley.

Moody, R.T.J. and Sutcliffe, P.J.C. 1991. The Cretaceous deposits of the lullemmeden Basin of Niger, central West Africa. Cretaceous Research, 12:137-157.

Mudroch, A., Richter, U., Joger, U., Kosma, R., Amadou, I., and Maga, A. 2011. Didactyl tracks of paravian theropods (Maniraptora) from the ?Middle Jurassic of Africa. PLoS ONE, 6(2):e14642.

Nesbitt, S.J. and Ezcurra, M.D. 2015. The early fossil record of dinosaurs in North America: A new neotheropod from the base of the Upper Triassic Dockum Group of Texas. Acta Palaeontologica Polonica, 60(3):513-526.

Noto, C.R. and Grossman, A. 2010. Broad-scale patterns of Late Jurassic dinosaur paleoecology. PLoS ONE, 5(9):e12553.

Olsen, P.E., Kent, D.V., Sues, H.-D., Koeberl, C., Huber, H., Montanari, A., Rainforth, E.C., Fowell, S.J., Szajna, M.J., and Hartline, B.W. 2002. Ascent of dinosaurs linked to an iridium anomaly at the TriassicJurassic boundary. Science, 296:1305-1307.

Olsen, P.E., Kent, D.V., and Whiteside, J.H. 2011. Implications of the Newark Supergroup-based astrochronology and geomagnetic polarity time scale (NewarkAPTS) for the tempo and mode of the early diversification of the Dinosauria. Earth and Environmental Science Transactions of the Royal Society of Edinburgh, 101:201-229.

Olsen, P.E., Shubin, N.H., and Anders, M.H. 1987. New Early Jurassic tetrapod assemblages constrain Triassic-Jurassic tetrapod extinction event. Science, 237:1025-1029.

Osborn, H.F. 1912. Crania of Tyrannosaurus and Allosaurus. Memoirs of the American Museum of Natural History, 1:1-30.

Otero, A., Krupandian, E., Pol, D., Chinsamy, A., and Choiniere, J.N. 2015. A new basal sauropodiform from South Africa and the phylogenetic relationships of basal sauropodomorphs. Zoological Journal of the Linnean Society, 174:589-634.

Owen, R. 1842. Report on British fossil reptiles, part II. Reports of the British Association for the Advancement of Science, 11:60-204.

Pálfy, J. and Smith, P.L. 2000. Synchrony between Early Jurassic extinction, oceanic anoxic event, and the Karoo-Ferrar flood basalt volcanism. Geology, 28:747-750.
Peng, G.-Z., Ye, Y., and Gao, Y. 2005. Jurassic Dinosaur Faunas in Zigong. People's Publishing House of Sichuan Province, Chengdu, China. (In Chinese)

Pol, D. and Rauhut, O.W.M. 2012. A Middle Jurassic abelisaurid from Patagonia and the early diversification of theropod dinosaurs. Proceedings of the Royal Society $B, 279: 3170-3175$.

Prondvai, E., Stein, K.H.W., de Ricqlès, A., and Cubo, J. 2014. Development-based revision of bone tissue classification: the importance of semantics for science. Biological Journal of the Linnean Society, 112:799-816.

Raath, M.A. 1977. The anatomy of the Triassic theropod Syntarsus rhodesiensis (Saurischia: Podokesauridae) and a consideration of its Biology. Unpublished PhD Thesis, Rhodes University, Grahamstown.

Rauhut, O.W.M. 2003. The interrelationships and evolution of basal theropod dinosaurs. Special Papers in Palaeontology, 69:1-213.

Rauhut, O.W.M. 2004. Provenance and anatomy of Genyodectes serus, a large-toothed ceratosaur (Dinosauria: Theropoda) from Patagonia. Journal of Vertebrate Paleontology, 24(4):894-902.

Rauhut, O.W.M. 2005. Osteology and relationships of a new theropod dinosaur from the Middle Jurassic of Patagonia. Palaeontology, 48:87-110.

Rauhut, O.W.M. 2011. Theropod dinosaurs from the Late Jurassic of Tendaguru (Tanzania). Special Papers in Palaeontology, 86:195-239.

Rauhut, O.W.M. and Carrano, M.T. 2016. The theropod dinosaur Elaphrosaurus bambergi Janensch, 1920, from the Late Jurassic of Tendaguru, Tanzania. Zoological Journal of the Linnean Society, published online. doi: 10.1111/zoj.12425

Rauhut, O.W.M., Cladera, G., Vickers-Rich, P., und Rich, T.H. 2003. Dinosaur remains from the Lower Cretaceous of the Chubut Group, Argentina. Cretaceous Research, 24(5):487-497.

Rauhut, O.W.M., Foth, C., Tischlinger, H., and Norell, M. A. 2012. Exceptionally preserved juvenile megalosauroid theropod dinosaur with filamentous integument from the Late Jurassic of Germany. Proceedings of the National Academy of Sciences, 109:11746-11751.

Rauhut, O.W.M. and Hungerbühler, A. 2000. A review of European Triassic theropods. GAIA, 15:75-88.

Rauhut, O.W.M. and López-Arbarello, A. 2008. Archosaur evolution during the Jurassic: a southern perspective. Revista de la Asociación Geológica Argentina, 63(4):557-585.

Rauhut, O.W.M. and López-Arbarello, A. 2009. Considerations on the age of the Tiouaren Formation (lullemmeden Basin, Niger, Africa): Implications for Gondwanan Mesozoic terrestrial vertebrate faunas. Palaeogeography, Palaeoclimatology, Palaeoecology, 271:259-267.

Rauhut, O.W.M., Milner, A.C., and Moore-Fay, S. 2010. Cranial osteology and phylogenetic position of the theropod dinosaur Proceratosaurus bradleyi (Wood- 
ward, 1910) from the Middle Jurassic of England. Zoological Journal of the Linnean Society, 158:155195.

Remes, K., Ortega, F., Fierro, I., Joger, U., Kosma, R., Marín Ferrer, J.M., Ide, O.A., and Maga, A. 2009. A new basal sauropod dinosaur from the Middle Jurassic of Niger and the early evolution of Sauropoda. PLoS ONE, 4(9):e6924.

Riegraf, W. 1994. Der Ornatenton in Deutschland und seine Äquivalente, pp. 7-72. In Martill, D.M. and Hudson, J.D. (eds.), Fossilien aus Ornatenton und Oxford Clay. Goldschneck-Verlag, Korb. (In German)

Sadleir, R., Barrett, P.M., and Powell, H.P. 2008. The anatomy and systematics of Eustreptospondylus oxoniensis, a theropod dinosaur from the Middle Jurassic of Oxfordshire, England. Monograph of the Palaeontographical Society, London, 160:1-82.

Sampson, S.D. and Witmer, L.M. 2007. Craniofacial anatomy of Majungasaurus crenatissimus (Theropoda: Abelisauridae) from the Late Cretaceous of Madagascar. Society of Vertebrate Paleontology Memoir, 8:32-102.

Sereno, P.C. 1999. The evolution of dinosaurs. Science, 284:2137-2147.

Sereno, P.C., Beck, A.L., Dutheil, D.B., Gado, B., Larsson, H.C.E., Rauhut, O.W.M., Sadleir, R.W., Sidor, C.A., Varricchio, D.J., Wilson, G.P., and Wilson, J.A. 1998. A long-snouted predatory dinosaur from Africa and the evolution of spinosaurids. Science, 282:1298-1302.

Sereno, P.C., Dutheil, D.B., larochene, M., Larsson, H.C.E., Lyon, G.H., Magwene, P.M., Sidor, C.A., Varricchio, D.J., and Wilson, J.A. 1996. Predatory dinosaurs from the Sahara and Late Cretaceous faunal differentiation. Science, 272:986-991.

Sereno, P.C., Forster, C.A., Larsson, H.C.E., Dutheil, D.B., and Sues, H.-D. 1994. Early Cretaceous dinosaurs from the Sahara. Science, 266:267-271.

Sereno, P.C., Wilson, J.A., and Conrad, J.L. 2004. New dinosaurs link southern landmasses in the mid-Cretaceous. Proceedings of the Royal Society of London, $B, 271: 1325-1330$.

Serrano-Martínez, A., Ortega, F., Sciscio, L., Tent-Manclús, J.E., Bandera, I.F., and Knoll, F. 2015. New theropod remains from the Tiourarén Formation (?Middle Jurassic, Niger) and their bearing on the dental evolution in basal tetanurans. Proceedings of the Geologists' Association, 126:107-118.

Smith, A.G., Smith, D.G., and Funnell, B.M. 1994. Atlas of Mesozoic and Cenozoic coastlines. Cambridge University Press, Cambridge.

Smith, N.D., Makovicky, P.J., Pol, D., Hammer, W.R., and Currie, P.J. 2007. Osteology of Cryolophosaurus ellioti (Dinosauria: Theropoda) from the Early Jurassic of Antarctica and implications for early theropod evolution. Zoological Journal of the Linnean Society, 151:377-421.

Sues, H.-D., Frey, E., Martill, D.M., and Scott, D.M. 2002. Irritator challengeri, a spinosaurid (Dinosauria:
Theropoda) from the Lower Cretaceous of Brazil. Journal of Vertebrate Paleontology, 22:535-547.

Sullivan, C., Wang, Y., Hone, D.W.E., Wang, Y., Xu, X., and Zhang, F. 2014. The vertebrates of the Jurassic Daohugou Biota of northeastern China. Journal of Vertebrate Paleontology, 34(2):243-280.

Taquet, P. and Welles, S.P. 1977. Redescription du crâne de dinosaure théropode de Dives (Normandie). Annales de Paléontologie (Vertébrés), 63:191-206. (In French)

Van Damme, D., Bogan, A.E., and Dierick, M. 2015. A revision of the Mesozoic naiads (Unionoida) of Africa and the biogeographic implications. Earth Science Reviews, 147:141-200.

Varricchio, D.J. 1993. Bone microstructures of the Upper Cretaceous theropod dinosaur Troodon formosus. Journal of Vertebrate Paleontology, 13:99-104.

von Huene, F. 1923. Carnivorous Saurischia in Europe since the Triassic. Bulletin of the Geological Society of America, 34:449-458.

von Huene, F. 1926. The carnivorous Saurischia in the Jura and Cretaceous formations, principally in Europe. Revista del Museo de La Plata, 29:35-167.

von Huene, F. 1932. Die fossile Reptil-Ordnung Saurischia, ihre Entwicklung und Geschichte. Monographien zur Geologie und Palaontologie, Series 1, 4:1361. (In German)

von Meyer, H. 1832. Paläologica zur Geschichte der Erde. Siegmund Schmerber Verlag, Frankfurt am Main. (In German)

Waite, S. 2000. Statistical Ecology in Practice: a Guide to Analysing Environmental and Ecological Field Data. Pearson Education Limited, Harlow, U.K.

Waldman, M. 1974. Megalosaurids from the Bajocian (Middle Jurassic) of Dorset. Palaeontology, 17:325339.

Walker, A.D. 1964. Triassic reptiles from the Elgin area: Ornithosuchus and the origin of carnosaurs. Philosophical Transactions of the Royal Society of London, Series B, 248:53-134.

Weishampel, D.B., Barrett, P.M., Coria, R.A., Le Loeuff, J., Xu, X., Zhao, X.-J., Sahni, A., Gomani, E.M.P., and Noto, C.R. 2004. Dinosaur Distribution, pp. 517606. In Weishampel, D.B., Dodson, P., and Osmólska, H. (eds.), The Dinosauria. Second edition. University of California Press, Berkeley.

Welles, S.P. 1984. Dilophosaurus wetherilli (Dinosauria, Theropoda). Osteology and comparisons. Palaeontographica A, 185:85-180.

Welles, S.P. and Long, R.A. 1974. The tarsus of theropod dinosaurs. Annals of the South African Museum, 64:191-218.

Werning, S. 2012. The ontogenetic osteohistology of Tenontosaurus tilletti. PLoS ONE, 7(3):e33539.

Wignall, P.B. 2005. The link between large igneous province eruptions and mass extinctions. Elements, 1:293-297.

Wignall, P.B., Newton, R.J., and Little, C.T.S. 2005. The timing of paleoenvironmental change and cause-and- 
effect relationships during the Early Jurassic mass extinction in Europe. American Journal of Science, 305:1014-1032.

Witmer, L.M. 1997. The evolution of the antorbital cavity of archosaurs: a study in soft-tissue reconstruction in the fossil record with an analysis of the function of pneumaticity. Society of Vertebrate Paleontology, Memoir, 3:1-73.

Woodward, A.S. 1910. On a skull of Megalosaurus from the Great Oolite of Minchinhampton (Gloucestershire). Quarterly Journal of the Geological Society of London, 66:111-115.

Wu, X.-C., Currie, P.J., Dong, Z., Pan, S., and Wang, T. 2009. A new theropod dinosaur from the Middle Jurassic of Lufeng, Yunnan, China. Acta Geologica Sinica, 83:9-24.

Xing, L.D., Bell, P.R., Rothschild, B.M., Ran, H., Zhang, J.P., Dong, Z.M., Zhang, W., and Currie, P.J. 2013. Tooth loss and alveolar remodeling in Sinosaurus triassicus (Dinosauria: Theropoda) from the Lower Jurassic strata of the Lufeng Basin, China. Chinese Science Bulletin (English version), 58(16):19311935.
Xing, L.D., Paulina Carabajal, A., Currie, P.J., Xu, X., Zhang, J.P., Wang, T., Burns, M.E., and Dong, Z.M. 2014. Braincase anatomy of the basal theropod Sinosaurus from the Early Jurassic of China. Acta Geologica Sinica (English edition), 88(6):1653-1664.

Xu, X., Clark, J.M., Forster, C.A., Norell, M.A., Erickson, G.M., Eberth, D.A., Jia, C., and Zhao, Q. 2006. A basal tyrannosauroid dinosaur from the Late Jurassic of China. Nature, 439:715-718.

Xu, X., Zheng, X.-T., Sullivan, C., Zhang, F.-C., O'Connor, J.K., and Wang, X.-L. 2015. A bizarre Jurassic maniraptoran theropod with preserved evidence of membranous wings. Nature, 521:70-73.

You, H.-L., Azuma, Y., Wang, T., Wang, Y.-M., and Dong, Z.-M. 2014. The first well-preserved coelophysoid theropod dinosaur from Asia. Zootaxa, 3873:233249.

Zanno, L.E., Varricchio, D.J., O'Connor, P.M., Titus, A.L., and Knell, M.J. 2011. A new troodontid theropod, Talos sampsoni gen. et sp. nov., from the Upper Cretaceous Western Interior Basin of North America. PLOS ONE, 6(9):e24487. 


\section{APPENDIX 1.}

List of characters used in the phylogenetic analysis. Characters were mainly taken from Carrano et al. (2012), often with modifications. A complete documentation of the changes in character definition and character codings will be presented elsewhere (Rauhut and Pol, in prep.).

\section{Cranial skeleton}

1. Premaxilla, inter-premaxillary suture in adults: open (0), fused (1).

2. Premaxilla, height/length ratio ventral to external naris (length measured along ventral border of bone): < 0.5 (0), 0.5-0.99 (1), 1-1.49 (2), 1.5 or higher (3)

3. Premaxilla, subnarial process and ventral border of naris: contacts nasals, excluding maxilla from narial margin (0), reduced and separate from nasals by maxillary contribution to narial margin (1).

4. Premaxilla, posterior extent of nasal process relative to posterior tip of subnarial process: considerably more anterior (0); even (1); posterior (2).

5. Premaxilla, form of premaxilla-nasal suture: V-shaped (0), W-shaped (1).

6. Position of anterior end of external nares: over anterior half of ventral margin of premaxillary body (0); over the posterior half of the ventral margin of the premaxillary body (1); posterior to the ventral margin of the premaxillary body (2).

7. Premaxilla, diastema ('subnarial gap') adjacent to maxilla along dentigerous margin: absent (0), present (1).

8. Premaxilla, mediolateral constriction of posterior portion: absent (0), present (1).

9. Premaxilla, development of subnarial (maxillary) process: well-developed, rod or plate-like (0), reduced to a short, stout triangle, as long as or shorter than its basal width (1).

10. Subnarial foramen on the premaxilla-maxilla suture: absent (0), present (1).

11. Premaxilla, articulation with maxilla: planar (0), interlocking (1).

12. Anterior ramus of the maxilla: absent, anterior margin of maxillary body confluent with anterior margin of the ascending process (0); present but very short (length/height ratio less than 1) (1); present moderately long (1-1.35) (2); present, long (1.35-1.7) (3); present, very long (more than 2) (4).

13. Maxilla, orientation of anteriormost alveolus: vertical (0), angled anteriorly (1).

14. Anterodorsal margin of the ascending process of the maxilla: straight or gently curved (0), with pronounced kink at about mid-length, with a more anteriorly facing margin ventral and a more dorsally facing margin dorsal to the kink (1).
15. Maxilla, morphology of palatal process: long, ridged or fluted prong (0), long and plate-shaped (1).

16. Maxilla, position of palatal process: ventral, immediately dorsal to paradental plates $(0)$, dorsal, immediately ventral to dorsal surface of maxillary anterior ramus (1).

17. Maxilla, horizontal ridge (prominent 'lingual bar') between palatal process and antorbital fenestra: absent (0), present (1).

18. Maxilla, depth of paradental plates relative to anteroposterior width: low, < $1.8(0)$; tall > $1.8(1)$.

19. Maxilla, ventral extent of paradental plates relative to lateral wall: as far ventral (0); fall short (1).

20. Maxilla, arrangement of nutrient foramina on lateral surface: single row or no distinct pattern (0); a second, more dorsally placed row is present anteriorly and converges with the ventral row posteriorly (1); a second, dorsally placed row is present and extends posteriorly more or less parallel to the ventral row (2).

21. Maxilla, anteroventral border of antorbital fossa: graded or stepped (0), demarcated by raised ridge (1).

22. Maxilla, anterior margin of antorbital fossa: rounded (0); squared (1).

23. Maxilla, ventral extent of antorbital fossa (as measured from the rim of the antorbital fenestra to the highest point of the ridge marking its border) at the level of about the half length of the antorbital fenestra: small or absent, less than $1 / 3$ the height of the maxillary body at this level (0); moderate, between $1 / 3$ and half the height (1), dorsoventrally deep, more than half the height (2).

24. Maxilla, position of anterior end of antorbital fossa: posterior to or level with posterior rim of external nares (0), ventral to external nares (1).

25. Medial wall of the anterior end of the maxillary antorbital fossa: lacking depressions or foramina (0); with a large depression without sharply defined margins (1); with a sharply rimmed maxillary fenestra (2).

26. Development of maxillary fenestra: opens medially into a small maxillary antrum with a robust medial wall (0); opens medially into a large maxillary antrum that is medially open or only covered by a very thin bony wall (1); opens anteriorly into a large antrum within the ascending process of the maxilla (2) This character is inapplicable in taxa that lack a maxillary fenestra.

27. Promaxillary foramen: absent (0), present and opens anteriorly into pneumatic recesses in the ascending process of the maxilla (1).

28. Size of the promaxillary foramen in relation to the maxillary fenestra: smaller (0); larger (1). This character is inapplicable in taxa that lack a maxillary fenestra. 
29. Maxilla, development of pneumatic fossa (excavatio pneumatica) in ascending process: absent (0), present (1).

30. Maxilla, pneumatic region on medial side of maxilla posteroventral to maxillary fenestra: absent (0); present (1).

31. Maxilla, posterior end of tooth row relative to orbit: beneath (0), anterior (1).

32. Maxilla and nasal, external surface texture: smooth (0), sculptured (1).

33. Nasal, inter-nasal contact in adults: separate (0), partly or fully fused (1).

34. Nasal, posterior narial margin: absent or weak fossa (0), large fossa (1), laterally splayed hood (2).

35. Posteriorly pointed, sharply rimmed depression on the lateral side of the nasal posterodorsal to the external nares: absent (0), present (1).

36. Nasal, participation in antorbital fossa: absent or at edge (0), present (1).

37. Nasal, antorbital fossa in lateral view: visible (0); occluded by ventrolaterally overhanging lamina (1).

38. Nasal, pneumatic foramina: absent (0), present (1).

39. Nasal, development of dorsolateral surfaces: none, nasals low and dorsally convex (0), pronounced dorsolateral rims, sometimes with lateral crests (1), tall, parasagittal crests (2), inflated and forming a hollow midline crest (3).

40. Nasal, sculpturing: low rugosity (0), deeply rugose, bears large excresences (1) [inapplicable in taxa that lack craniofacial rugosity].

41. Antorbital fossa and dorsal rim on the anterior process of the lacrimal: present, but fossa is largely hidden in lateral view by an overhanging lateral lamina and only exposed anteriorly (0); present, widely exposed laterally and confluent with the antorbital fossa of the dorsal part of the ventral process (1); dorsal rim absent, no differentiation between fossa and rim on the lateral surface of anterior process (2).

42. Lacrimal, morphology of lateral lamina of ventral process of lacrimal: forming a continuous sheet of bone between the ventral and anterior processes (0); invaginated dorsally and convex anteriorly, anteriormost point situated dorsal to midheight of ventral process (1); anteriormost point situated around midheight of ventral process (2).

43. Lacrimal, dorsal and ventral portions of antorbital fossa: separated by anterior projection of lateral lamina (0), continuous, lateral lamina does not project far anteriorly (1).

44. Lacrimal fenestra: absent (0); present (1).

45. Lacrimal, openings in lacrimal recess: single (0), multiple (1).

46. Lacrimal horn: absent (0); small dorsal rugosity (1); low, broad, rugose bar (2); large triangular horn (3).
47. Lacrimal, suborbital process: absent (0), present (1).

48. Lacrimal, angle between anterior and ventral rami: $\sim 90^{\circ}(0),<75^{\circ}(1)$.

49. Lacrimal, length of anterior process relative to ventral process: more (0), or less than $80 \%(1)$.

50. Jugal, position of anterior end: posterior to internal antorbital fenestra, but reaching its posterior rim (0), excluded from internal antorbital fenestra (1), expressed at rim of internal antorbital fenestra, with distinct anterior process extending beneath it (2).

51. Jugal, pneumatisation: absent (0), internally hollowed and transversely inflated by foramen in posterior rim of antorbital fossa (1).

52. Jugal, antorbital fossa: absent (0), present (1).

53. Anterior end of jugal: slender and not or only slightly expanded (0); strongly expanded, and expansion forms at least a small part of the anterior margin of the orbit (1).

54. Jugal, orientation of orbital margin: angled posterodorsally (0), vertical (1).

55. Dorsoventral height of the posterior process of jugal: less than $(0)$ or subequal or more than dorsoventral height of suborbital part (1).

56. Postorbital, articulation with jugal: planar (0), grooved, ventral process with U-shaped cross-section (1).

57. Postorbital, suborbital flange: absent (0), present (1).

58. Development of suborbital flange of postorbital: small, triangular eminence (0), dorsoventrally elongate, large rounded flange (1), jugal process curved anteroventrally and suborbital process developed as large, sharply angled, triangular flange (2) This character is not applicable to taxa that do not have a suborbital flange.

59. Postorbital, ventral extent relative to ventral margin of orbit: substantially above (0), approximately same level (1).

60. Medial side of posterior process of the postorbital: straight or concave, dorsal margin forms a sharp rim (0); convex, medial margin curves into dorsal margin (supratemporal fossa extends onto process) (1).

61. Supratemporal fossa on the anterior process of the postorbital: forms a large shelf on the dorsal surface of the process (0); reduced, restricted to the posteriormost part of the anterior process and faces more posterodorsally than dorsally (1).

62. Supraorbital brow: absent, anterior end of postorbital tapers (0); preset as a dorsoventrally expanded, anteriorly rounded, rugose swelling over the posterior part of the orbit (1); large, strongly rugose supraorbital brow (possible formed by a separate palprebal ossification fused to the postorbital) that connects the postorbital with the lacrimal present (2). 
63. Posterior process of the postorbital: Pointed and transversely narrow (0); broadened transversely posteriorly and wider than high (1).

64. Parietal-postorbital contact at the anterior end of the supratemporal fenestra: absent, parietal and postorbital separated by posterior process of frontal that reaches the laterosphenoid (0); present, frontal excluded from laterosphenoid (1).

65. Prefrontal in adult individuals: Exposed on the anterodorsal margin of the orbit (0), reduced, not exposed at the anterior margin of the orbit, might only be visible at the dorsal margin of the orbit (1), partially or completely fused to the lacrimal (2).

66. Prefrontal, articulation with frontal: planar (0), pegand-socket (1).

67. Frontal, exposure along orbital rim: broad (0), narrow or absent (1).

68. Parietal, articulation with supraoccipital: abuts (0), overlaps (1).

69. Parietal, development of median skull table: flat and broad (0), narrow with sagittal crest (1), very broad, widely separating upper temporal fenestrae (2).

70. Parietal, size and elevation of nuchal wedge and alae: moderate (0), tall and expanded (1).

71. Supratemporal fossa, anteromedial corner: open dorsally (0); partially roofed over by a small shelf of the frontalparietal (1).

72. Squamosal, constriction of lower temporal fenestra: absent (0), present (1).

73. Squamosal, anterodorsal lamina: emarginated by upper temporal fenestra (0); continuous (1).

74. Squamosal, flange covering quadrate head laterally: absent (0), present (1).

75. Squamosal, articulation with quadratojugal: at tip (0), absent (1), broad (2).

76. Quadratojugal, anteriormost point of ventral process relative to lower temporal fenestra: ventral (0), anterior (1).

77. Quadrate, pneumatisation: absent (0), present (1).

78. Quadrate, height of dorsal ramus relative to orbit height: less (0), greater (1).

79. Quadrate, axis in posterior view: vertical (0), oblique (1).

80. Quadrate, height of pterygoid flange relative to complete bone: $2 / 3$ (0) subequal (1).

81. Quadrate foramen: present (0), absent (1).

82. Quadrate, axis in lateral view: vertical $(0)$, anterior (1), posterior (2).

83. Quadrate, head shape in dorsal view: oval (0), subrectangular (1).

84. Quadrate, medial foramina adjacent to condyles: absent (0), present (1).

85. Paroccipital process, position of ventral rim of base relative to occipital condyle: at same level (0), below (1).
86. Paroccipital process, position of ventral edge of distal end relative to occipital condyle: at or above dorsal border of condyle, process approximately horizontal or dorsolaterally inclined (0), at or below midheight of condyle, process ventrolaterally oriented (1).

87. Supraoccipital, anteroposterior depth of median ridge relative to occipital condyle length: less (0), greater (1).

88. Supraoccipital, width of knob relative to foramen magnum diameter: equal (0), 1.5x (1).

89. Supraoccipital, participation in foramen magnum: absent, exoccipitals contact dorsally (0), narrow, separating exoccipitals on dorsal edge of foramen (1), wide, supraoccipital extends ventrolaterally around foramen magnum (2).

90. Basioccipital, ventrolateral pair of pneumatic cavities invading neck of occipital condyle and joining medially: absent (0), present (1).

91. Basioccipital, sharp dorsoventrally oriented lamina situated immediately ventral to occipital condyle: absent (0), present (1).

92. Basioccipital, fossa ventral to occipital condyle in basioccipital apron: narrow and groove-like, onehalf or less the width of the occipital condyle (0), broad depression approximately two-thirds the width of occipital condyle (1).

93. Basioccipital, notch along contact with exoccipital/ opisthotic: absent (0), present (1).

94. Basioccipital, width of basal tubera relative to occipital condyle width: $\geq(0),<(1)$.

95. Basisphenoid, location of basipterygoid processes relative to basal tubera: anterior or slightly anteroventral, basisphenoid recess opens ventrally (0), anteroventrally, basisphenoid recess opens posteroventrally (1), almost directly ventral, basisphenoid recess anteroposteriorly narrow and opens more posteriorly than ventrally (2).

96. Basisphenoid, depth of basisphenoid recess: shallow (0), very deep (1).

97. Basisphenoid, shape of opening for basisphenoid recess: ovoid (0), teardrop-shaped (1).

98. Basisphenoid, depth of indentation between basal tubera and basipterygoid processes: deep notch (0), shallow embayment (1).

99. Basisphenoid, proportions of basipterygoid processes: elongate (0), broad (1).

100. Braincase, number of foramina (representing cranial nerves $\mathrm{XII}, \mathrm{XI}$ and $\mathrm{X}$ ) exiting ventrolateral to occipital condyle: two (0); three (1).

101. Braincase, ventral extension of subcondylar recess: pronounced (0); shallow/absent (1); narrow incisure (2).

102. Braincase, shape of ventral margin of paroccipital process and stapedial groove/foramen ovale: open curve (0); acute/closed curve (1). 
103. Braincase, anteroposterior angle of occiput in lateral view: vertical (0), sloping anterodorsally-posteroventrally (1).

104. Braincase, morphology of trigeminal foramen: single (0), partly split (1), fully split (2).

105. Braincase, median ridge separating exits of left and right sixth cranial nerves: present (0), absent (1).

106. Braincase, number of tympanic recesses: two (0), three (1).

107. Braincase, internal carotid pneumatization: absent (0), fossa (1), opening (2).

108. Braincase, ossification of interorbital region: weak or absent (0), extensive, ossified sphenethmoid and interorbital septum (1).

109. Palatine, shape: triradiate $(0)$, tetraradiate, welldeveloped jugal process (1).

110. Palatine, anteroposterior extent of maxillary flange: short (0), extended (1).

111. Palatine, morphology of jugal process: tapered process (0), expanded process (1).

112. Palatine, orientation of maxillary contact: lateral $(0)$, ventral (1).

113. Palatine, pneumatic recess: absent (0), present (1).

114. Pterygoid, pocket on ectopterygoid flange: absent (0), present (1).

115. Ectopterygoid, dorsoventral depth: narrow (0), deep (1).

116. Ectopterygoid, ventral fossa: absent (0), present (1).

117. Ectopterygoid, lateral depth of ectopterygoid fossa: shallow (0), deep (1).

118. Mandible, size of external mandibular fenestra: small to moderate (0), large (1).

119. Mandible, position of anterior end of external mandibular fenestra relative to last dentary tooth: posterior (0), ventral (1).

120. Dentary, shape of anterior end in lateral view: blunt and unexpanded (0), dorsoventrally expanded, rounded, and slightly upturned (1), 'squared off' in lateral view via anteroventral process (2).

121. Dentary, size of mesialmost alveoli: subequal (0), third alveolus circular and enlarged (1).

122. Dentary, shape in dorsal view: straight (0), curves anteromedially (1).

123. Dentary, paradental groove: narrow along entire length (0), wide anteriorly defining a distinct gap between medial dentary wall and paradental plates (1).

124. Dentary, longitudinal groove housing dorsally situated row of neurovascular foramina on lateral surface: absent or weak (0), present and well-defined (1).

125. Dentary, number of Meckelian foramina: one (0), two (1).
126. Dentary, morphology of posterior end: notched by external mandibular fenestra (0), straight or slightly concave (1).

127. Dentary, morphology of surangular articulation just above external mandibular fenestra: small notch (0), large socket (1).

128. Splenial, contour of posterior edge: straight (0), curved (1), notched (2).

129. Splenial, size of splenial ('mylohyoid') foramen: small (0), large (1).

130. Splenial, foramen in ventral part: completely enclosed by bone (0), open anteroventrally (1).

131. Surangular, horizontal ridge on lateral surface below mandibular joint: weak or absent (0), strong (1).

132. Surangular, number of posterior surangular foramina: one (0), two (1).

133. Mandibular glenoid, morphology of medial edge: flat or rounded (0), projecting (1).

134. Mandibular glenoid, development of anterior wall: weak (0), tall (1).

135. Retroarticular process, length: long (0), blunt (1).

136. Retroarticular process, mediolateral width relative to posterior width of dentary: $\leq(0),>(1)$.

137. Retroarticular process, orientation of attachment surface: posterodorsal (0), posterior (1).

138. Paradental plates, continuity and replacement groove: separated, groove present (0), forming a continuous medial lamina ('fused'), groove absent (1).

139. Paradental plates, visibility in medial view: widely exposed, subpentagonal and moderate-tall (0), obscured by medial wall of dentary, triangular apices only may be visible (1).

140. Paradental plates, surface texture: smooth (0), vertically striated or ridged (1).

141. Teeth, curvature: present, marked (0), reduced or absent (1).

142. Teeth, crown striations: absent (0), present (1).

143. Teeth, enamel wrinkles: absent (0), present, extending as bands across labial and lingual tooth surfaces (1), pronounced marginal enamel wrinkles (2).

144. Teeth, mid-crown cross-section: elliptical (0), circu$\operatorname{lar}(1)$.

145. Teeth, root shape: broad (0), tapered (1).

146. Teeth, maxillary and dentary, serrations: present (0), absent (1)

147. Teeth, maxillary and dentary, extent of anterior carina: to base of crown (0), at mid-height of crown or more dorsally (1).

148. Premaxillary teeth, arrangement of carinae: nearly symmetrical, on opposite sides (0), more asymmetrical, both on lingual side (1). 
149. Premaxillary teeth, serrations: present (0), absent (1).

150. Premaxillary teeth, number: four (0), three (1), five (2), six/seven (3).

151. Premaxillary teeth, spacing: even (0), paired and spaced (1).

152. Premaxillary teeth, size of tooth 1 relative to others: subequal (0), smaller (1).

153. Maxillary teeth, number: > $17(0), 11-17(1),<11$.

154. Maxillary teeth, mid-tooth spacing: adjacent (0), with diastemata (1).

155. Dentary teeth, size and number relative to maxillary teeth: approximately equal (0), smaller and approximately 1.5 times as numerous (1).

\section{Axial Skeleton}

156. Presacral vertebrae, anterior face of anterior elements: flat (0), convex (1).

157. Presacral vertebrae, pleurocoel posterior to parapophysis (anterior pleurocoel) in anterior elements: absent (0), present (1).

158. Presacral vertebrae, posterior pleurocoel in anterior elements: absent (0), present (1).

159. Presacral vertebrae, extent of anterior pleurocoel: to D4 (0), to sacrum (1).

160. Vertebrae, internal structure of pneumatic centra: absent, 'pleurocoels' if present, form fossae, not foramina (0), camerate (1), camellate (2).

161. Atlas, length of epipophyses: moderate (0), elongate (1).

162. Axis, spinous process shape: dorsal end expanded transversely (0), tapers mediolaterally (1).

163. Axis, orientation of intercentrum ventral surface: horizontal or slightly anteroventral $(0)$, tilted anterodorsally (1).

164. Axis, length of epipophyses: moderate (0), long (1), short (2).

165. Axis, morphology of spinopostzygapophyseal lamina: broad, well-developed (0), invaginated (1).

166. Axis, development of parapophyses: moderate/ large (0), reduced/absent (1).

167. Axis, development of diapophyses: moderate (0), reduced or absent (1).

168. Axis, pleurocoels: absent (0), present (1).

169. Cervical vertebrae, morphology of anterior pleurocoel: single opening ( 0$)$, two openings oriented anteroventralposterodorsal or very plastic morphology (1).

170. Cervical vertebrae, middle, shape of anterior pleurocoel: round (0), anteroposteriorly elongate (1).

171. Cervical vertebrae, anterior, ventral keel: present (0), absent or weak ridge (1)

172. Cervical vertebrae, anterior, demarcation of dorsal surface of neural arch from diapophyseal surface: gently sloping (0), ridge (prominent prezygapophyseal-epipophyseal lamina) (1).

173. Cervical vertebrae, position of parapophysis on centrum: anterior (0), middle (1).

174. Cervical vertebrae, articular surface of prezygapophyses: planar (0), flexed (1).

175. Cervical vertebrae, perimeter of anterior articular surface: not rimmed by a flattened peripheral band (0), flat, forming a distinct rim (1).

176. Cervical vertebrae, anterior, transverse distance between prezygapophyses relative to width of neural canal: < $(0),>$, prezygapophyses situated lateral to neural canal (1).

177. Cervical vertebrae, anterior, morphology of epipophyses: low, blunt (0), long, thin (1), long, robust (2).

178. Cervical vertebrae, anteroposterior length of neural spines: nearly as long as centrum (0), $\leq 75 \%$ centrum length (1).

179. Cervical vertebrae, longest post-axial elements: first five (0), last five (1).

180. Cervical vertebrae, middle, length/height ratio of centra: less than $3(0)$, more than $3(1)$.

181. Dorsal vertebrae, pneumaticity/webbing at base of neural spines: absent (0), present (1).

182. Dorsal vertebrae, accessory centrodiapophyseal lamina: absent (0), present (1).

183. Dorsal vertebrae, size of infraprezygapophyseal fossa: small (0), expanded (1).

184. Dorsal vertebrae, anterior, ventral keel: absent or developed as a weak ridge (0), pronounced, around $1 / 3$ the height of centrum and inset from lateral surfaces (1).

185. Dorsal vertebrae, anterior, size of pneumatic foramen in centrum: small (0); enlarged (1).

186. Dorsal vertebrae, elevation of parapophyses: slightly elevated from centrum (0), project far laterally, more than half the diapophyseal length (1).

187. Dorsal vertebrae, orientation of hyposphene laminae: diverge ventrolaterally (0), parallel and sheetlike (1).

188. Dorsal vertebrae, position of parapophyses in posteriormost elements: on the same level as transverse process (0); distinctly below transverse process (1).

189. Dorsal vertebrae, distinct step-like ridge lateral to hyposphene, running posterodorsally from dorsal border of neural canal to posterior edge of postzygapophyses: absent (0); present (1); ridge present and is developed into a prominent lamina that bisects the infrapostzygapophyseal fossa in posterior dorsal vertebrae (2).

190. Dorsal vertebrae, middle and posterior, postzygapophyses with tab-like lateral extensions of articular facets: absent (0); present (1). 
191. Dorsal vertebrae, morphology of neural spines: transversely compressed sheets (0), transversely broad anteriorly and posteriorly, central regions of lateral surface embayed by deep vertical troughs (1).

192. Dorsal vertebrae, posterior, inclination of neural spines: vertical or posterior (0), anterior (1).

193. Dorsal vertebrae, height of neural spines relative to centrum height: low, $\leq 1.3 \times(0)$, moderate, $1.4-1.8 x$ (1); tall, $\geq 2.0 \times(2)$.

194. Dorsal vertebrae, posterior, centrum constriction: weak (0), strong (1).

195. Dorsal vertebrae, centrum length relative to height: more than $2(0)$, less than $2(1)$.

196. Sacral vertebrae, centrum pneumaticity: absent (0), pleurocoelous fossae (1); pneumatic foramina (2).

197. Sacral vertebrae, number: 2 [primordial sacrals only] (0), 5 [1 dorsosacral, 2 caudosacrals] (1), 6 [2 dorsosacrals, 2 caudosacrals] (2).

198. Sacral vertebrae, transverse dimensions of middle centra relative to other sacrals: equivalent $(0)$, constricted (1).

199. Sacral vertebrae, orientation of ventral margin of middle centra: approximately horizontal (0), strongly arched (1).

200. Sacral vertebrae, dorsal edge of neural spines: as thin as remainder of spine (0), transversely thickened (1).

201. Sacral vertebrae, pneumaticity of neural arches: weak or absent (0), paired fossa ventral to diapophyses (1).

202. Caudal vertebrae, anterior, morphology of ventral surface: flat (0), groove (1), ridge (2).

203. Caudal vertebrae, L-shaped neural spines: absent (0), present (1).

204. Anterior to mid-caudal vertebrae, depressions or pneumatic foramina in centrum: absent (0), large, pronounced pleurocentral depressions on the dorsal part of the lateral side (1), pneumatic foramina (2).

205. Caudal vertebrae, anterior, centrodiapophyseal laminae on neural arch: weak or lacking (0), as prominent as in dorsal vertebrae, defining deep infradiapophyseal fossa that penetrates neural arch (pneumatic) (1).

206. Caudal vertebrae, anterior, proportions of neural arch base relative to centrum proportions: $<(0), \geq$ (1).

207. Caudal vertebrae, middle, morphology of neural spines: rod-like and posteriorly inclined (0), subrectangular and sheet-like (1), rod-like and vertical (2).

208. Cervical ribs, articulation with cervical vertebrae in adults: separate (0), fused (1).

209. Cervical ribs, length of anterior process: short (0), long (1).
210. Gastralia, posteriormost gastral segments: separate $(0)$, united into single, boomerang-shaped elements (1).

211. Sacral ribs, articulations in adults: separate (0), fused together (1).

212. Sacral ribs, position of posterior attachment to ilium: ventral (0), posterodorsal (1).

213. Sacral ribs, depth relative to ilium height: $<85 \%(0)$, $\geq 90 \%$ (1).

214. Chevrons, morphology in middle caudal vertebrae: rodlike or only slightly expanded ventrally (0), Lshaped (1).

215. Chevrons, proximal articular surface: divided into anterior and posterior facets by distinct transverse ridge (0), no ridge, but low lateral mounds may be present, one on each side (1).

216. Chevrons, curvature: straight or gently curved (0), strongly curved (1).

217. Chevrons, anterior process: absent (0); present (1).

218. Chevrons, morphology of distal end in anterior and middle elements: expanded anteroposteriorly (0), unexpanded, tapers ventrally (1).

\section{Appendicular Skeleton}

219. Scapula, angle between blade and acromion: gradual, oblique (0), abrupt, perpendicular (1).

220. Scapula, size of acromion process: moderate (0), marked (1).

221. Scapula, midshaft expansion of blade: absent (0), present (1).

222. Scapula, distal expansion of blade: marked (0), weak/absent (1).

223. Scapula, length:width ratio of blade: $\leq 7(0), 7.5-9$ (1), > 10 (2).

224. Scapulocoracoid, shape of anterior margin: indented or notched between acromial process and coracoid suture (0), smoothly curved and uninterrupted across scapula-coracoid contact (1).

225. Scapulocoracoid, glenoid lip: moderate (0), marked (1).

226. Coracoid, development of posteroventral process: low, rounded posteroventral eminence (0), pronounced, posteroventrally tapering process (1).

227. Coracoid, development of biceps tubercle (= acrocoracoid process): absent or poorly developed (0), conspicuous and well developed as tuber (1), developed as a posteroventrally oriented ridge (2).

228. Coracoid, prominent fossa on ventral surface posteroventral to glenoid (subglenoid fossa): absent (0); present (1).

229. Humerus, shape of head: elongate (0), globular (1).

230. Humerus, longitudinal torsion of shaft: absent $(0)$, present (1).

231. Humerus, size of trochanters relative to midshaft diameter: $<(0),>150 \%(1)>250 \%(2)$. 
232. Humerus, development of internal tuberosity: low/ rounded (0), hypertrophied (1).

233. Humerus, length of deltopectoral crest relative to total bone length: < $0.4(0), 0.43-0.49$ (1) $>0.52$ (2).

234. Humerus, development of deltopectoral crest: large rectangular crest $(0)$, reduced to a low, rounded flange (1).

235. Humerus, orientation of deltopectoral crest apex: anteriorly (0), anterolaterally (1).

236. Humerus, relative orientation of proximal \& distal condyles in anteroposterior view: parallel, humerus straight (0), distal canted (1).

237. Humerus, anterior surface of bone adjacent to ulnar condyle: smooth or gently depressed (0), bears well-defined fossa (1).

238. Humerus, shape of distal condyles: rounded (0), flattened (1).

239. Radius and ulna, development of radial external tuberosity and ulnar internal tuberosity: low, rounded (0), hypertrophied distal ends of radius and ulna broadened (1).

240. Radius, shaft: straight (0); curves laterally (1).

241. Radius, development of medial biceps tubercle: small or indistinct (0), hypertrophied (1).

242. Ulna, olecranon process: absent (0), present (1).

243. Ulna, morphology of olecranon process: transversely robust (0); transversely compressed and 'blade-like' (1).

244. Ulna, crest extending distally along posterior surface from olecranon process: absent (0), present (1).

245. Ulna, hypertrophied medial and lateral processes on proximal end: absent (0), present (1).

246. Ulna, length relative to minimum circumference: stout, <2.3 (0); gracile > $2.6(1)$.

247. Carpus, morphology and articulations of distal carpals: separate dc1 and dc2 over separate metacarpals, flattened proximodistally (0), fused dc1 and dc2, dc1 overlaps metacarpals I and II, flattened proximodistally (1), fused dc1 and dc2, dc1 overlaps metacarpals I and II, strongly arched

proximodistally (2).

248. Manus, length of digit II relative to length of humerus: < (0), > (1) (modified from Carrano et al. 2012)

249. Manus, composition: digit IV and $V$ present (0), digit IV present, digit $\mathrm{V}$ absent (1), MC IV present, IV phalanges and digit $\mathrm{V}$ absent (2), digits IV and $\mathrm{V}$ absent (3).

250. Manual digits, lengths: III longest (0), II longest (1).

251. Metacarpals, transverse width of proximal articular ends relative to minimum transverse shaft width: < $(0), \geq 2 \times(1)$.

252. Metacarpal I, length to minimum width ratio: 1.4-1.9 $(0), \geq 2.4$ (1).
253. Metacarpal I, length relative to length of metacarpal II: $>50 \%(0),<50 \%(1)$.

254. Metacarpal I, extent of contact with metacarpal II relative to shaft length: < 1/3 (0), 1/2 (1).

255. Metacarpal I, angle between facet for metacarpal II and proximal articular facet: perpendicular (0), obtuse (1).

256. Metacarpal III, position of base relative to those of other metacarpals: at same level (0), on palmar surface (1).

257. Metacarpal III, shape of proximal end: rectangular (0), triangular (1).

258. Metacarpal III, width relative to width of metacarpal II: $>50 \%(0),<50 \%(1)$.

259. Manual ungual I, length:height ratio: $<2.5 x(0)$, $>$ 2.5x (1).

260. Manual unguals, proximal height:width ratio: transversely broad, < $2.0(0)$, transversely narrow, $>2.4$ (1).

261. Pelvic elements, articulations in adults: separate (0), fused (1).

262. Ilium, large external pneumatic foramina and internal spaces: absent (0), present (1).

263. llium, vertical ridge on lateral surface of blade dorsal to acetabulum: absent (0), low swollen ridge (1), low double ridge (2).

264. Ilium, posterior width of brevis fossa: subequal to anterior width, fossa margins subparallel (0), twice anterior width, fossa widens posteriorly (1).

265. Ilium, height of lateral wall of brevis fossa relative to medial wall: taller along whole length $(0)$, shorter anteriorly, exposing medial wall in lateral view (1).

266. Ilium, morphology between supraacetabular crest and brevis shelf on lateral surface: gap (0), continuous ridge (1).

267. Ilium, ventrolateral development of supraacetabular crest: large/pendant 'hood' (0), reduced shelf (1).

268. Ilium, orientation of pubic peduncle: mostly ventral (0), mostly anterior or 'kinked' double facet with anterior and ventral components (1).

269. llium, shape of acetabular margin of pubic peduncle: transversely convex or flat (0); transversely concave (1).

270. Ilium, relative sizes of pubic and ischial articulations: subequal (0), pubic articulation $\geq 130 \%$ of iliac articulation (1).

271. Ilium, morphology of ischial peduncle: rounded (0), acuminate (1).

272. Ilium, pubic peduncle length to width ratio: $\leq 1(0)$, 1.3-1.75 (1), > 2 (2).

273. llium, ridge on medial surface adjacent to preacetabular notch: absent (0), present (1), strongly developed, forming a shelf (2).

274. Ilium, preacetabulum length relative to anterior edge of pubic peduncle: reaches anteriorly to same 
point as ('brachyiliac') (0), or well past ('dolichoiliac') (1).

275. Ilium, depth of preacetabular process: shallow (0), deep (1).

276. llium, anteroventral lobe of preacetabular process: absent (0), present (1).

277. llium, shape of dorsal margin: convex (0), straight (1).

278 Ilium, postacetabulum length relative to ischial peduncle length: $\leq(0)$, > (1).

279. Ilium, depth of postacetabular process: shallow (0), deep (1).

280. Ilium, shape of posterior margin of postacetabular process: convex (0), concave (1), straight (2), with prominent posterodorsal process but lacking posteroventral process (3).

281. Puboischiadic plate, morphology and foramina/ notches: fully closed along midline, 3 fenestrae $(0)$, open along midline, 1 fenestra (obturator foramen of pubis) and 1-2 notches (1), open along midline, 0 fenestrae, 1-2 notches (2).

282. Pubis, shaft orientation: straight (0), ventrally curved (1).

283. Pubis, articulation between apices in adults: unfused (0); fused (1).

284. Pubis, contact between distal portions: separate distally (0), contacting (1), contacting with slit-like opening proximal to distal expansion (interpubic fenestra) (2).

285. Pubis, angle between long axes of shaft and boot: $75-90^{\circ}(0),<60^{\circ}(1)$.

286. Pubis, morphology of symphysis: marginal (0), broad (1).

287. Pubis, morphology of obturator foramen: small and subcircular (0), large and oval (1).

288. Pubis, anterior expansion of distal end: absent (0), present (1).

289. Pubis, boot length relative to shaft length: $<(0)$, > $30 \%$ (1), > 60\% (2).

290. Pubis, shape of boot in ventral view: broadly triangular (0), narrow, with subparallel margins (1).

291. Pubis, articulation with ilium: planoconcave (0), peg-and-socket (1).

292. Ischium, length relative to pubis length: $75-80 \%(0)$, $\leq 70 \%(1),>80 \%(2)$.

293. Ischium, shaft orientation: straight (0), ventrally curved (1).

294. Ischium, articulation with ilium: planoconcave (0), peg-and-socket (1).

295. Ischium, morphology of antitrochanter: large and notched (0), reduced (1).

296. Ischium, notch ventral to obturator process: absent (0), present (1).

297. Ischium, morphology of symphysis: unexpanded (0), expanded as apron (1).
298. Ischium, cross-sectional shape of paired midshafts: oval (0), heart-shaped, medial portions of shafts extend posteriorly as midline flange (1).

299. Ischium, morphology of distal end: rounded (0), expanded, triangular (1).

300. Ischium, articulation at distal end in adults: separate (0), fused (1).

301. Femur, head orientation: $45^{\circ}$ anteromedial (0), 10 $30^{\circ}$ anteromedial (1), medial (2).

302. Femur, head angle: ventromedial (0), horizontal (medial) (1), dorsomedial (2).

303. Femur, groove on proximal surface of head oriented oblique to long axis of head ('articular groove'): absent (0), present (1).

304. Femur, oblique ligament groove on posterior surface of head: shallow, groove bounding lip does not extend past posterior surface of head (0), deep, bound medially by well-developed posterior lip (1).

305. Femur, placement of lesser trochanter relative to femoral head: does not reach ventral margin (0), rises past ventral margin (1), rises to proximal surface (2).

306. Femur, morphology of anterolateral muscle attachments at proximal end: continuous trochanteric shelf $(0)$, distinct lesser trochanter and attachment bulge (1).

307. Femur, development of fourth trochanter: prominent semioval flange (0), very weak or absent (1).

308. Femur, distinctly projecting accessory trochanter (derived from lesser trochanter): weak, forms slightly thickened margin of lesser trochanter (0), present as triangular flange (1).

309. Femur, M. femorotibialis externus origin medially on anterodistal surface: faint, small rugose patch (0), pronounced rugose depression that extends to distal femur (1).

310. Femur, development of medial epicondyle: rounded (0), ridge (1).

311. Femur, distal extensor groove: absent (0), present (1).

312. Femur, morphology and orientation of tibiofibularis crest: broad (0), narrow, longitudinal (1), lobular, oblique (2).

313. Femur, infrapopliteal ridge connecting medial distal condyle and crista tibiofibularis: absent (0), present (1).

314. Femur, orientation of long axis of medial condyle in distal view: anteroposterior (0), posterolateral (1).

315. Femur, projection of lateral and medial distal condyles: approximately equal (0), lateral projects distinctly further than medial, distal surface of medial is gently flattened (1).

316. Femur, morphology of distal end: central depression connected to crista tibiofibularis by a narrow groove (0), anteroposteriorly oriented shallow trough separating medial and lateral convexities (1). 
317. Tibia, lateral malleolus: backs astragalus (0), overlaps calcaneum (1).

318. Tibia, shape of edge of lateral malleolus: smoothly curved (0), tabular notch (1).

319. Tibia, morphology of distal cnemial process: rounded (0), expanded proximodistally (1).

320. Tibia, morphology of lateral (fibular) condyle: large (0), small and lobular (1).

321. Tibia, anterolateral process of lateral condyle: absent or horizontal projection (0), prominent, curves ventrally (1).

322. Tibia, anteromedial buttress for astragalus: absent (0), ventral (1), marked oblique step-like ridge (2), reduced oblique ridge (3), bluntly rounded vertical ridge on medial side (4).

323. Tibia, morphology of fibular crest: narrow (0), bulbous (1).

324. Tibia, development of fibular crest: extends to proximal end of tibia as high crest (0), extends to proximal end of tibia as low ridge (1), does not extend to proximal end of tibia (2).

325. Groove or depression on the medial side of the proximal end of the fibula: absent or only shallow concavity present (0), deep groove on the posterior half of the medial side of the proximal end, offset from anterior margin and opening at least partially posteromedially (1), large, deep depression that opens medially and is offset from the anterior margin only by a thin ridge or lip (2)

326. Ridge on the medial side of the proximal end of the fibula that extends anterodistally from the posteroproximal part: absent (0), present (1).

327. Fibula, size of iliofibularis tubercle: faint scar (0), large (1), anterolaterally curving flange (2).

328. Fibula, size of proximal end relative to width of proximal tibia: < 75\% (0), $\geq 75 \%$ (1).

329. Astragalus, articulation between ascending process and fibula in adults: separate (0), fused (1).

330. Astragalus, orientation of distal condyles: ventral (0), $30-45^{\circ}$ anterior (1).

331. Astragalus, ascending process morphology: blocky (0), laminar (1).
332. Astragalus, angle of dorsal margin of ascending process: low and oblique (0), high and oblique (1).

333. Astragalus, ascending process height relative to depth of astragalar body: less (0), subequal (1), > 1.6 times (2).

334. Astragalus, prominent proximolateral extension: absent (0); present (1).

335. Astragalus, round fossa at base of ascending process: absent (0), small (1), large (2).

336. Astragalus, development of articular surface for distal end of fibula: large, dorsal (0), reduced, lateral (1).

337. Astragalus, posterolateral crest: absent (0), present (1).

338. Astragalus, posteromedial crest: absent (0), present (1).

339. Astragalus, articulation with calcaneum in adults: separate (0), fused (1).

340. Metatarsal I, length relative to length of metatarsal II: $\geq 50 \%$ (0), < 50\% (1).

341. Metatarsal III, shape of proximal end: rectangular (0), shallow notch (1), deep notch (2).

342. Metatarsal III, midshaft cross-sectional shape: rectangular (0), wedge-shaped, plantar surface pinched (1).

343. Metatarsal III, relative proportions of shaft: short and thick, length:transverse width ratio $<12.0(0)$, long and gracile, ratio > 12.5 (1).

344. Metatarsal IV, proportions of distal end: broader than tall (0), taller than broad (1).

345. Metatarsal V, morphology of distal end: articular (0), non-articular (1).

346. Metatarsal $\mathrm{V}$, length relative to length of metatarsal IV: $>50 \%$ (0), <50\% (1).

347. Antarctometatarsus: absent (0), present (1).

348. Pedal unguals, morphology of lateral and medial grooves: single (0), double (1).

349. Pedal unguals, digits III and IV, cross-sectional shape: triangular (0), elliptical (0).

350. Pedal unguals, digit II, mediolateral symmetry: symmetrical (0), asymmetrical (1).

351. Pedal digit phalanges, length of $\mathrm{I}-1+\mathrm{I}-2$ relative to III-1: greater (0), less than or equal (1). 


\section{APPENDIX 2.}

Middle and Late Jurassic theropod-bearing localities (available online as oversize PDF - palaeoelectronica.org/content/2016/1536-german-jurassic-megalosaurid). 